ص ص[Mr|r|r|r

$$
\begin{aligned}
& \text { تحديد تأثير المخاطرة على اتجاهات المديرين نحو الاعثماد }
\end{aligned}
$$

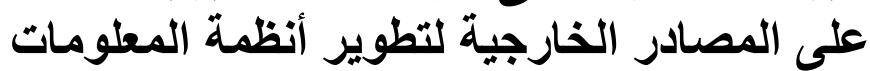

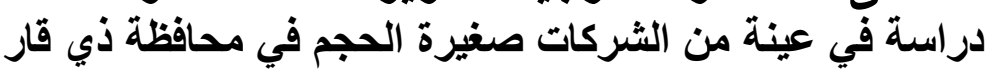

$$
\begin{aligned}
& \text { الدكتور عبد العظيم دريفش جبار الزيادي } \\
& \text { أستاذ مساعد } \\
& \text { كلية الإدارة والاقتصاد -جامعة ذي قار }
\end{aligned}
$$

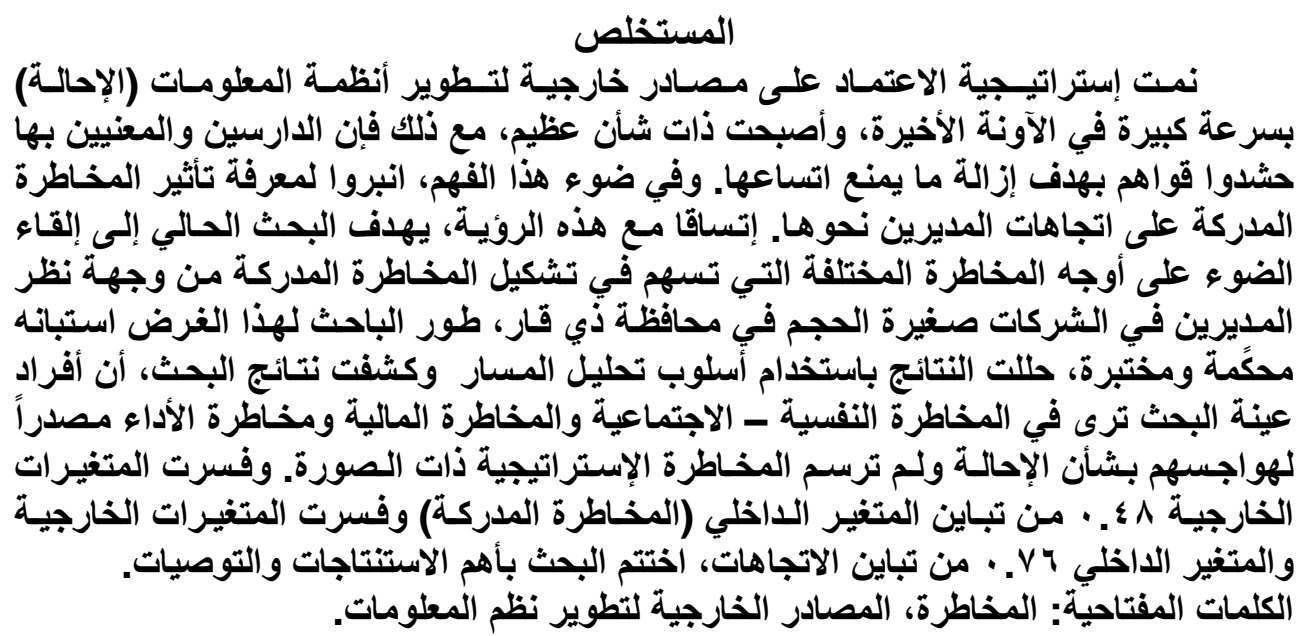

\title{
Determination Of Perceived Risk Effect On Manager's Attitude \\ Toward Outsourcing \\ A Study In Sample Of Small Business In Thi-Qar Government
}

\author{
Abdul Adheem D. Al-Zeyadi (PhD) \\ Assistant Professor \\ Department of Business Administration \\ Thi-Qar University
}

\begin{abstract}
Outsourcing is highly estimated strategy; it has been rapidly grown lately for developing information systems. Nevertheless, researchers spared no effort to curb its expansion. In the light of such concept, they approached the effect of perceived risk on attitude of managers. According to this, the current research aims at highlighting the aspect


of risks which contribute to form perceived risk stemming from viewpoints of small business firms managers in Thi-Qar. Data were collected via evaluated and refereed questionnaire. Results were analyzed by using path analysis method .The final results of the study showed that the sample seen in social-psychosocial risk, financial and performance risk, as source of their obsession regarding the outsourcing, whereas, the strategic risk did not give the same result. The exogenous variables $(0.48)$ were explained out of the variance of exogenous variable (perception risk) the independent variables $(0.76)$ were explained out of the variance of attitude. The research is ended with the most important conclusions and recommendations.

Key Words: Risk, Outsourcing for developing in formation system.

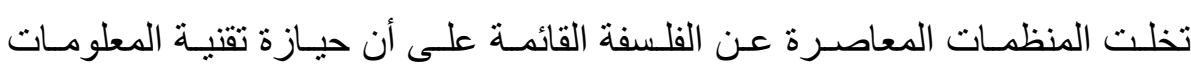
ووضـعها تحت رقابـة محكمـة في داخل حدود المنظمـة طريـق لاكتساب المز ابـا التتافسية،

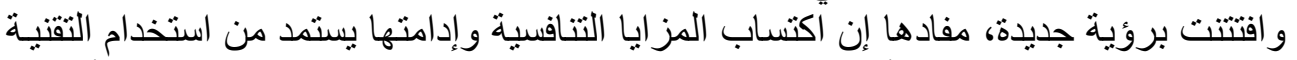

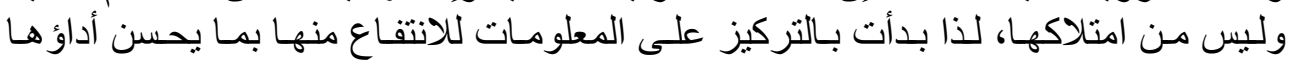
ويحقق لها التفوق التنافسي وليس مجرد التركيز على التقنية نفسها. و أصبح من الأجدى لهـا لها إحالة إدارتها والانتفاع مما يوفره المجهز الخارجي. و على هدى من هذا التصوي التصور، تعزز موقف إستر اتيجية الاعتماد على مصادر خارجية لتطوير أنظمة المعلومـات (Outsourcing)

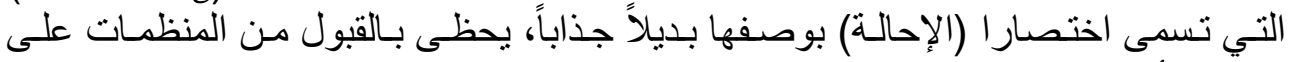

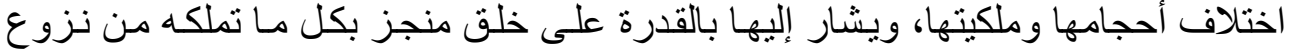

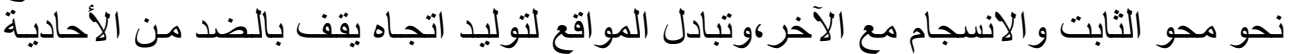

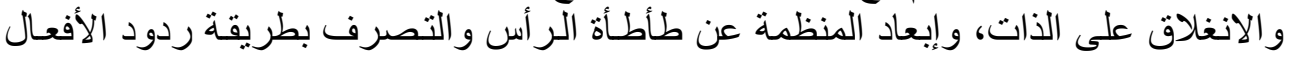

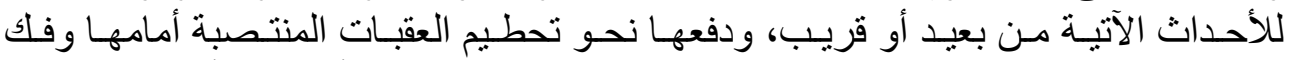

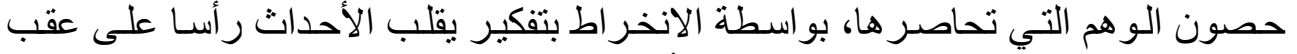

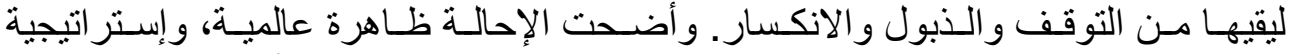

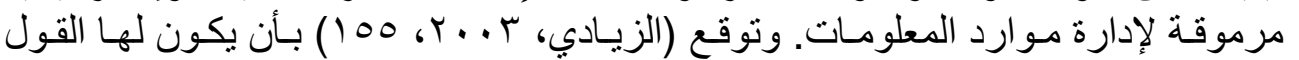

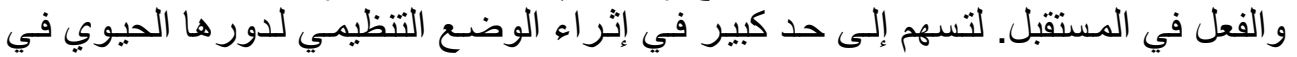
عملية التغبير و على كافة المجالات في المنظمة،وترتقي بالعلاقة بين متلقي الخدمـة ومقدمها

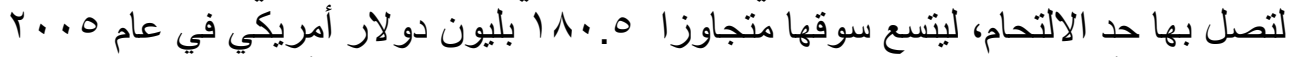

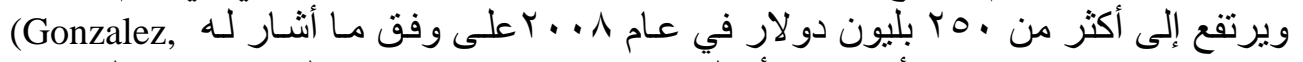

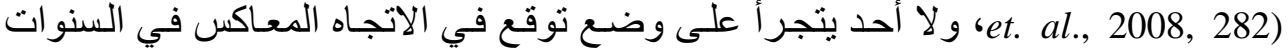

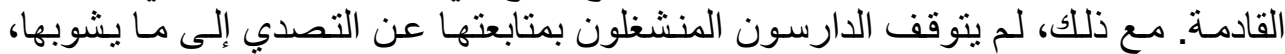

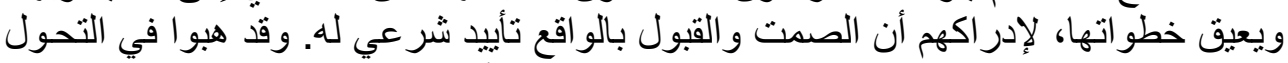

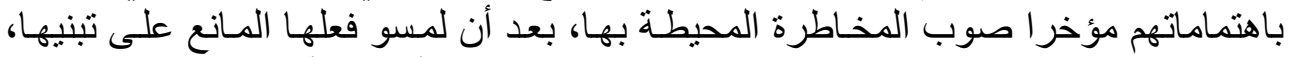

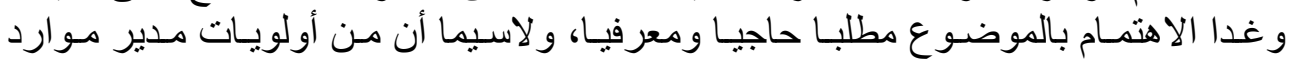

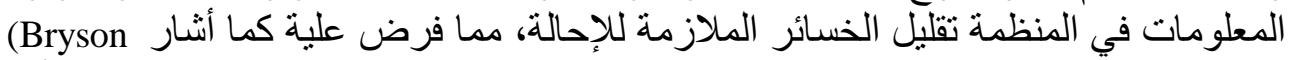
and Ngwenynma, 2006, 247) يسهم و على وفق مـا سوق لـه (Aubert, et. al.,2005, 8) في تحليلها و الحصول على فهم

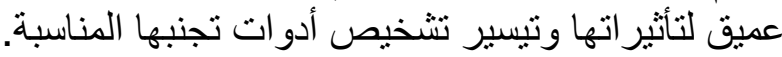

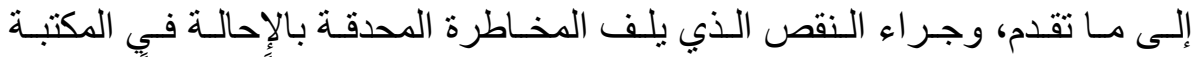

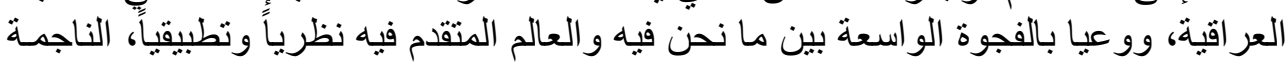




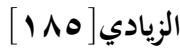

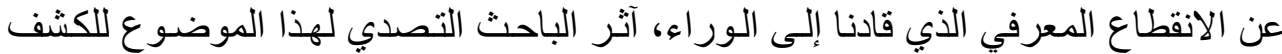

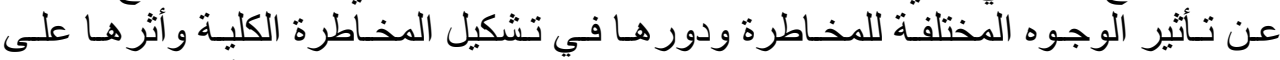
اتجاهات المديرين في الثركات صغيرة الحجم في محافظة ذي قار لإن لاسيما أن سوق الإحالة

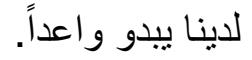

الاداسات السابقة ومنهجية البحث

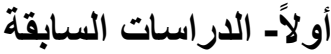

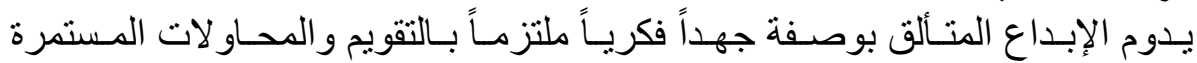

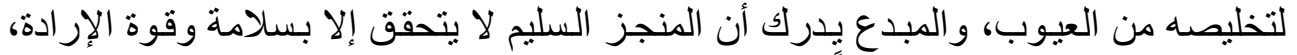

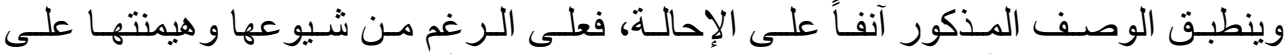

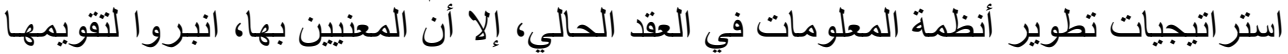

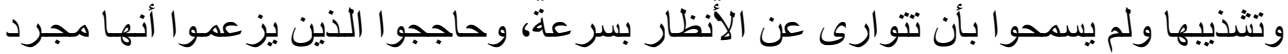

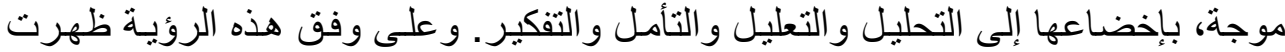

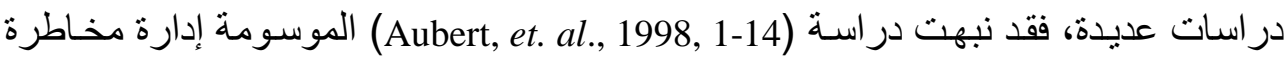

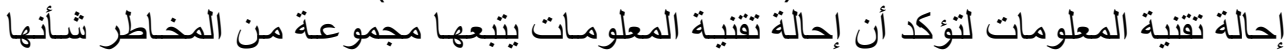

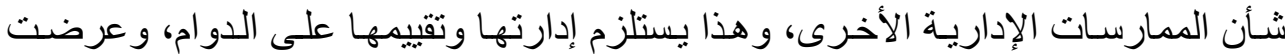

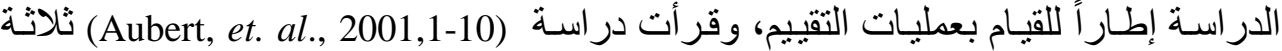

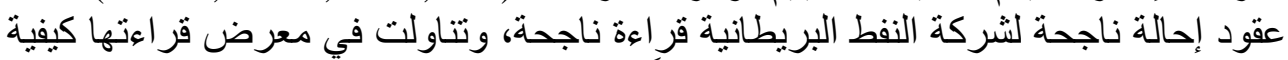

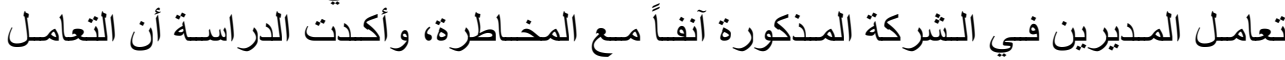

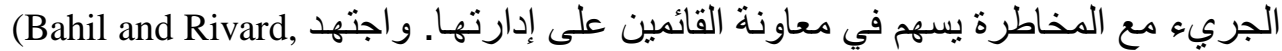

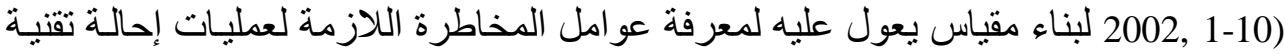

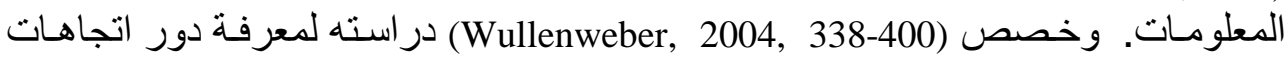

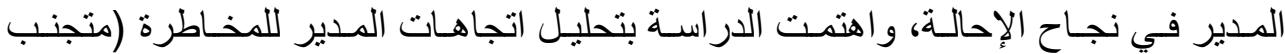

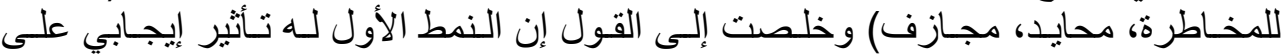

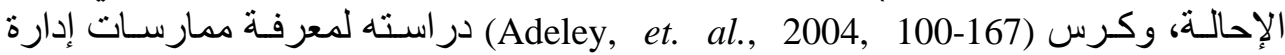

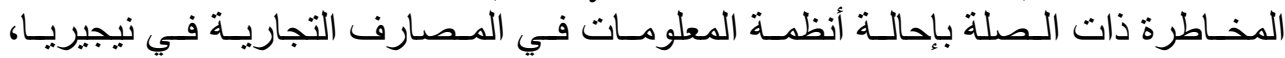

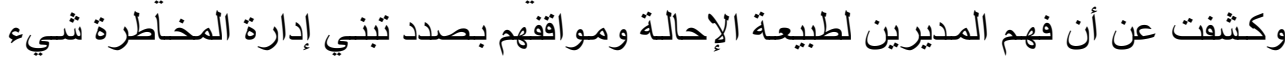

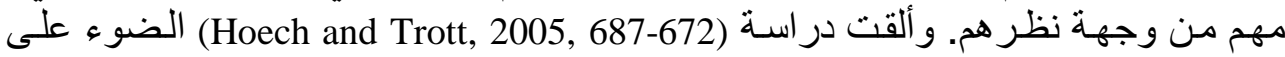

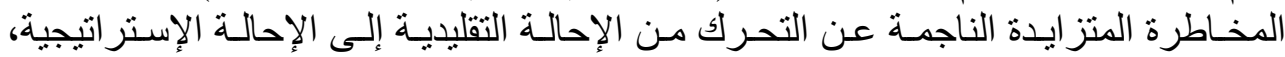

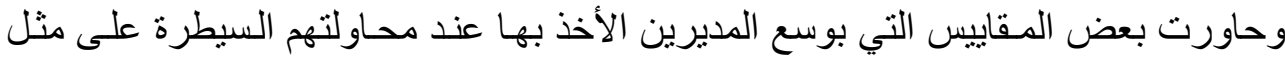

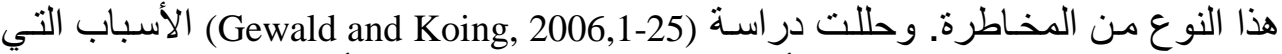

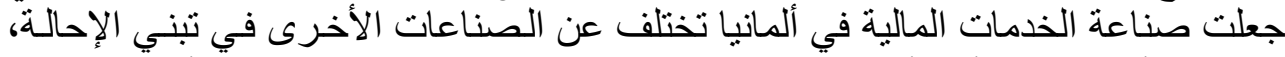

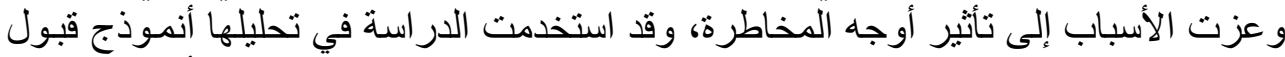

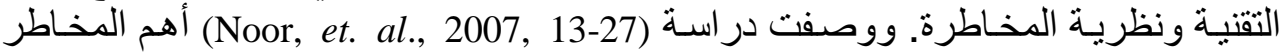

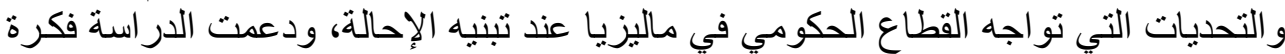

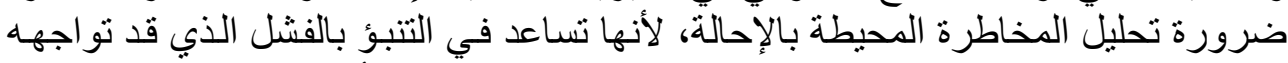

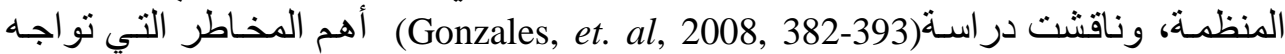
الثركات الاسبانية عند اعتمادها الإحالة. 


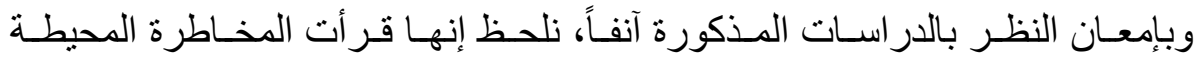

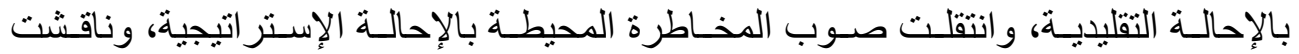

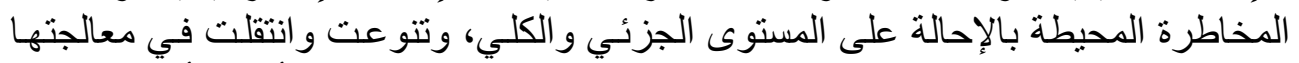

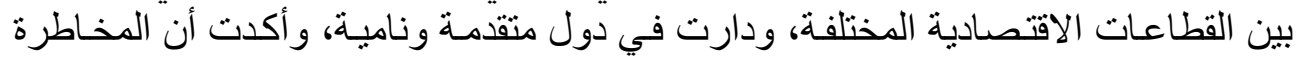

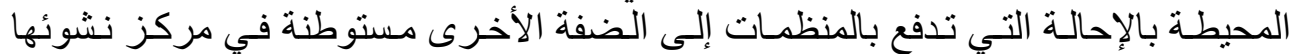

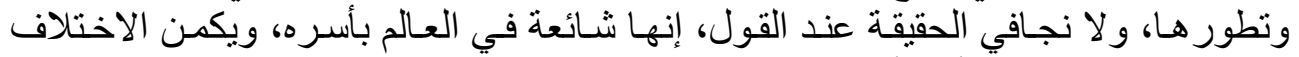

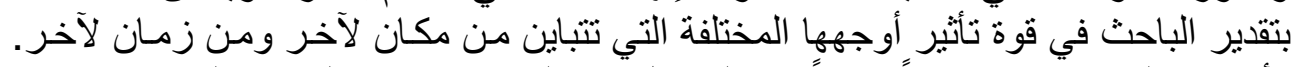

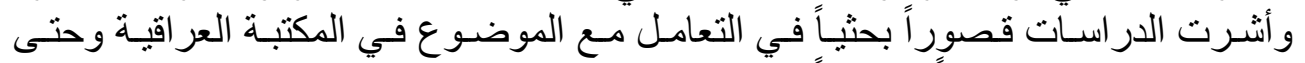

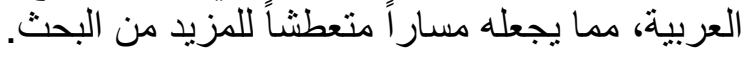

\section{ثانياً- منهجية البحث}

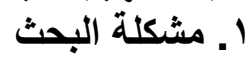

تؤدي الثركات صغيرة الحجم دوراً مهماً في الاقتصاد العر اقي كونها مشاريع تدر البها

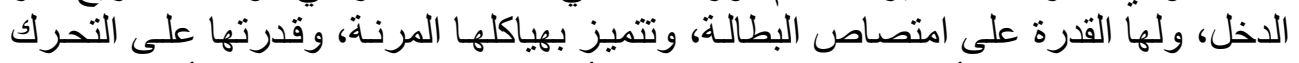

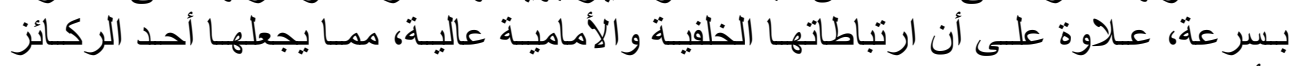

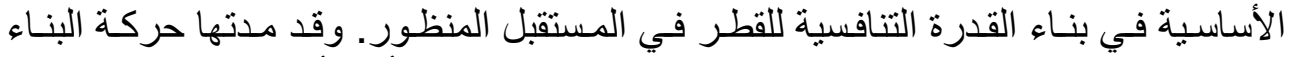

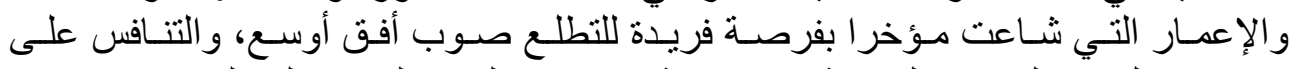

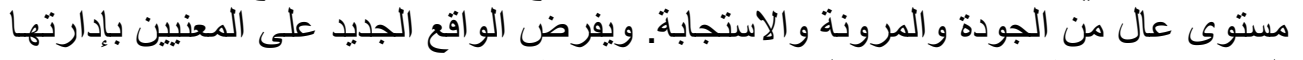

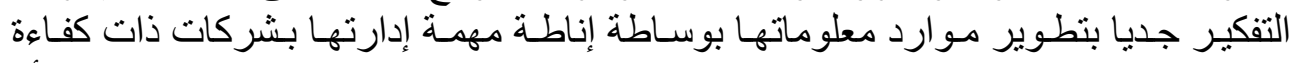

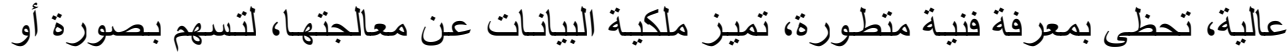

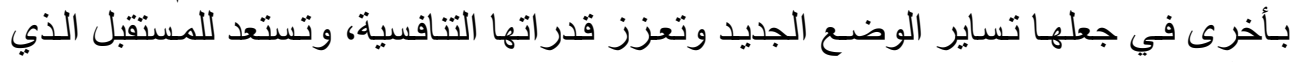

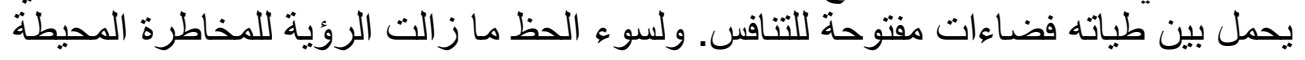

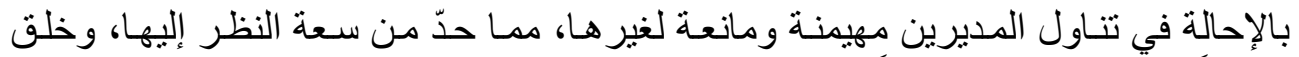

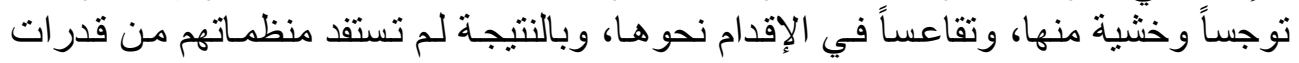

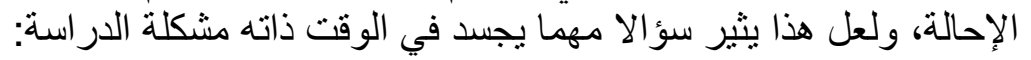

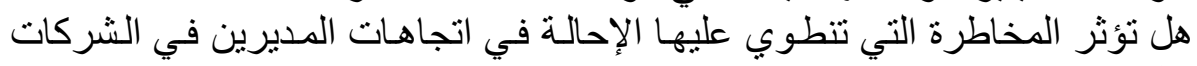

صغيرة الحجم نحو ها؟

$$
\text { r ـ أهداف البحث البحث إلى: }
$$

ا ـ التعرف على واقع الإحالة في الثركات صغيرة الحجم عينة البحث.

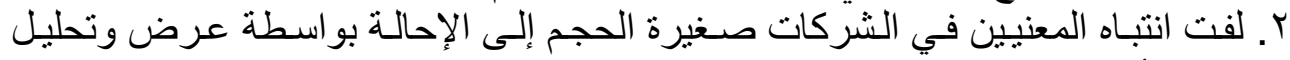
مجمل أسرار ها.

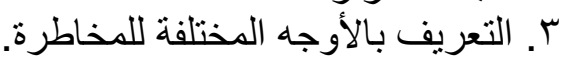

ع. بناء مقياس يسهم في تفسير تأثير أوجه المخاطرة التهارة ودور ها في تنكيل المخاطرة الكلية.

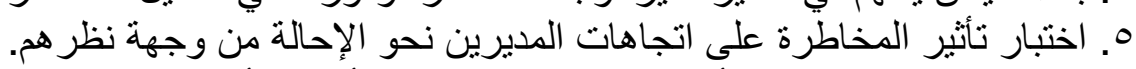

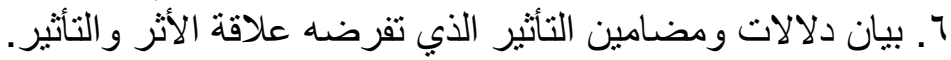




\section{الزيادي[Av}

احتل موضوع تطوير أنظمـة المعلومـات المحسوسة أهميـة ومكانـة خاصـة في أدب

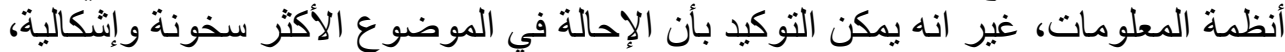

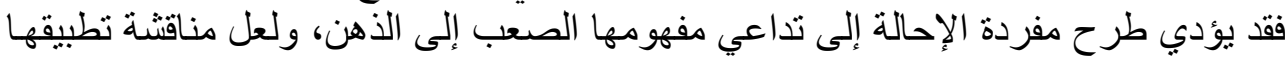

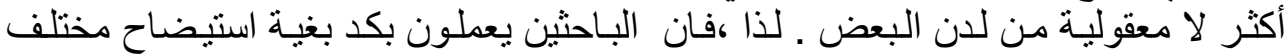

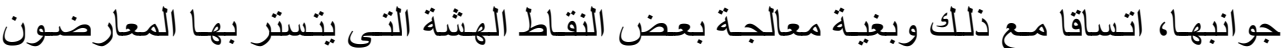

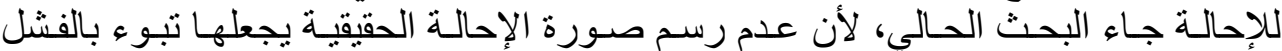
وتتعثر على نحو مخجل في سوق حاجتها ماسة لإن لها.

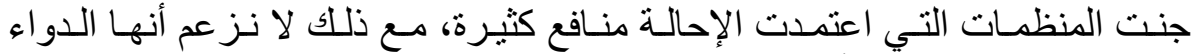

\section{ع .عرض مخطط البحث الفرضي وتفسير متغيراته}

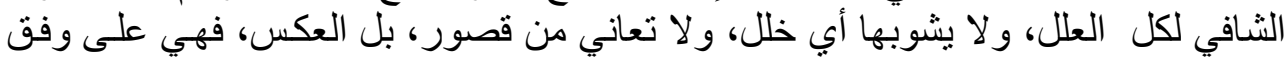

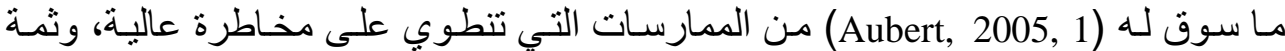

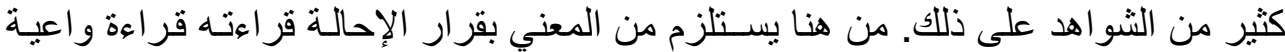

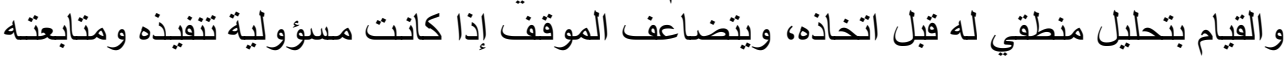

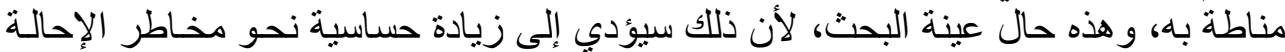

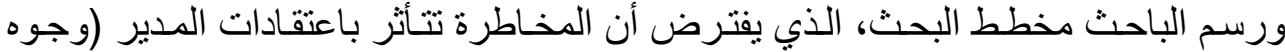

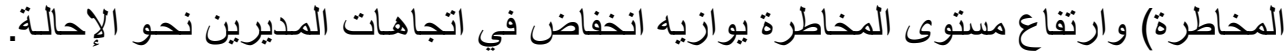

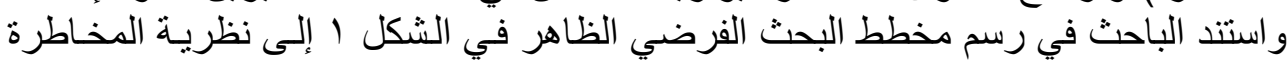

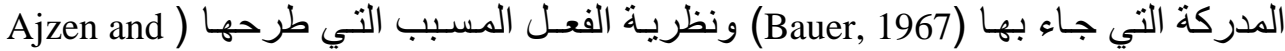
(Wullenweber, 2004,Wullenweber, 2005, Gewald, et. al, ودر اسات (Fishbien, 1980 (2006 ويلفت الباحث الانتباه إلى أن مخططه لم يفترض وجود علاقة تأثير مباثـرة بين أي

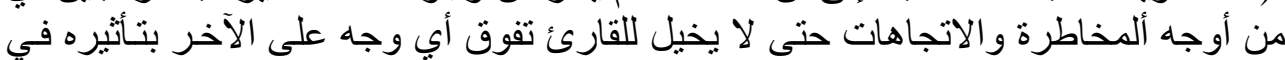
الاتجاهات. ويظهر المخطط على النحو الآتي:

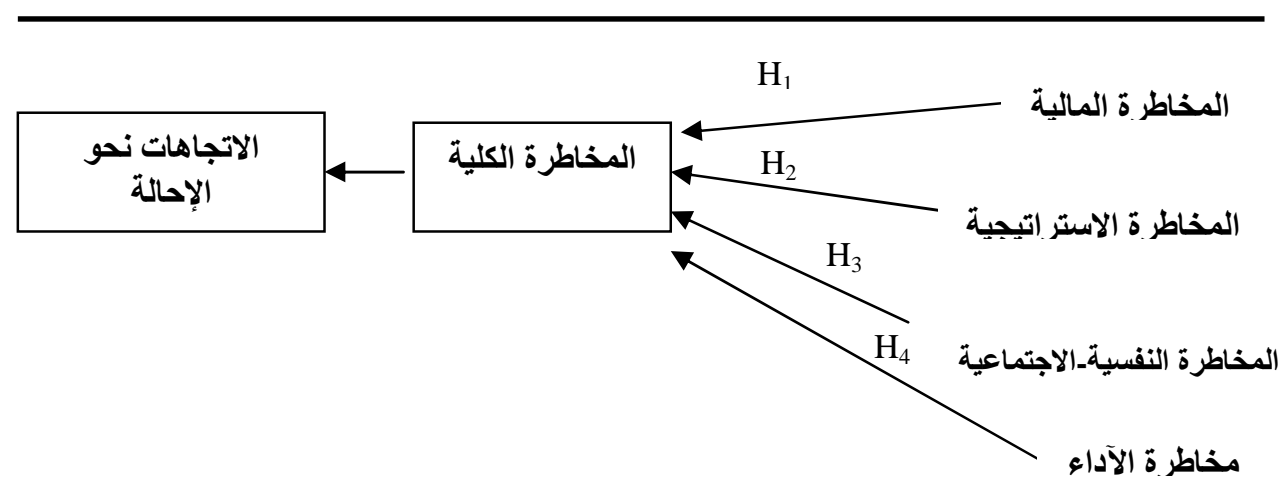




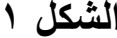 \\ مخطط البحث الفرضي}

\section{وفيما يأتي تفسير لمتغير ات المخطط:}

وجوه المخاطرة

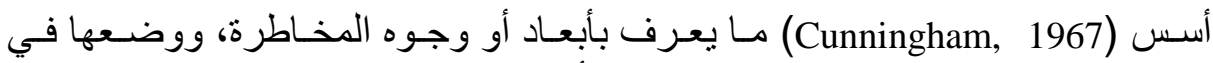

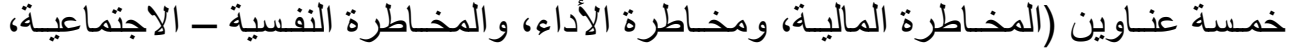

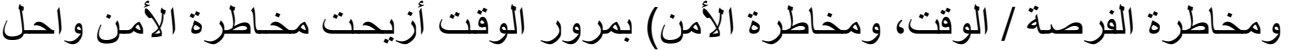

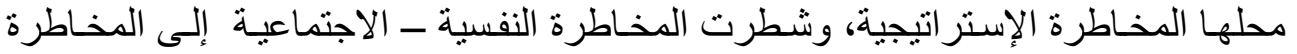

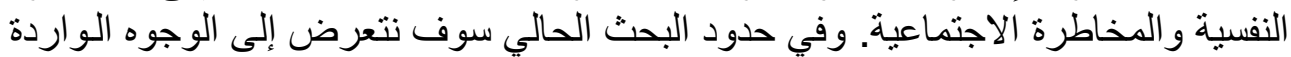
في مخطط البحث.

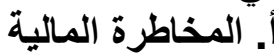

تعني على ر أي (Featherman and Paulou, 2003, 455) المخاطرة الناجمة عن زيادة

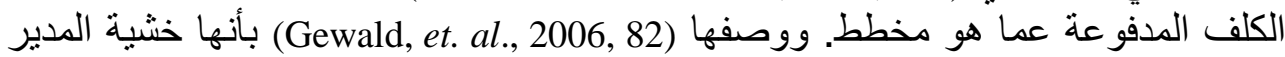
المعني من دفع مبالغ أكثر مما هو منوقع. وفسرها (Wullenweber, 2004, 430) بالمخاطرة التي قد تظهر بسبب دفع مبالغ أكثر بالمقارنة مع التوقعات الأولية. وتظهر المخاطرة المالية

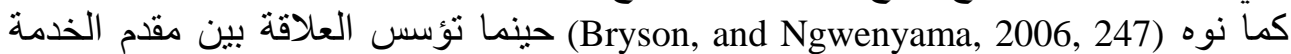

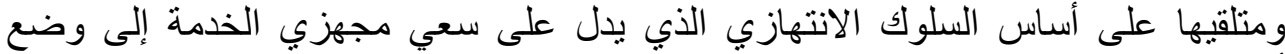
أسعار تجاوز السعر السائد في السوق. بما يؤدي في نهاية المطاف إلى ارتفاع التياع الكلف الخفية (Lacity and Willcock, 1995, 214) وتصاعد في كلف التحول (Earl, 1996, 28). ب. المخاطرة الإستر اتيجية قصد بها (Gawald, et. al., 2006, 85 فقدان متلقي الخدمة لقدرتهـ على رد الفعل المرن و غير المحدود للتغيرات في السوق. ووصفها (Gewald and Dibbern, 2005, 81)

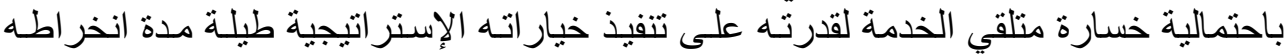

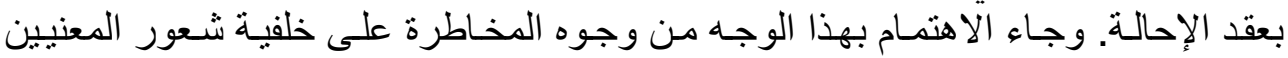

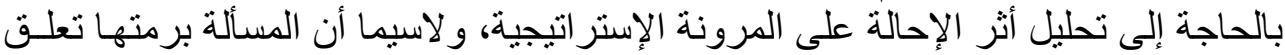

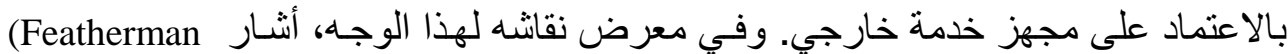
and Pavlou, 2003, 454)

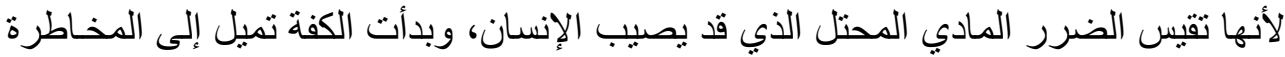

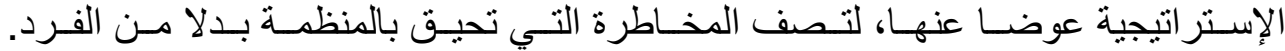

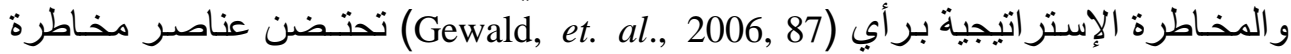

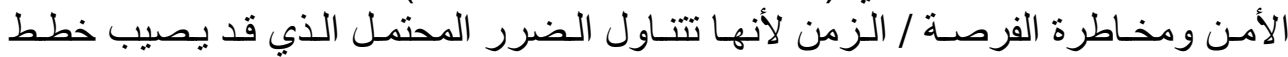

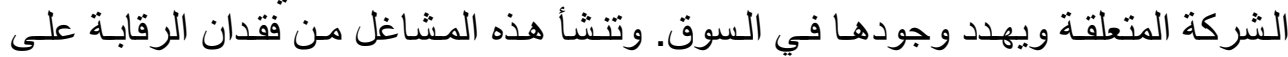

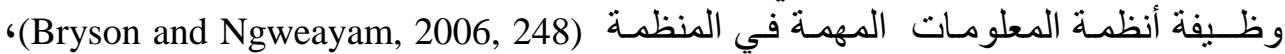

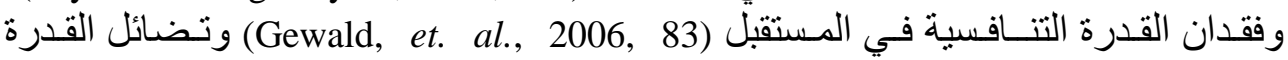

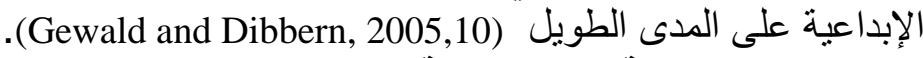
ت. المخاطرة النفسية ــ الاجتماعية الطية وصفها (Gewald and Dibbern, 2005, 5) باحتمالية إصـابة سمعة المدير المسؤول 


\section{[1/19 الزيادي}

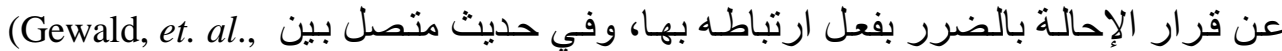
2006, 81 أنها تمثنل التأثير السلبي في راحة بال المدير المعني أو إدراكه الذاني.

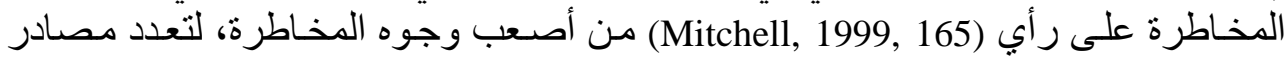

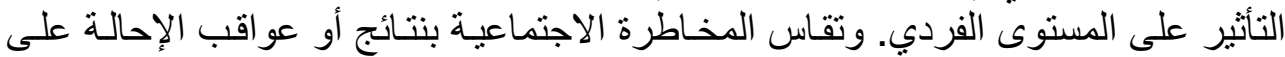

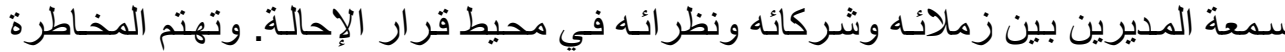

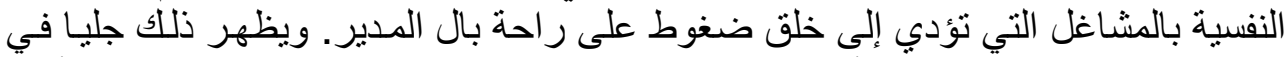

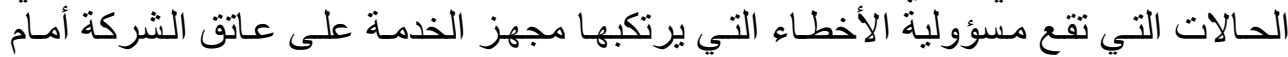

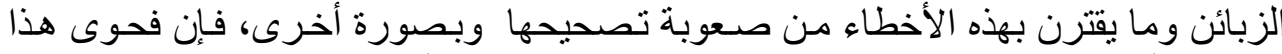

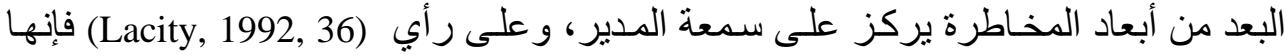

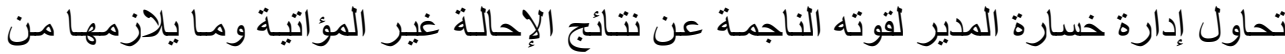

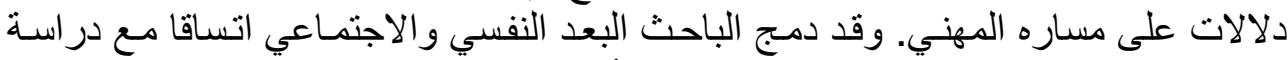
(Gewald, et. al., 2006, 81) الاجتماعي عن البعد النفسي في تعاملهم في بيئة العمل.

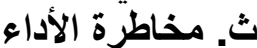

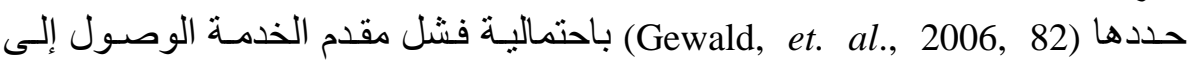

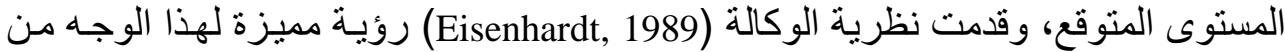

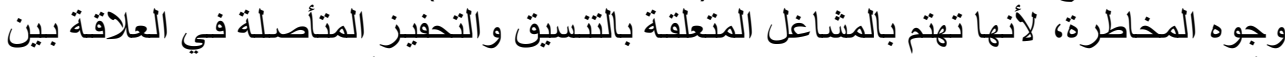

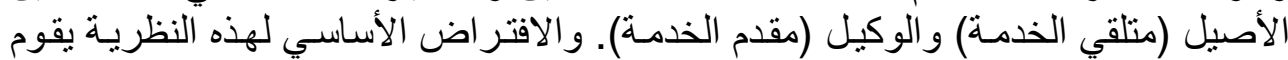

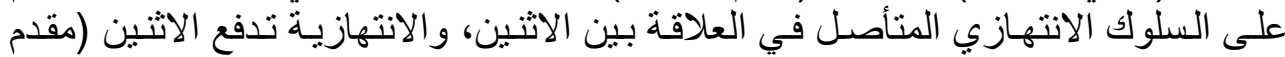

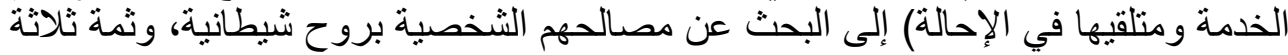

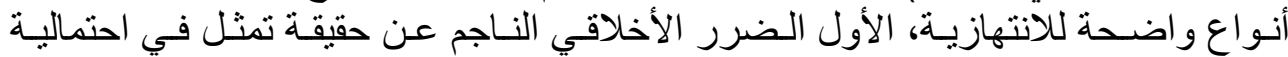

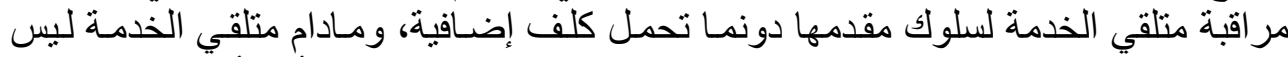

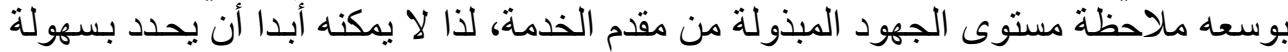

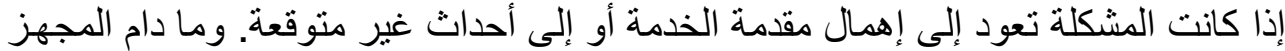

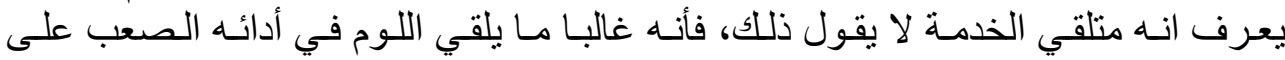

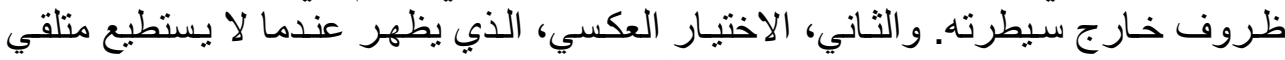

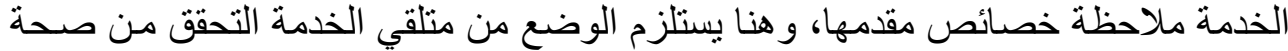

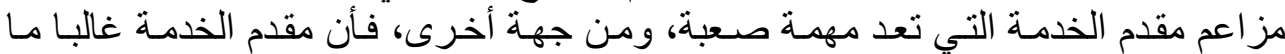

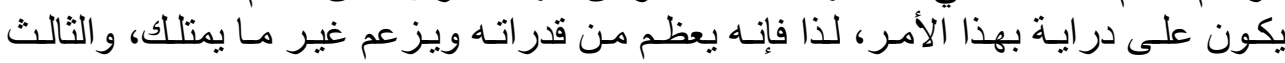

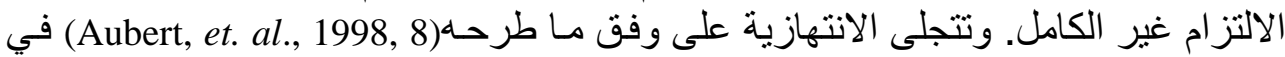
ضعف إمكانات متلقي الخدمة على ملاحظة سلوك مقدمها دون تحمل كلف إضافية.

ج. المخاطرة الكلية

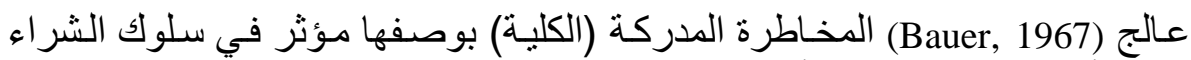

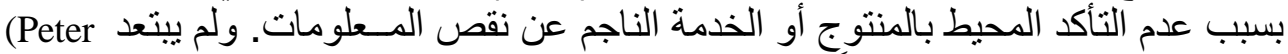

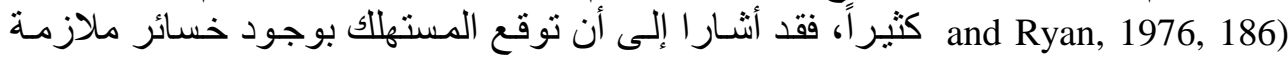

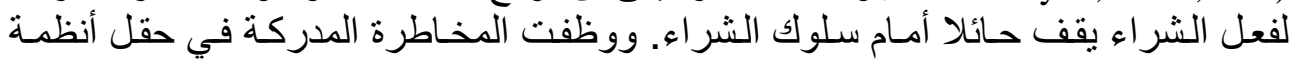

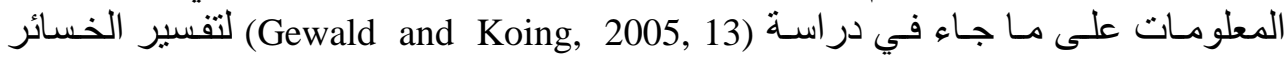
المدركة الناجمة عن استخدام التقنية الجديدة على معدل تبنيها. وقد وصفها aأنها احتمالية الخسارة في تحصيل النتائج المرغوبة من الإحالة. 


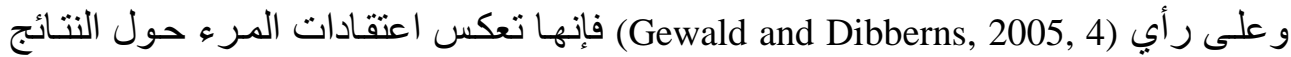

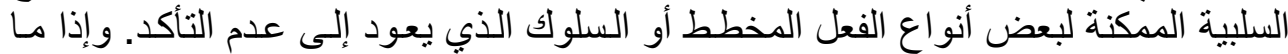

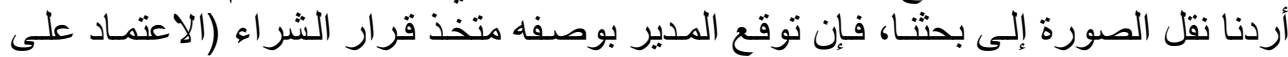

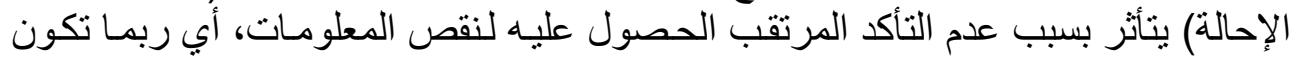

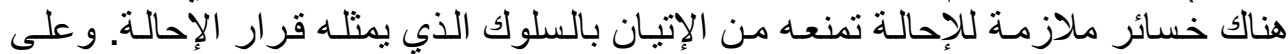

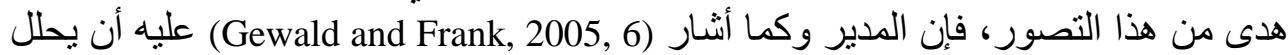

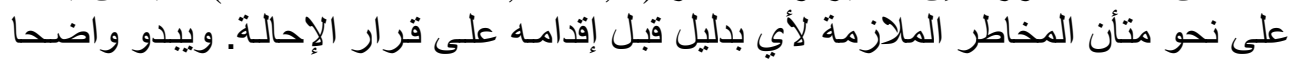

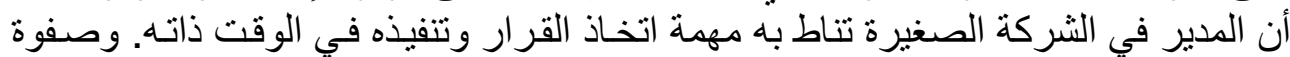

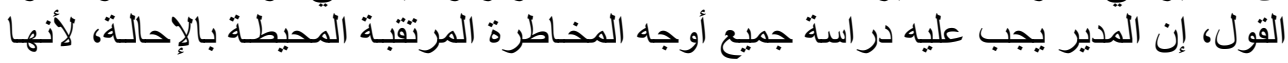

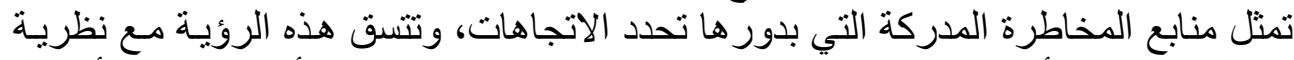

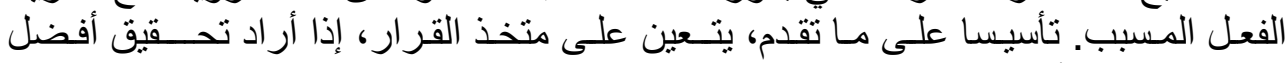

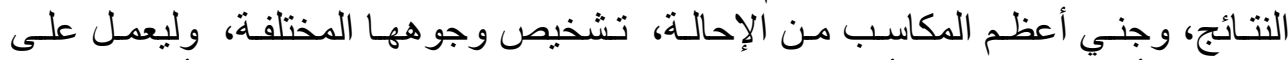

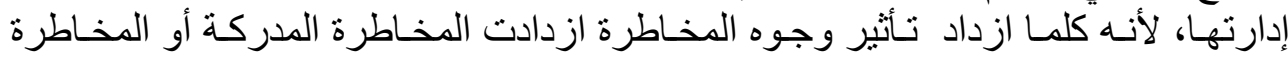
الكلية كما يسميها لانه (Wullenweber, 2004, 432)

ح. الاتجاهات نحو الإحالة

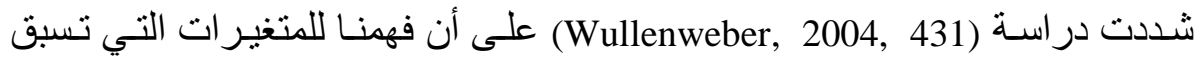

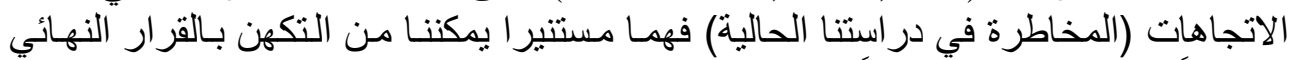

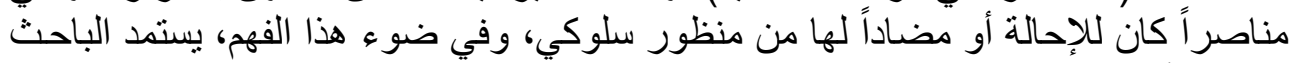

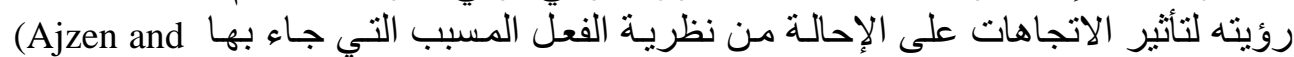

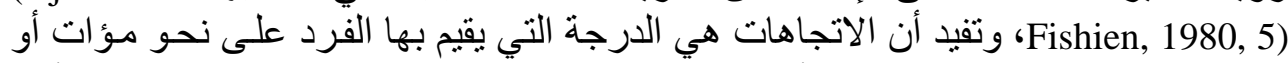

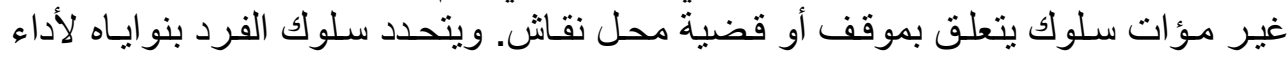

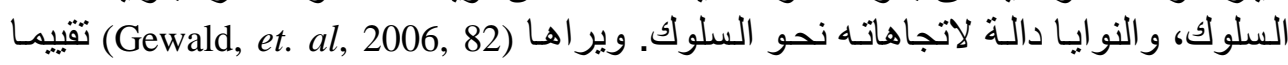

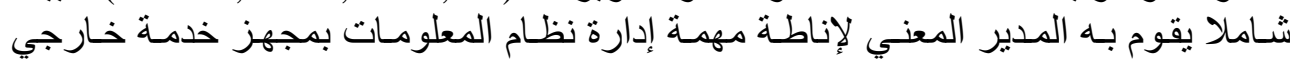

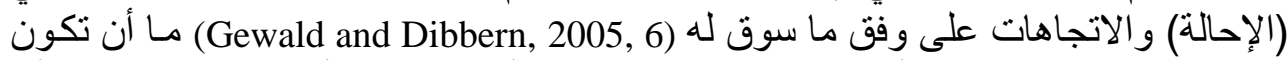

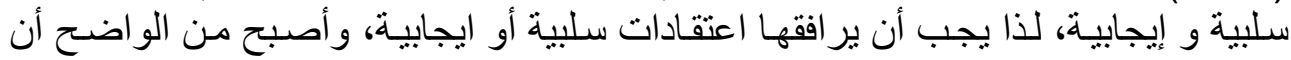

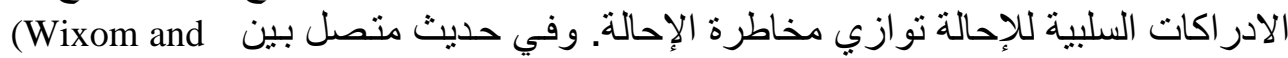

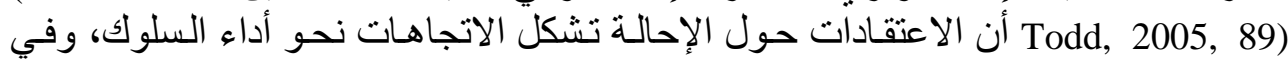

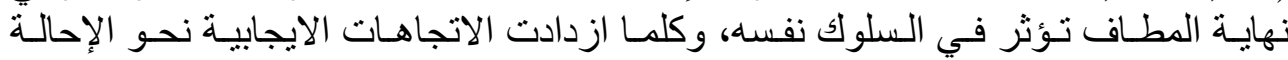

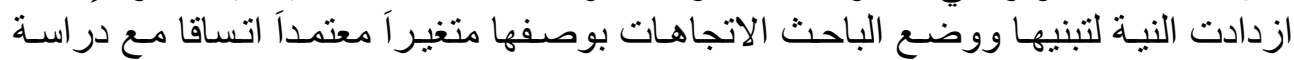

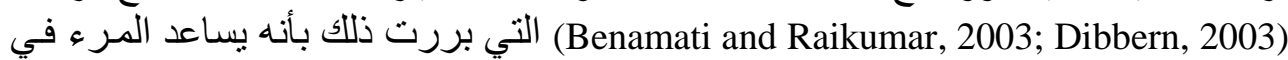

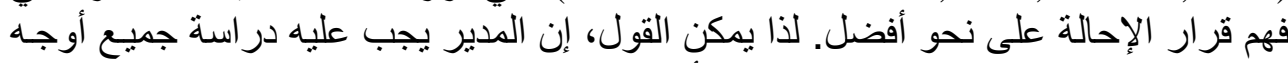

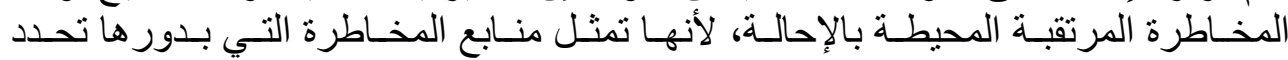

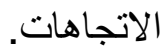

\section{0. فرضيات البحث}

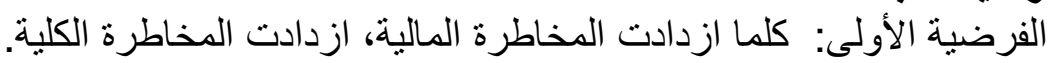

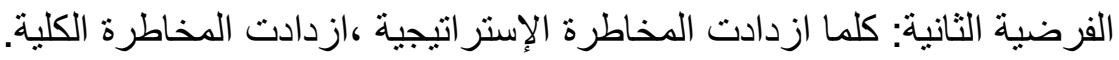

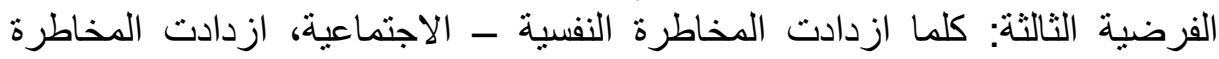
الكلية. 


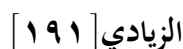

الفرضية الر ابعة: كلما ازدادت مخاطرة الأداء ازدادت المخاطرة الكلية.

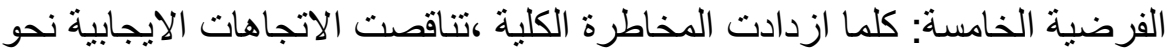
الإحالة.

7 . مجتمع البحث وعينته ومجاله الزماني والمكاني

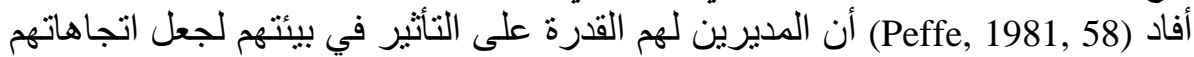

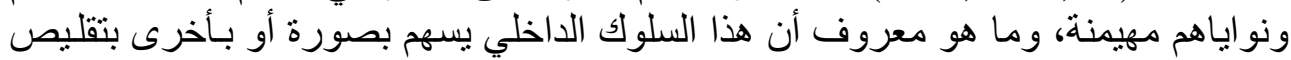

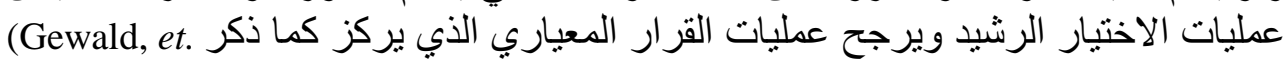

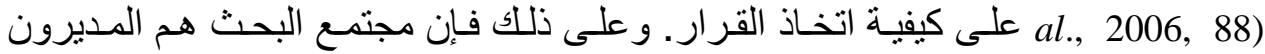

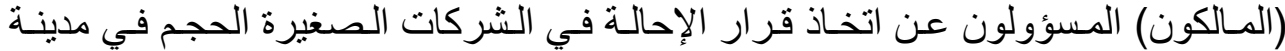

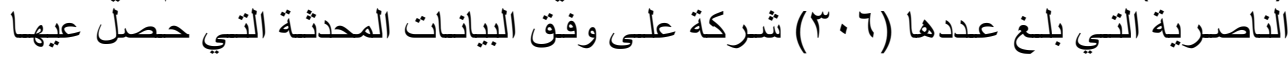

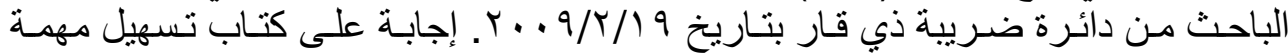

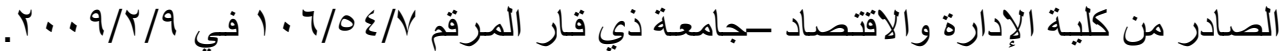
وقد حددت عينة البحث على وفق معيار (Chin, 1995) الذي يقوم على الأد أن عينة البحث يجب

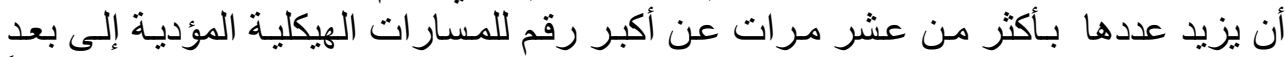

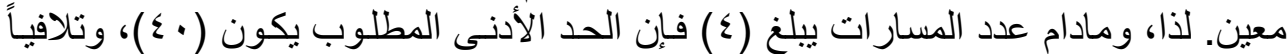
للمشاكل التي تحصل بسبب عدم ورود الإجابات من العينة المختارة أو وجود استبانات الات غير الإن

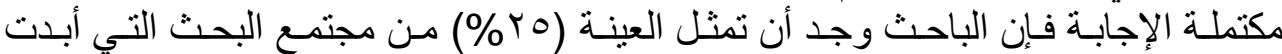

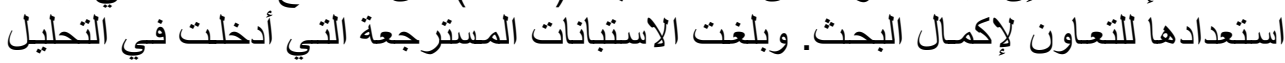

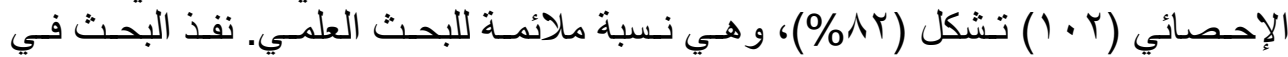

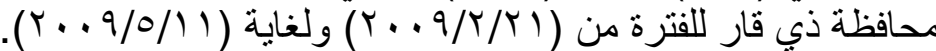

$$
\begin{aligned}
& \text { V. طريقة إجراء البحث }
\end{aligned}
$$

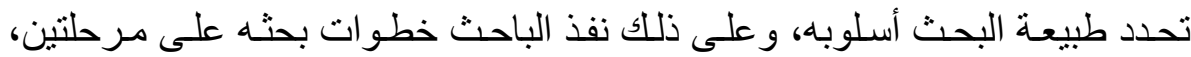

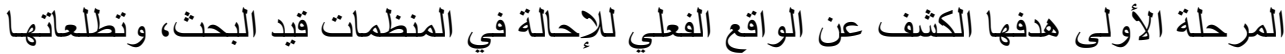

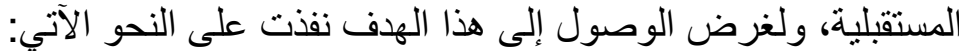

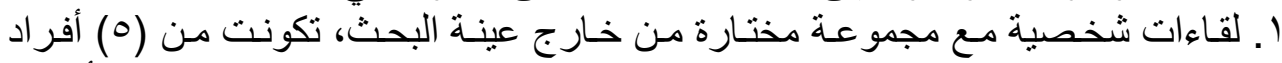

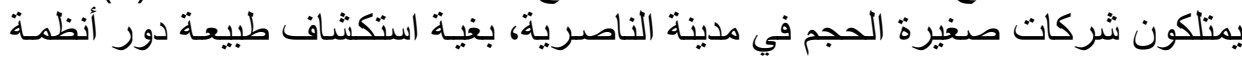
المعلومات وتقنية المعلومات في شركاتهم، و التعرف على على إدر اكهم لحجم و أهميـة الإحالة

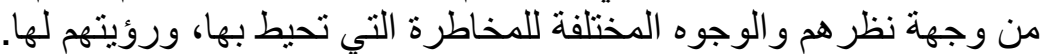

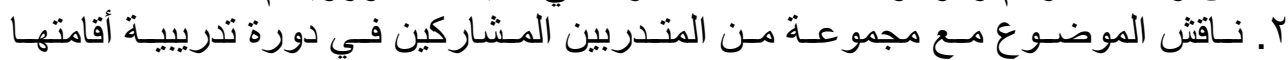

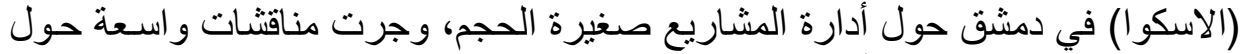

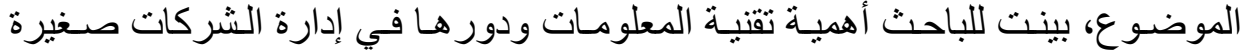

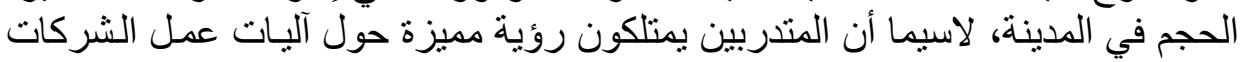

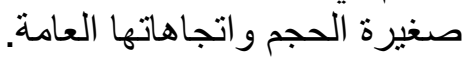

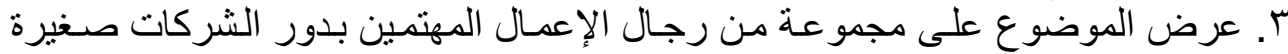

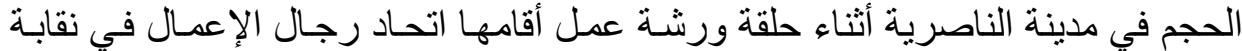

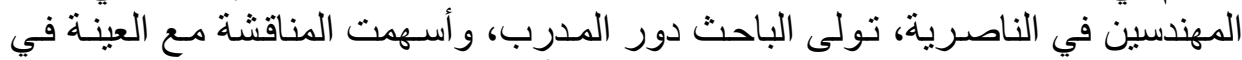

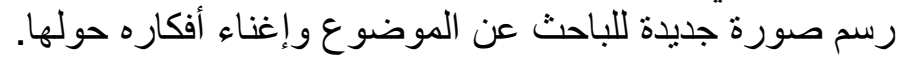

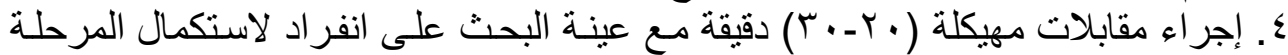

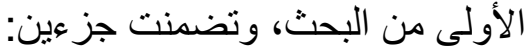




$$
\text { أ. هل ثفكرون في الأول: دارت حول أربعة أنظمة المعلومات وهي: }
$$

ب. هل تقفون بالضد من إحالة أنظمة المعلومات الحمات ولماذا؟

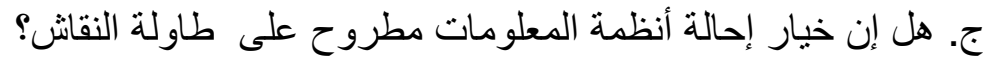

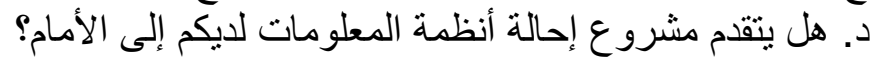

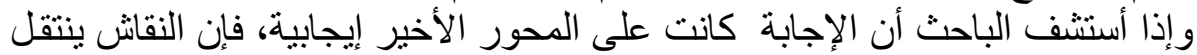
لمعرفة الوظائف التي يجري إحالتها حاليا.

$$
\begin{aligned}
& \text { و. تدريب وتطوير المنتسبين. } \\
& \text { ز. دعم الاتصال بالزبائن. }
\end{aligned}
$$

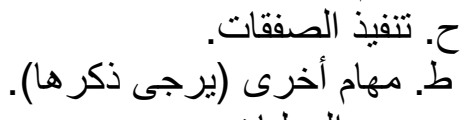

$$
\begin{aligned}
& \text { ي. دعم العطليات. }
\end{aligned}
$$

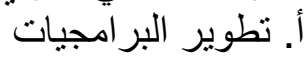

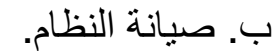

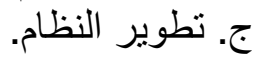

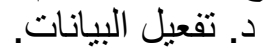

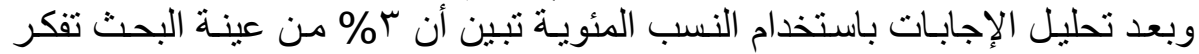

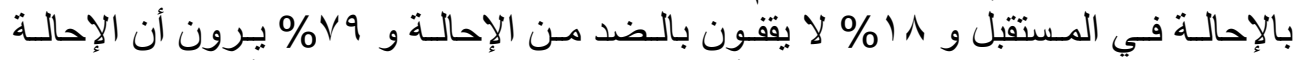

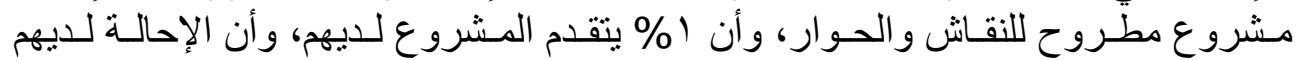

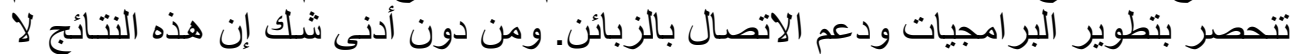

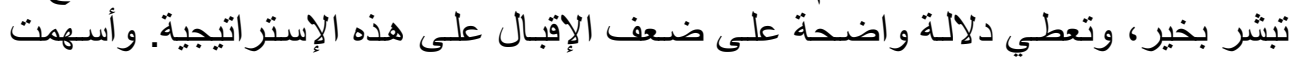

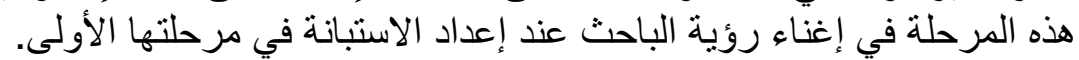

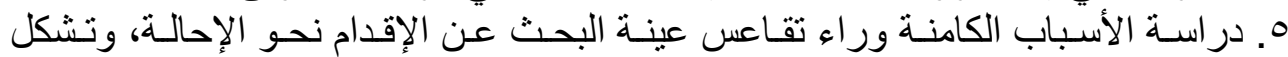

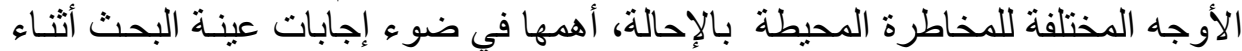

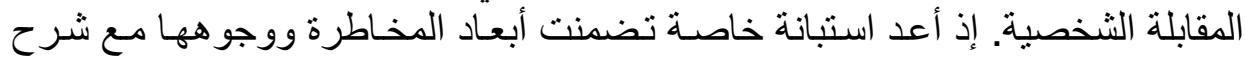

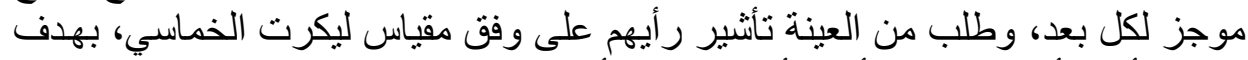

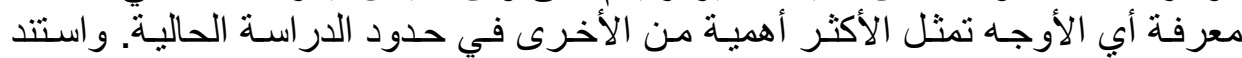

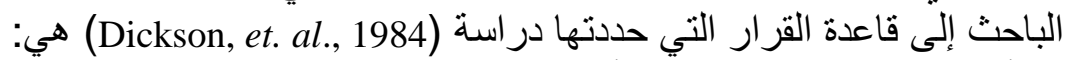

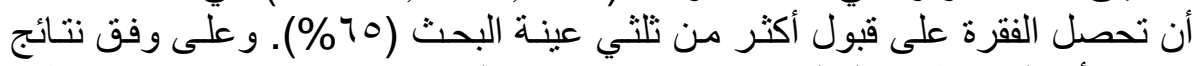

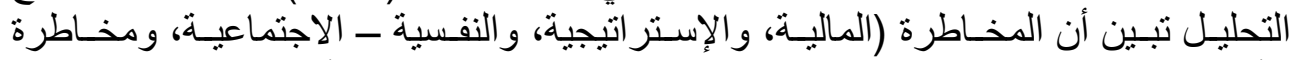

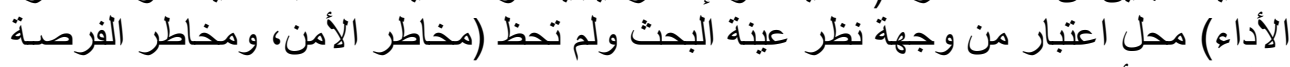

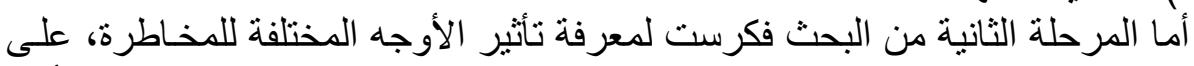
/ الوقت) الأهمية نفسها.

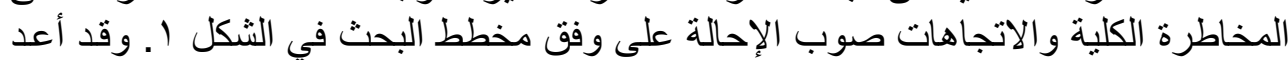

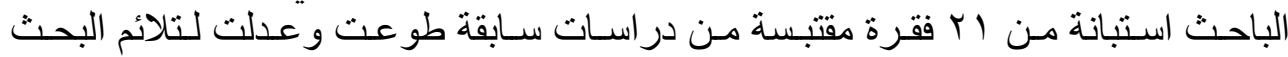

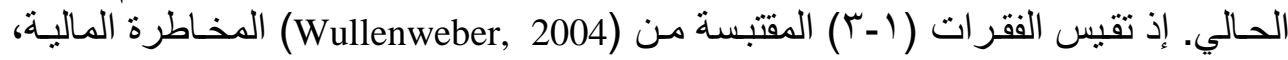

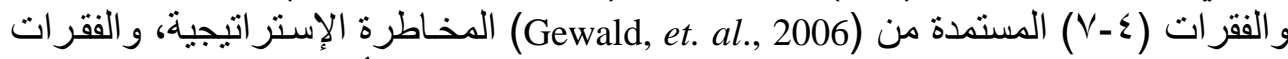

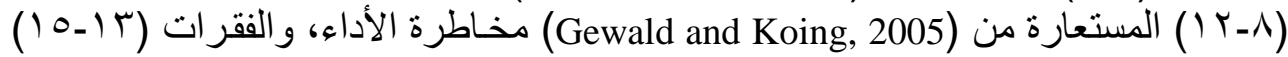

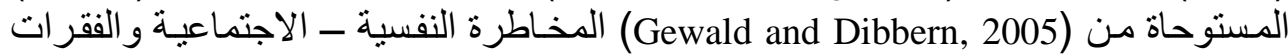

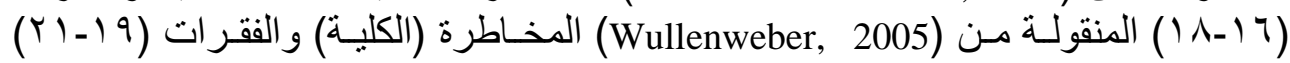
المستخلصة من (Gewald, et. al., 2006) الاتجاهات نحو الإحالة. 


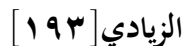

يوصف صدق الأداة على وفق مـا ذكره (Eble, 1972, 555) بأنه درجة تقارب أو أو أنس

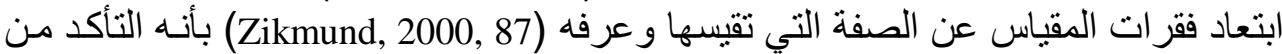

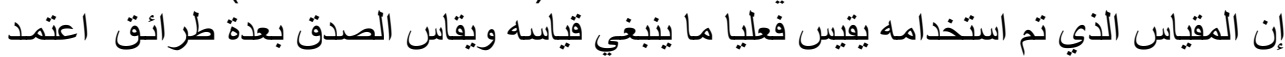

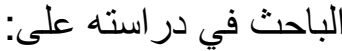

الصدق الظاهري

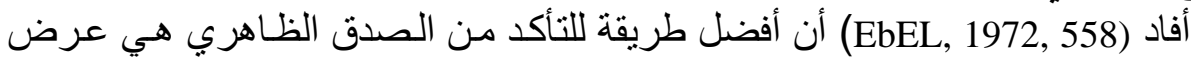

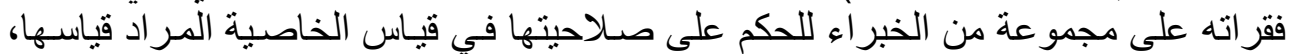

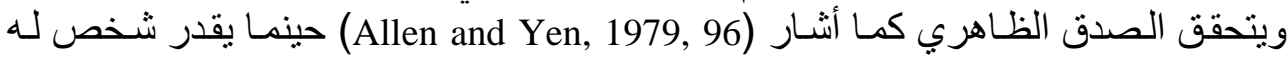

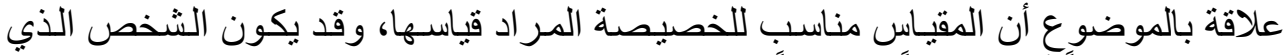

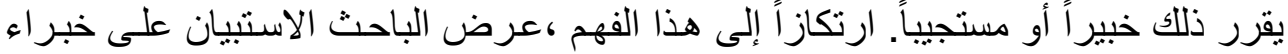

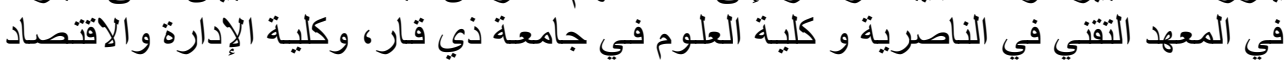

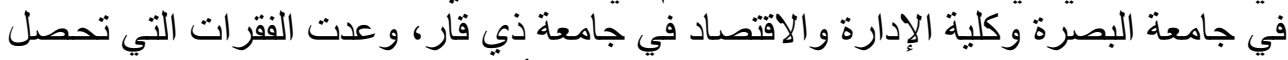

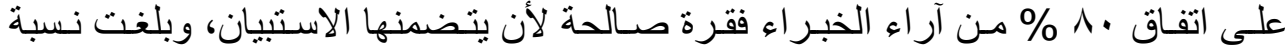

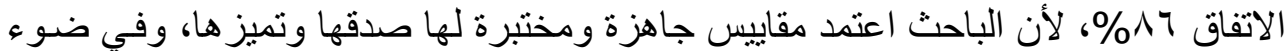

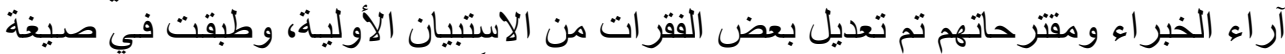

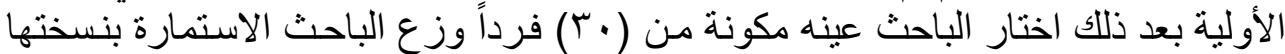

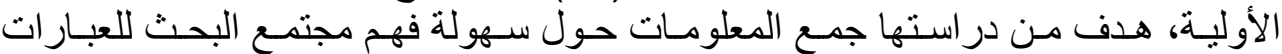

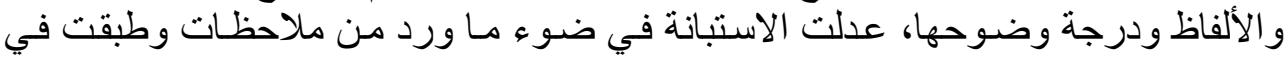

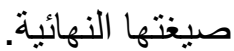

أثنارت در اسة (Premkumar and Bahattachrjee, 2008, 71) إلى أن الباحث عندما

الصدق العاملي

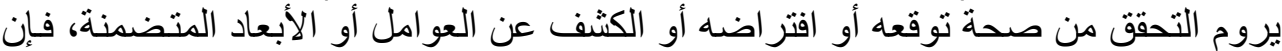

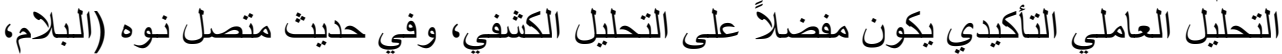

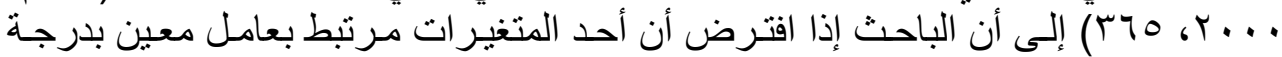

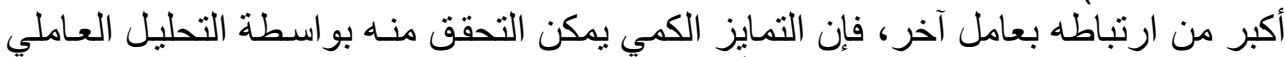
التأكيدي، وينطبق الوصف المذكور آنفاً على الدراسة الحالية، لأن فقراتها التها التي تقيس الأبعاد

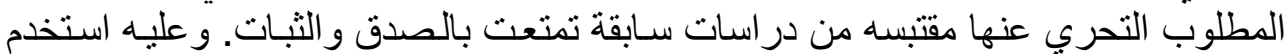

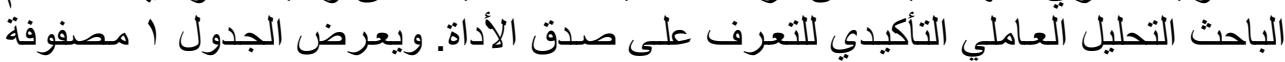

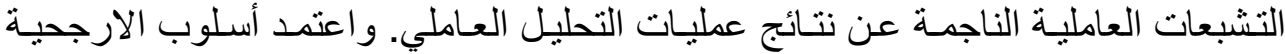

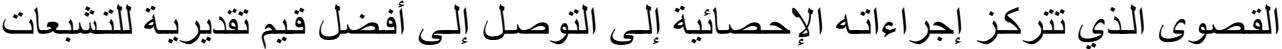

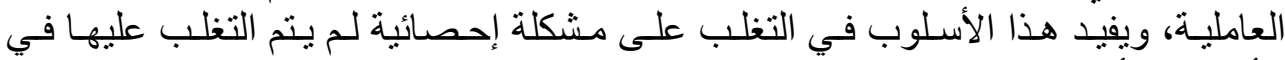

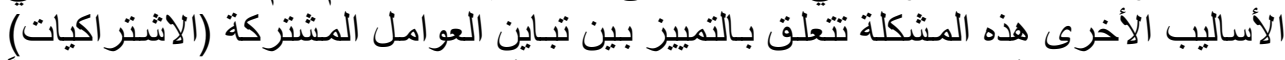

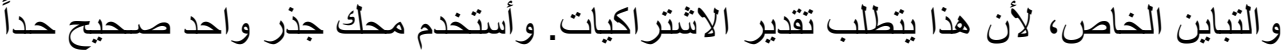

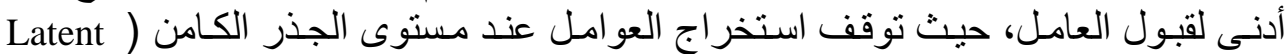
Factor

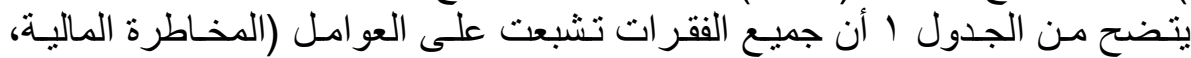

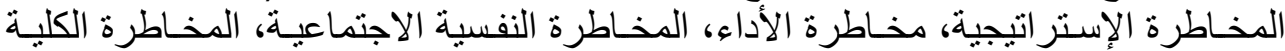

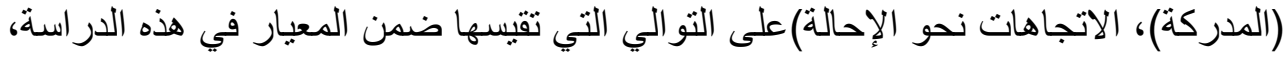




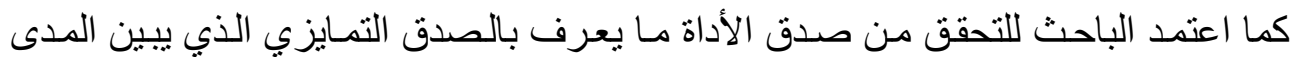

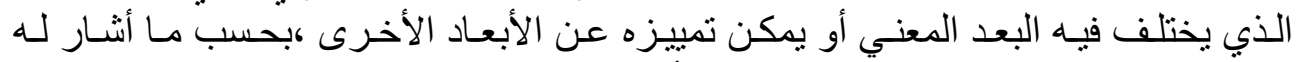

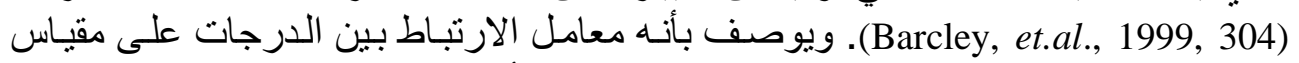

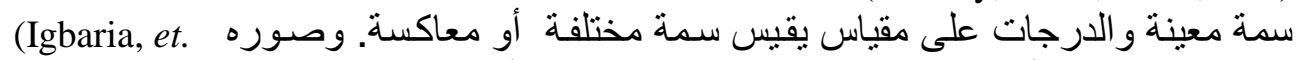
al., 1995, 229 بأنه الدرجة التي تتمايز الفقرات بين الأبعاد، ويتحقق حينمـا تتشبع الفقرات

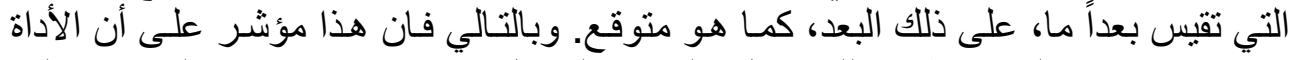

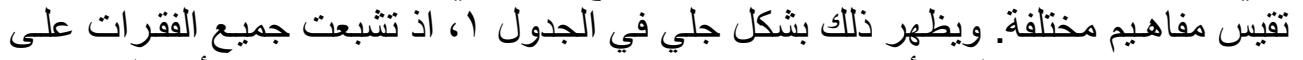

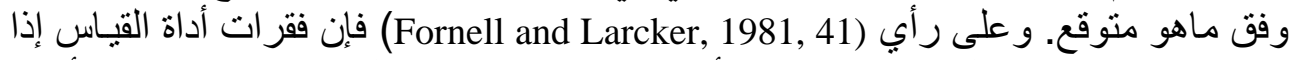

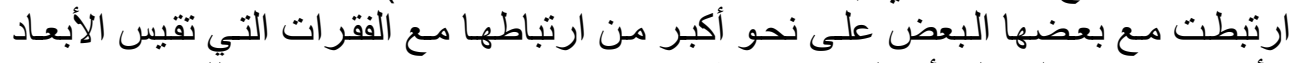

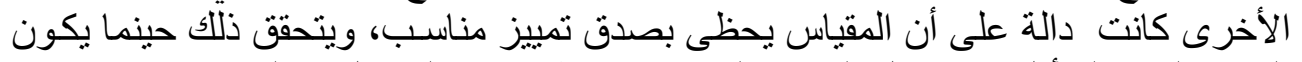

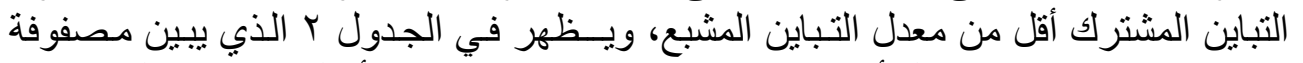

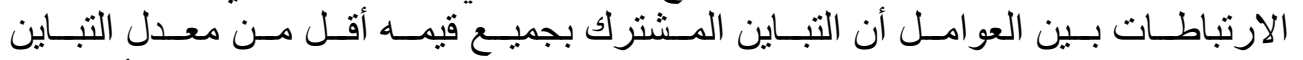

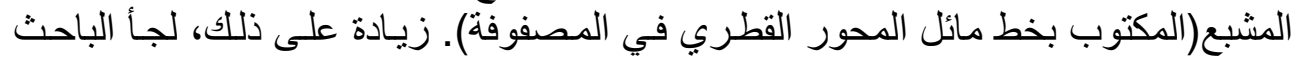

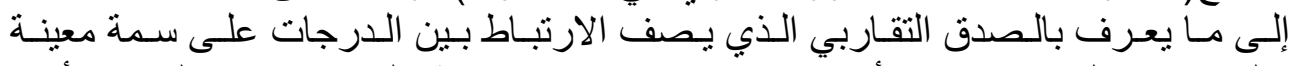

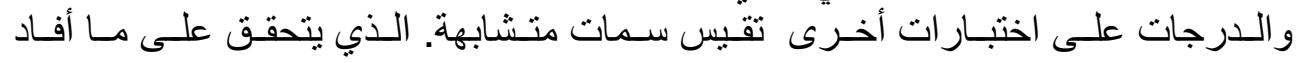

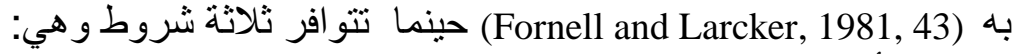
ا . يجب أن يزيد معدل التباين المشبع لكل بعد عن (0. • ( ).

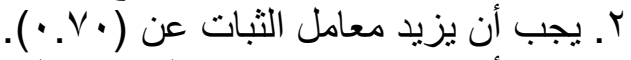

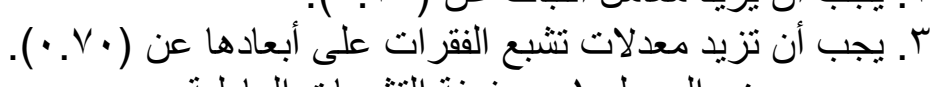
ويعرض الجدول ا مصفوفة التشبعات العاملية.

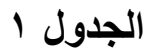

مصفوفة التحليل العاملي

\begin{tabular}{|c|c|c|c|c|c|c|c|c|}
\hline الاشتر اكيات & السادس العل & 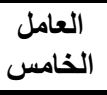 & 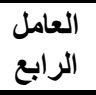 & التالث الثل & التاني & 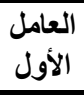 & مضمون الفقرة & $ت$ \\
\hline..$v 1$ & .11 & $.1 \leq$ &. .17 &. $.1 Y$ & .11 & $\mathrm{Vq.}$ & تتجاوز كلفة الإحالة ما يخطط له & 1 \\
\hline$\cdot . \wedge 1$ &. .11 &. $.1 Y$ &. .11 & $.1 \leqslant$ & .19 & $\cdot . \wedge 1$ & يحاول مجهز الخدمة زيادة أرباحه & $r$ \\
\hline$\because \vee \cdot$ & .14 & $\because \mathrm{IV}$ &. .14 &. $.1 \mathrm{~V}$ & .11 & $\because \vee \wedge$ & 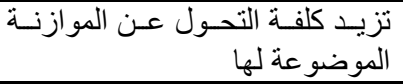 & $r$ \\
\hline$\cdot .94$ & .19 & .17 & $\cdot .11$ & $\cdot . r$ &.$\wedge r$ & $\cdot r$ & تصنبح شـركتي معتمدة على مجهز & $\varepsilon$ \\
\hline.$\wedge \wedge$ & $.1 \cdot$ & $\because \cdot 1$ & $\cdot .19$ & $\cdot r r$ &.$\wedge \uparrow$ & $\because$ r & 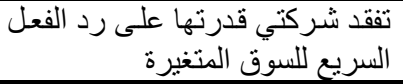 & 0 \\
\hline$\because \vee \wedge$ & .11 & سז. & $\cdot r \cdot$ & $\because \cdot \wedge$ & $\because V V$ & $\cdot .19$ & 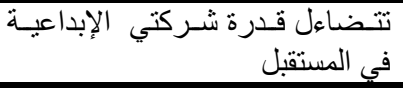 & 7 \\
\hline .91 & .0 &. ro & 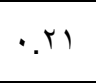 & $\because .9$ & $\cdot \wedge 7$ & $\because 11$ & تتخمة لديها شـركتني عـن إدارة وظيفـة & $\mathrm{V}$ \\
\hline .97 & .11 & $\because \cdot 1$ & . M & $\cdot \wedge \mathrm{V}$ & .14 & $\cdot .11$ & نحتاجر مجهز الخدمة إلى الخبرة التي & $\wedge$ \\
\hline
\end{tabular}


[190] الزيادي

\begin{tabular}{|c|c|c|c|c|c|c|c|c|}
\hline الاشتر اكيات & السادسل & 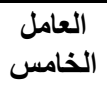 & المابعل - العل & المالث الثالث & التاني & الأول & مضمون الفقرة & $ت$ \\
\hline$\cdot{ }^{\wedge 1}$ & $\because$ IV & $.1 \leqslant$ & .19 & $\cdot . \wedge r$ & $\because 9$ & $.1 \leq$ & تلتجـهـ جـودة الخدمات المجهزة لنـا & 9 \\
\hline .77 & $\because \cdot 9$ & $\cdot .11$ & .17 & $\cdot \sqrt{ } 7$ & $.1 T$ & $.1 \mathrm{~V}$ & تقل عمام مجهز الخدمـة خدمات مختلفة & 1. \\
\hline$\because \vee 4$ & .11 & $\because \cdot 1$ & $.1 \leq$ & $\cdot . \wedge r$ & .11 &. .17 & لا يتعاون العاملون في شركتي مـع & 11 \\
\hline$\cdot \wedge T$ & $\because \cdot 7$ & .17 & $\because V 7$ & .1 & $.1 \leq$ &.$Y_{1}$ & 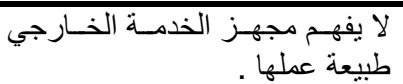 & $T$ \\
\hline$\cdot .71$ & $\because \cdot 1$ & $.1 \leqslant$ &.$V T$ & $\cdot .9$ & .17 & $.1 \leq$ & تضر الإحالة بمكانتي بين الزملاء & ir \\
\hline$\cdot . \wedge r$ & תו & $\cdot r_{1}$ & $\cdot{ }^{\wedge}$ & .19 & $\cdot r r$ & .11 & تخنــف الإحالــة ضـرر أ لا يمكـن & $1 \leq$ \\
\hline$\because \vee \wedge$ & $.1 \leqslant$ & $\cdot . \wedge$ &. $.1 r$ & . & $\cdot r_{1}$ & .11 & برتكبة شركتزا الخدمة أخطاء تضر & 10 \\
\hline$\because \vee 7$ & $\because \cdot 1$ & . & .11 & .11 & $\cdot .1 T$ & $\because 1$ & 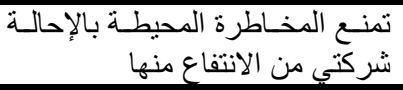 & 17 \\
\hline$. V \leqslant$ & $\because \cdot 1$ & $\cdot . \wedge r$ & .19 &. .11 & $\because \wedge$ &. .7 & تنطوي الإحالة على مخاطرة عالية & IV \\
\hline.$\vee V 7$ &. .19 & $\because .7$ & $\because \cdot V$ & $\because \cdot r$ & $\because .9$ & $\because \cdot \Lambda$ & انظر إلى الإحالة بايجابية & 11 \\
\hline .10 & .97 & $\because \varepsilon$ & $\cdot .7$ & $\therefore .9$ & $.1 \leq$ & $\because \cdot \wedge$ & تحظى الإحالة بالجاذبية & 19 \\
\hline$\cdot . \wedge r$ & $\cdot . \wedge \wedge$ & $\because .0$ & $\because+7$ & $\because \cdot V$ &. .14 & $\because 1 \cdot$ & 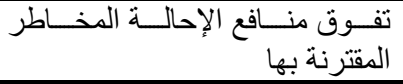 & $r \cdot$ \\
\hline 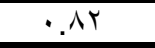 & .9 . &. .1 & $\because \cdot 1$ & $\therefore .9$ & .11 &. $.1 T$ & تضيف الإحالة قيمة إلى شركتي & YI \\
\hline \multirow[t]{4}{*}{17.1} & r.Ar & r.T & T.YY & $r .0$ & $r .9$ & r.tr & الجذر الكامن & \\
\hline & $\because 11$ & $\cdot .97$ & $.1 \leqslant$ &. .19 & .19 & $.1 \leqslant$ & التباين المشترك & \\
\hline & .11 &. .14 & .11 & .10 & .10 & .11 & التباين الكلي & \\
\hline & .10 & $\cdot .7 \varepsilon$ & $.0 Y$ &..$\leqslant 1$ &. .47 & .11 & النسبة المئوية للتباين المتر اكم & \\
\hline
\end{tabular}

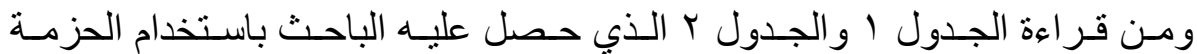

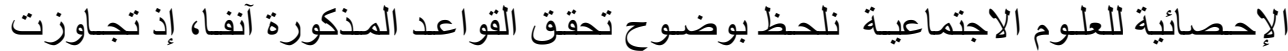
التشبعات لكل فقرات الدر اسة المستوى المطلوب. وان هذان هذا النسبة كما ذكر (Fornell, 1982)

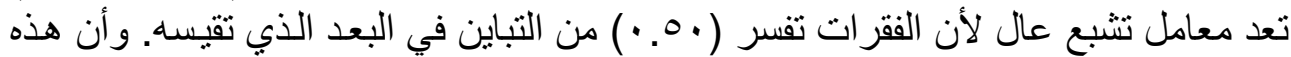

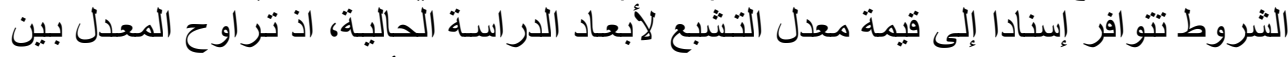

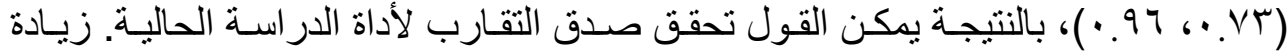

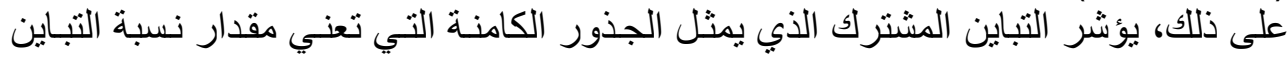

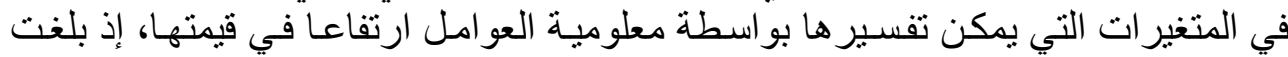

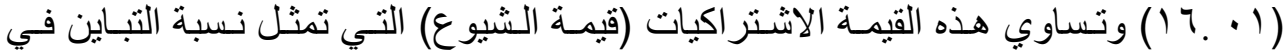

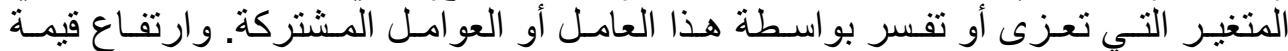

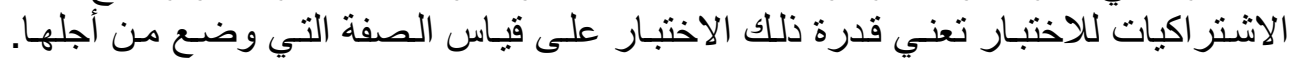

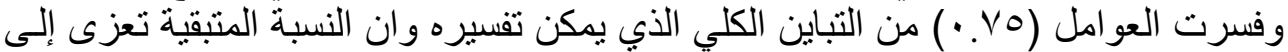

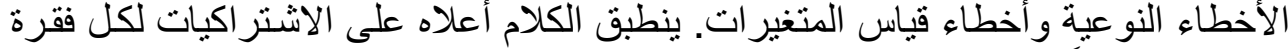

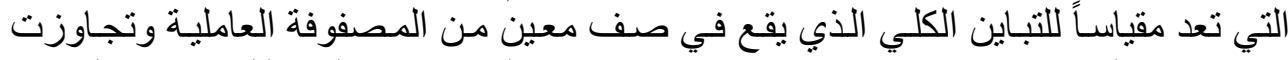

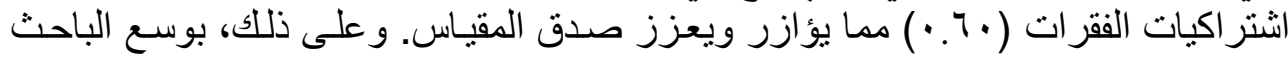


القول إن فقر ات القياس مميزه عاملياً وأحادية الاتجاه.

\begin{tabular}{|c|c|c|c|c|c|c|}
\hline \multicolumn{7}{|c|}{ مصفوفة الارتباط } \\
\hline الاتجاهات & المداطرة & الاجتماعية & مخاطرة & الإستر اتيجية & المالية & المتغير \\
\hline & & & & &. $.9 \mathrm{~V}$ & المخاطر المالية \\
\hline & & & & $\cdot . \wedge r$ &.. $\mathrm{VV}$ & المخاطر الإستر اتيجية \\
\hline & & & $\cdot . \wedge r$ & $\because .9$ &. .14 & مخاطر الأداء \\
\hline & & $\cdot .17$ &. $.1 \varepsilon$ & $\because 11$ &. .14 & المخاطر النفسية ـ الاجتماعية \\
\hline & $\cdot . \wedge \varepsilon$ & $\cdot . \varepsilon_{0}$ &. .49 & $\cdot .17$ & $\cdot . \S 1$ & المخاطر المدركة(الكلية) \\
\hline$\cdot . \wedge q$ & $\because .0 \mathrm{~V}_{-}$ & $\therefore \leqslant 9-$ & $\cdot . \varepsilon 9_{-}$ & $\theta \varepsilon Y_{-}$ & $\therefore \vee V \varepsilon-$ & الاتجاهات نحو الإحالة \\
\hline
\end{tabular}

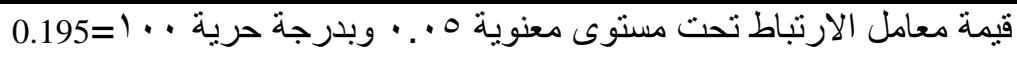

\section{ب. ثبات الأداة}

حُسب معامل التبات باستخدام معادلة (Cronbach alpha) التي تعد من أكثر مقاييس

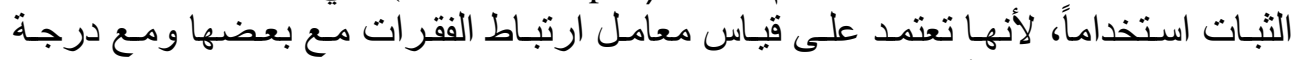

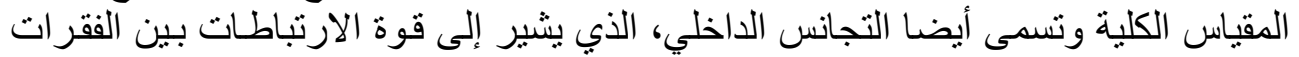

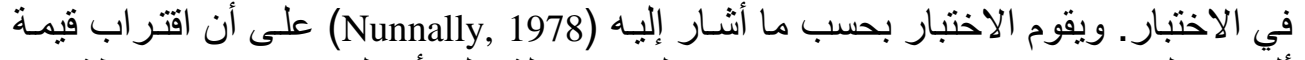

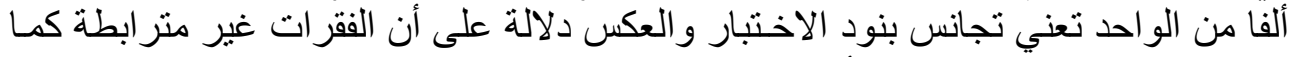

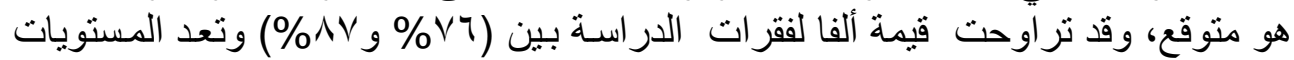
مقبولة معنويا للاختبار . مترك

\begin{tabular}{|c|c|c|}
\hline & معاملاث الجدول آثباد & \\
\hline الفاكرونباخ & البعد البع & \\
\hline .179 & المخاطرة المالية & 1 \\
\hline. .17 & المخاطرة الإستر اتيجية & $r$ \\
\hline.$\vee 17$ & مخاطرة الأداء & $\mu$ \\
\hline. .11 & المخاطرة النفسية ـ الاجتماعية & $\varepsilon$ \\
\hline.$\Delta r$ & المخاطرة الكلية & $\overline{0}$ \\
\hline.$\wedge \mathrm{V}$ & الاتجاهات نحو الإحالة & 7 \\
\hline
\end{tabular}

أولاً الإحالةّ (النشأة والمفهوم والتطور والأهمية)

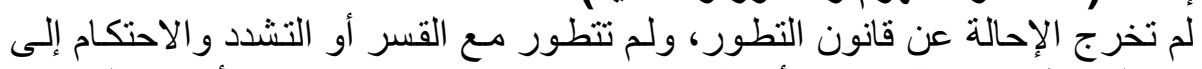

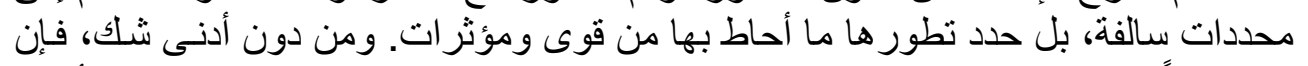

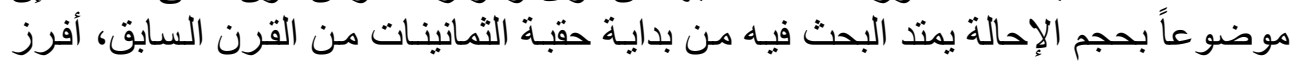

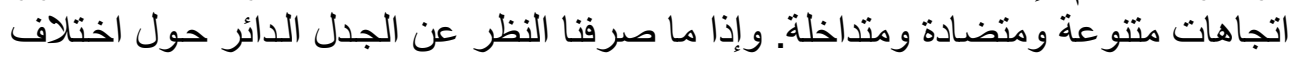




\section{الزيادي[9V}

مشاربها بين مناصر ومخالف لها، فإنتا نحاول في هذا القسم من البحث تلمس مسار اتها ومـا

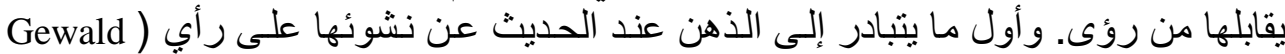

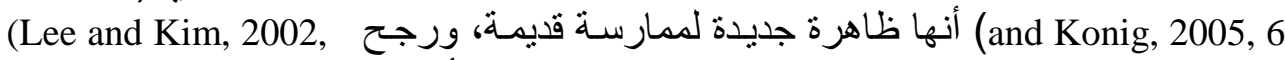

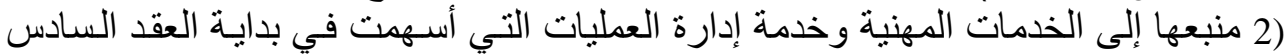

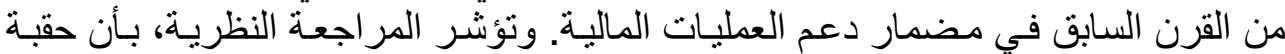

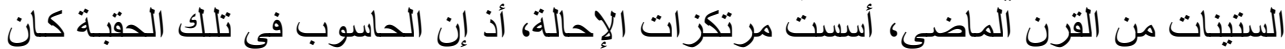

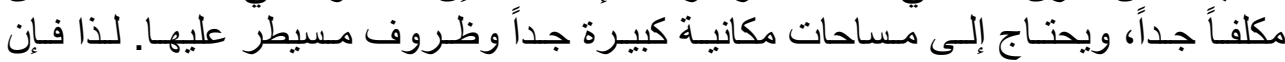
الثركات آنذاك ولغرض التخلص من هذه الاشتراط اطات المكلفة لجأت إلى التعاقد مع مكاتب

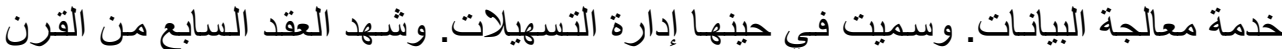

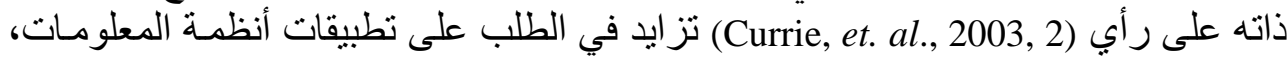

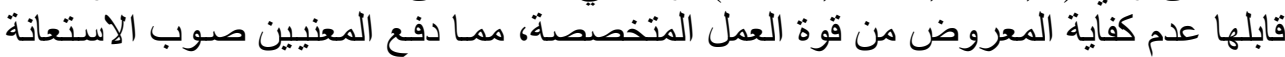

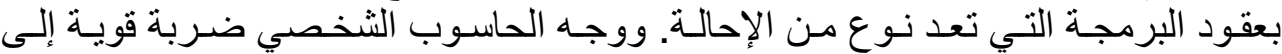

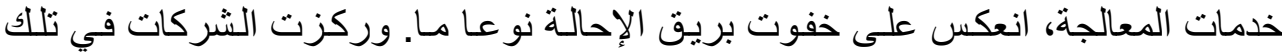

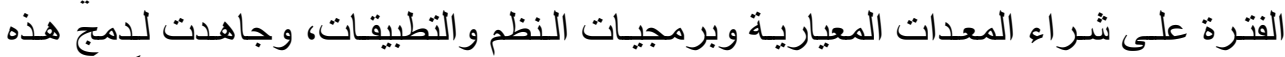

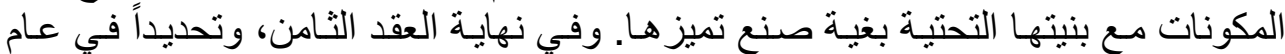

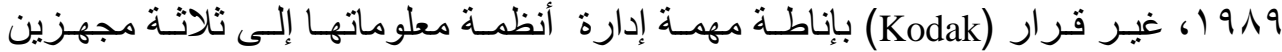

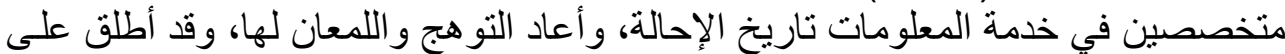

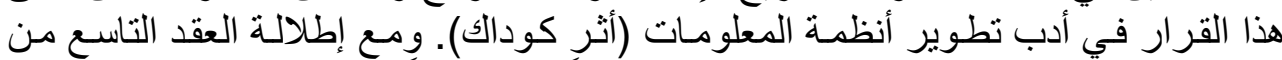

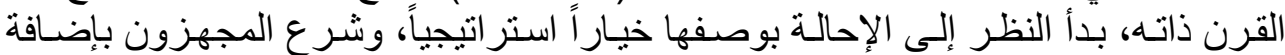

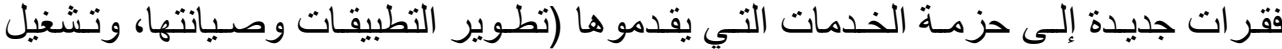

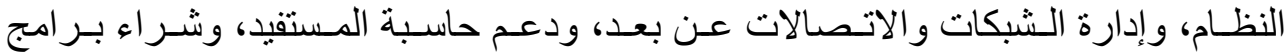

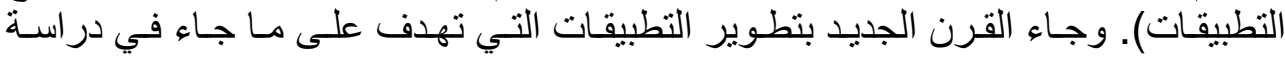
(Desai and Currie, 2003, 6) التطبيق إلى عدد من الكيانات من مركز البيانات عبر شبكات ودات واسعة.

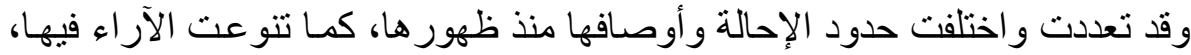

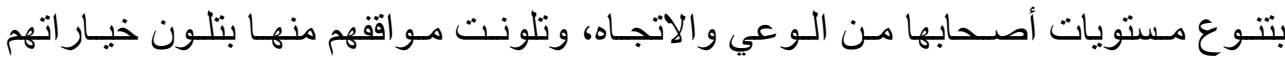

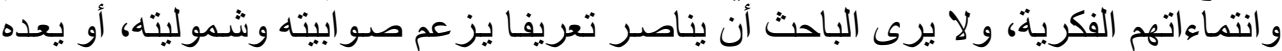

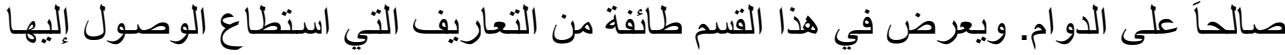

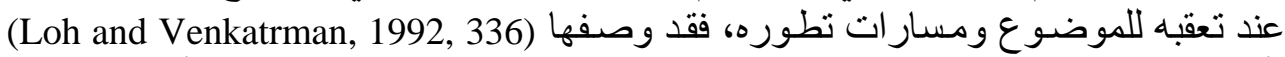

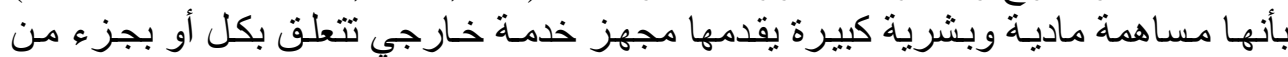

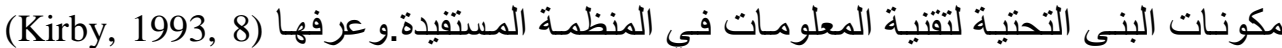

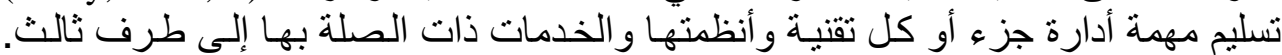

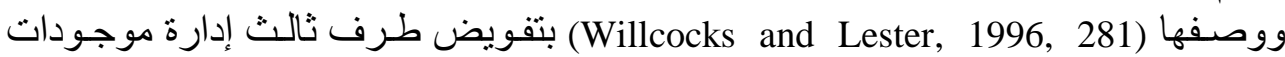
ونشاطات تقنية المعلومـات للوصول إلى النتائج المطلوبـة. وذكر (De Loof, 1995, 284)

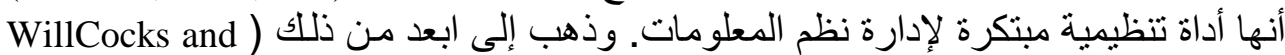

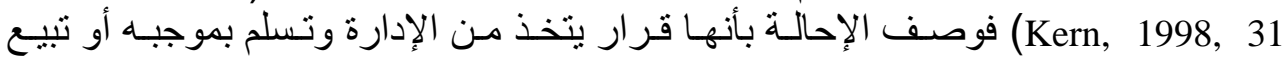

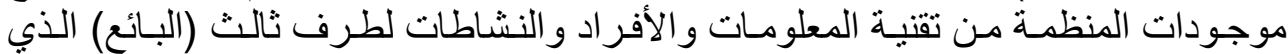

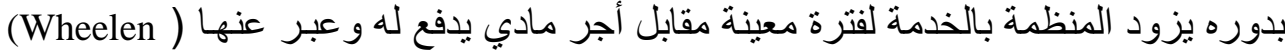
and Hunger, 2002, 431 
الاعتمـاد على القدر ات الداخلية للمنظمهة ووصفها (Beulen and Ribbers, 2002, 3) بأنها

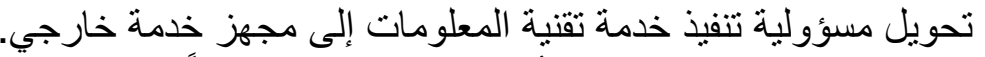

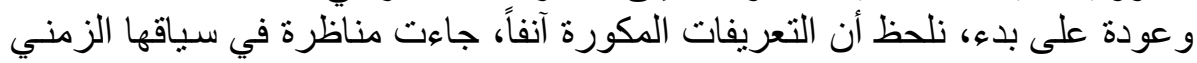

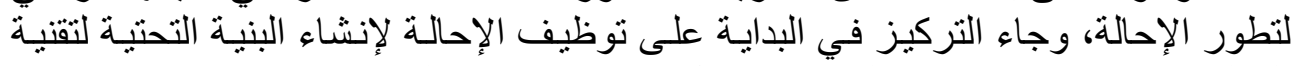

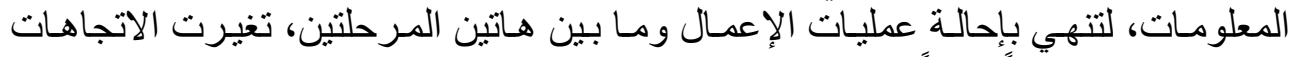

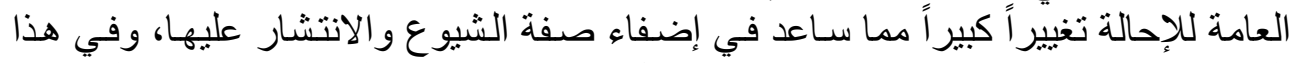

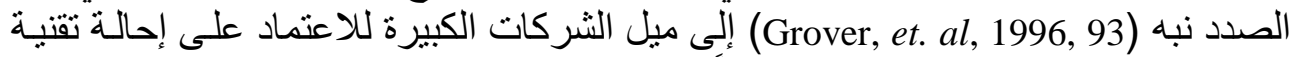

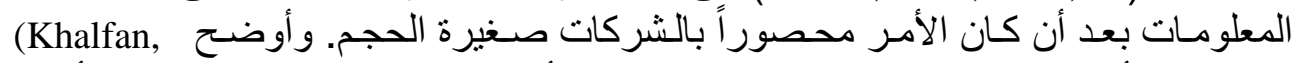

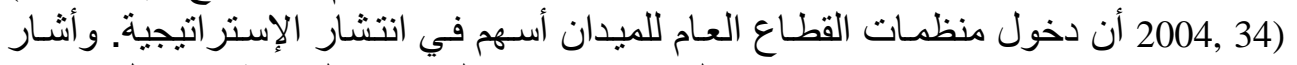
(Loh and Venkatrman, 1992, 336)

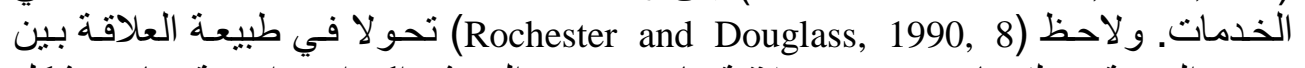

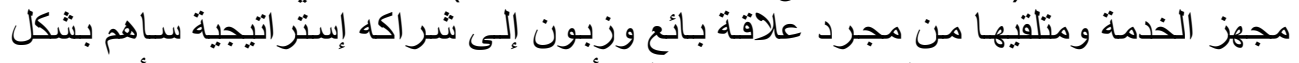

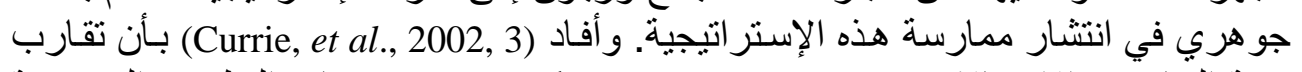

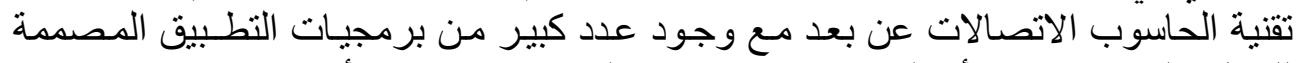

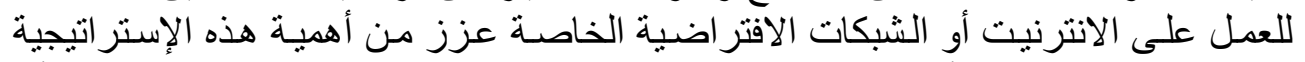

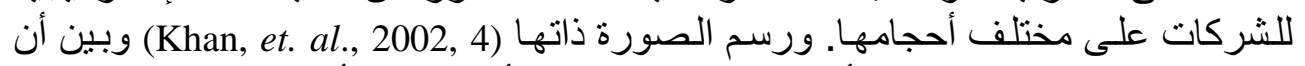

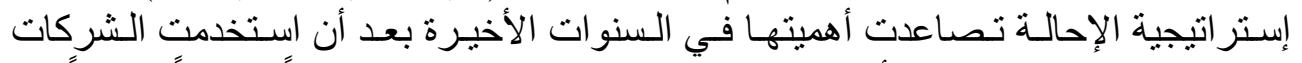

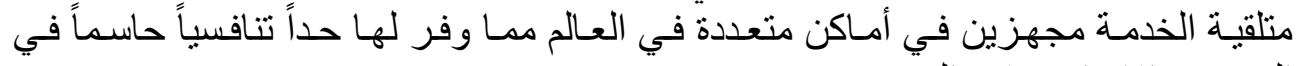

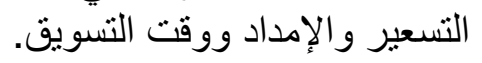

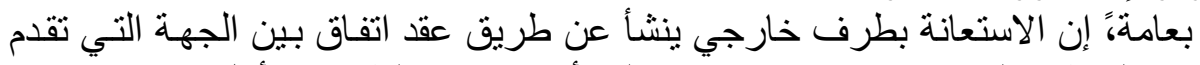

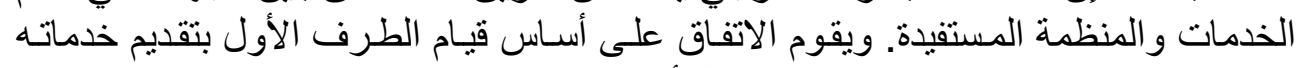

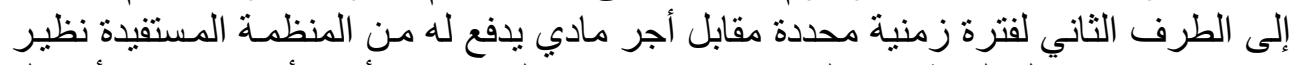

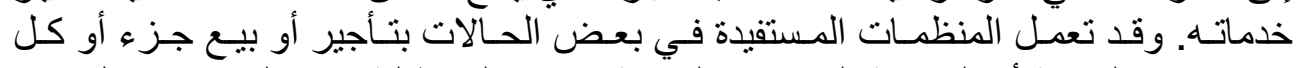

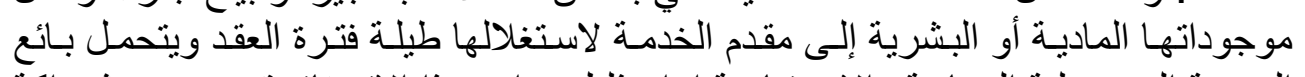

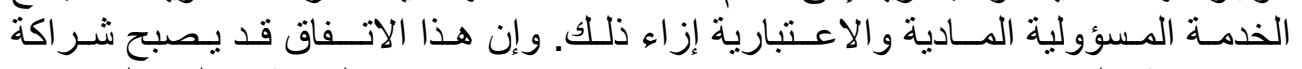

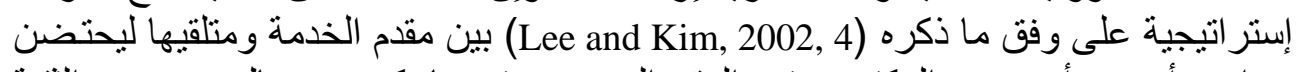

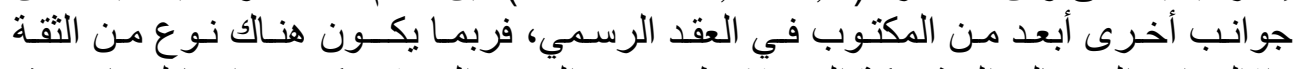

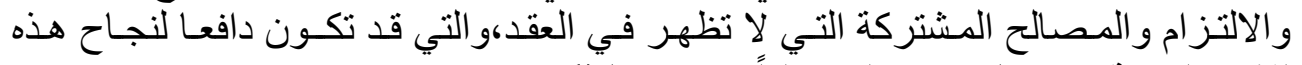

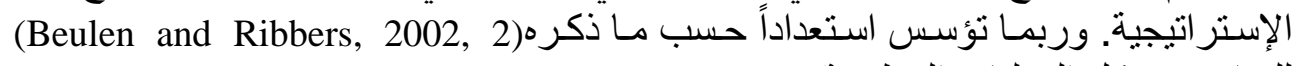
للتعاون في كل العمليات التنظيمية.

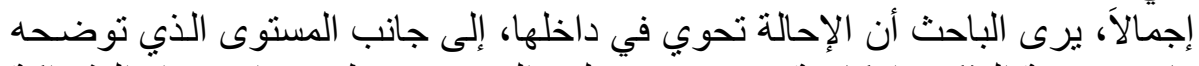

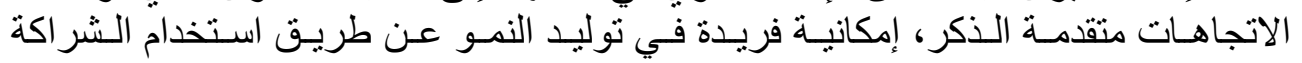

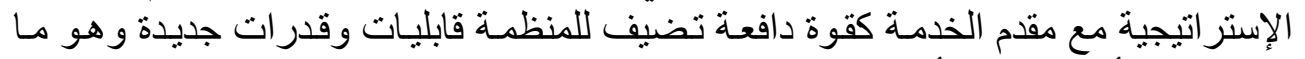

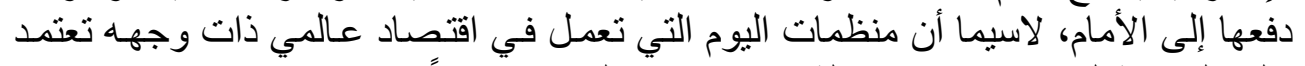

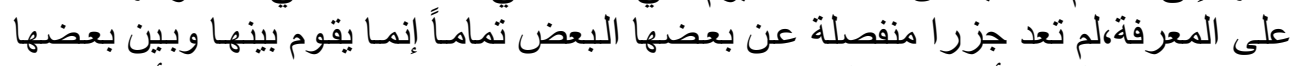

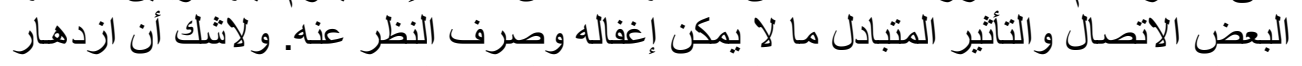

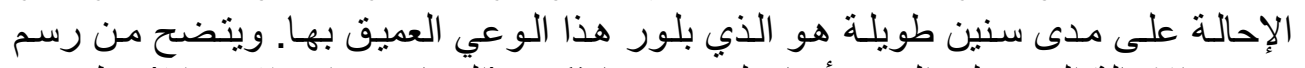

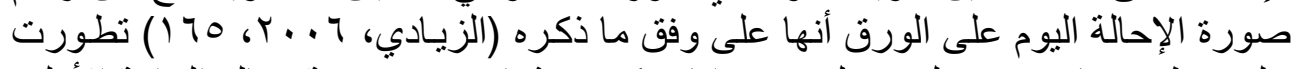

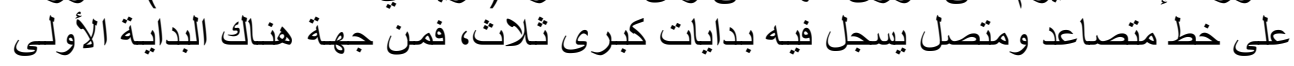




\section{الزيادي[199}

التي أنشرت ملامحها في العقد السادس من القرن السابق. ومن جهة أخرى هناك البداية

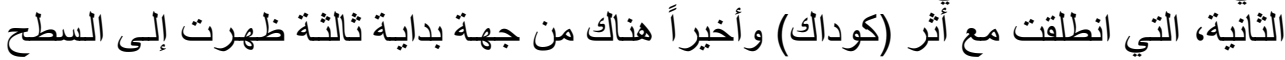

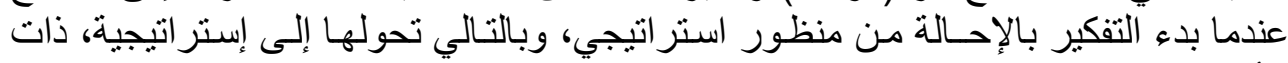
شأن في تطوير تقنية المعلومات.

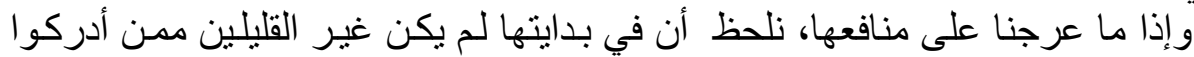

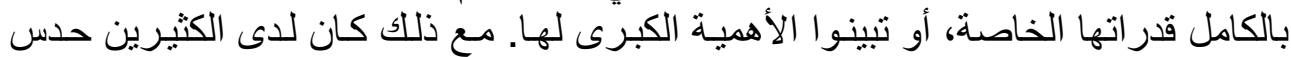

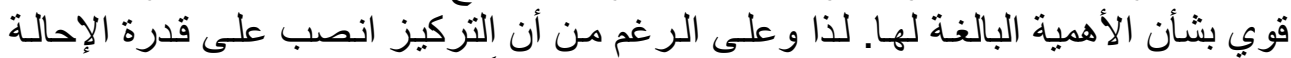

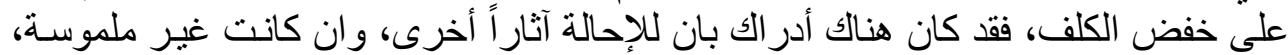

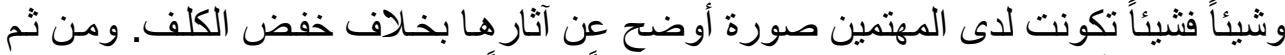

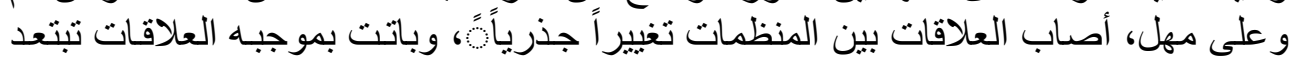

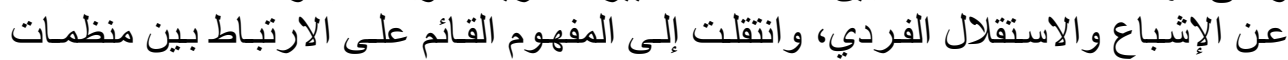

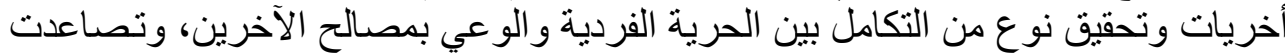

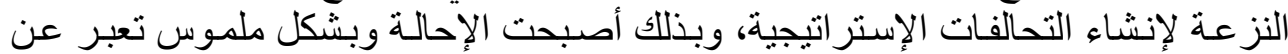

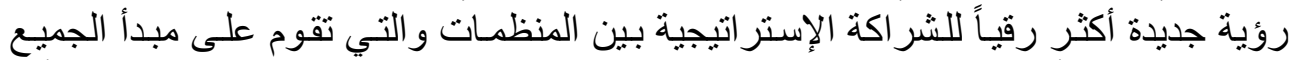

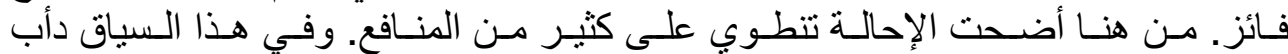

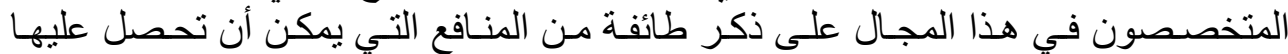

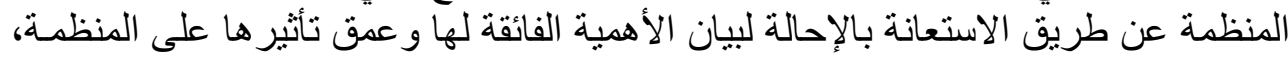

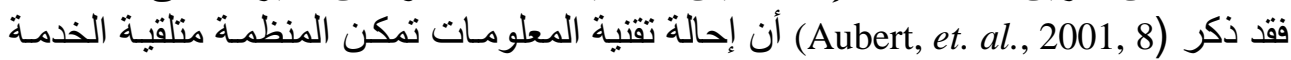

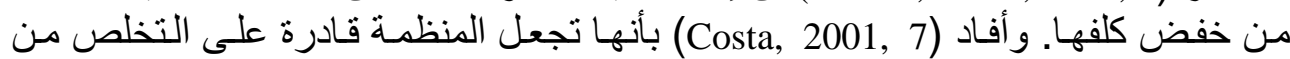

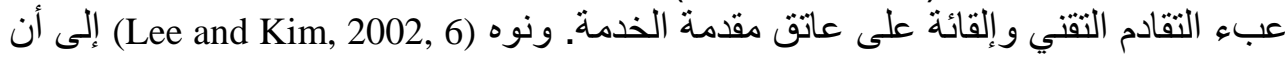

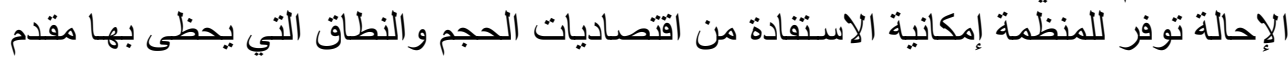

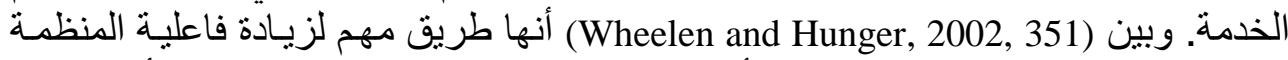
وتحسين نو عية خدماتها ومنتجاتها. وأوضح (Cohen and Young, 2005, 14) أنها تمكن التهن

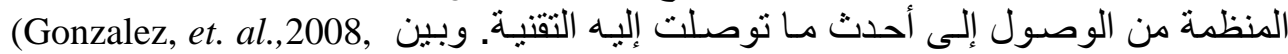

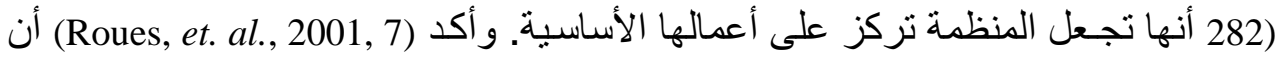

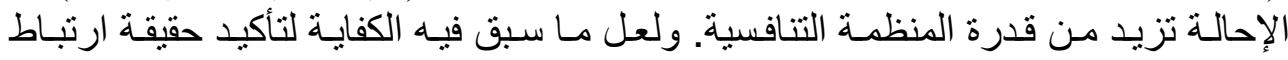

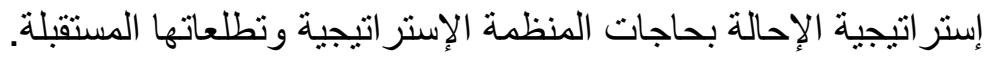

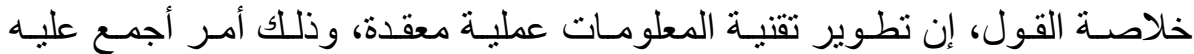

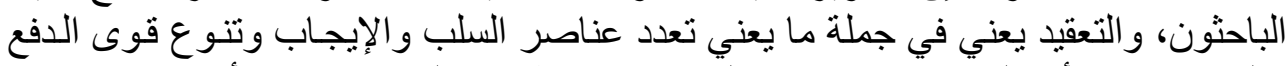

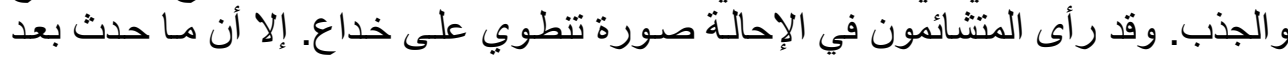

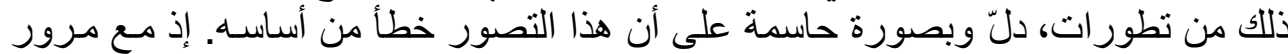

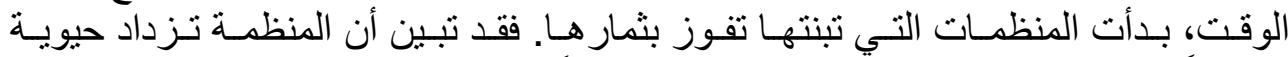

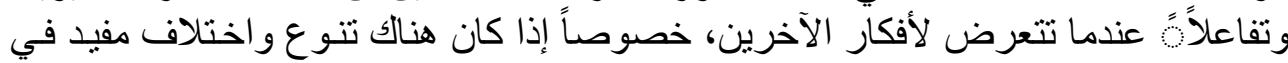

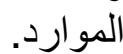

ثانيا- المخاطرة المحيطة بالإحالة

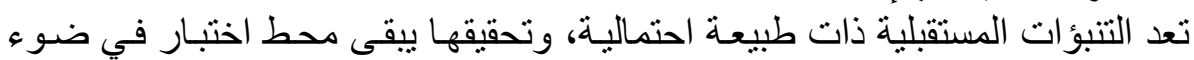

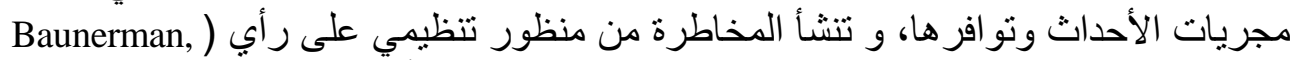

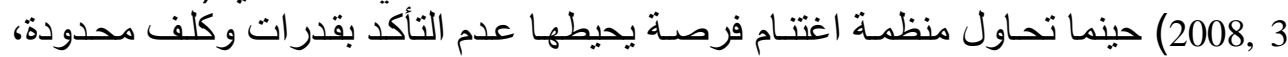

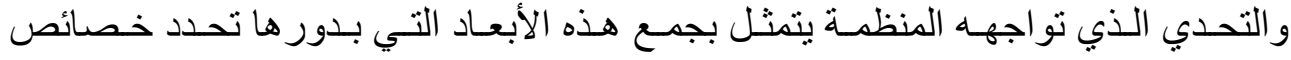


المخاطرة التي تعد مقبولة مبدئيا للمعنيين بها، ويتعين علينا وقبل الشروع بعرض مفهوم

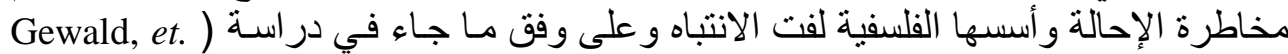
(al., 2006, 81

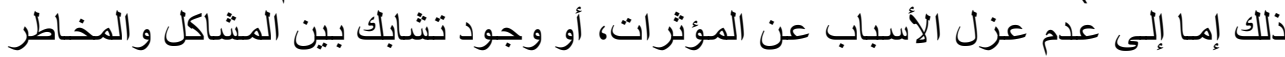

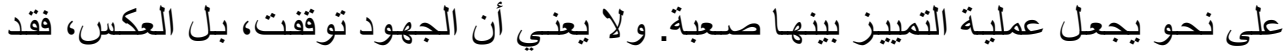

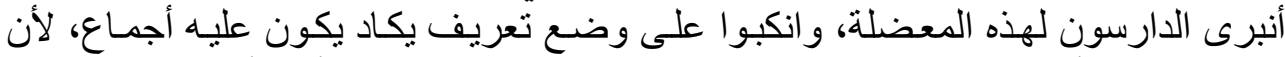

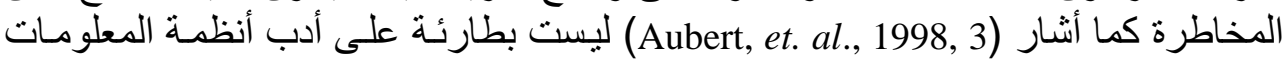

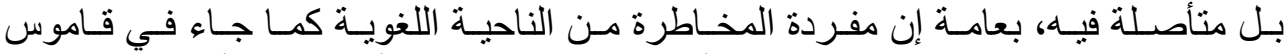
(Webster, 2005)

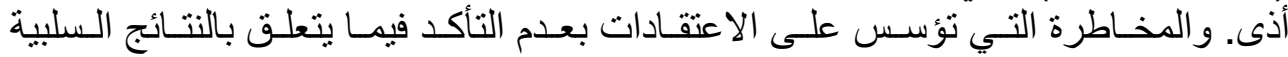

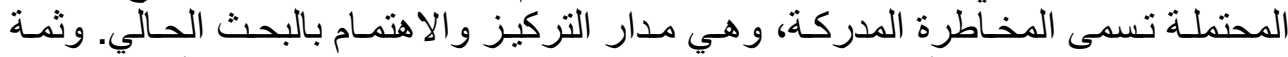

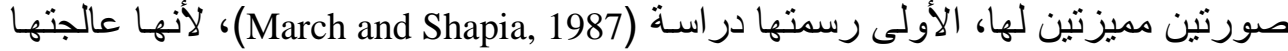

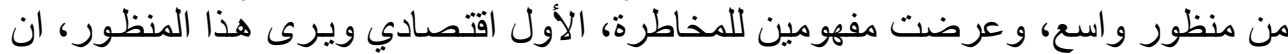

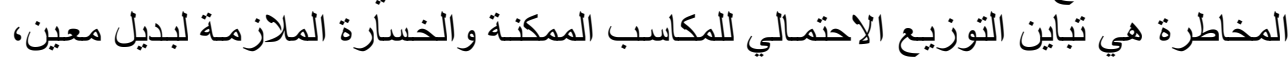

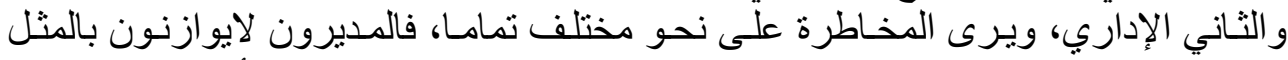

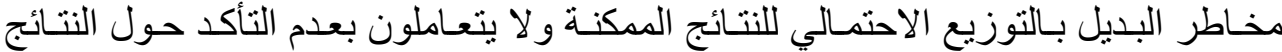

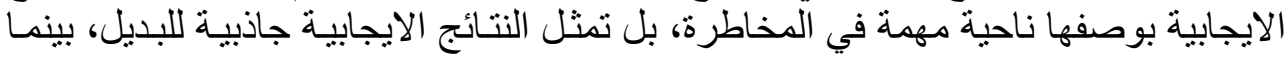

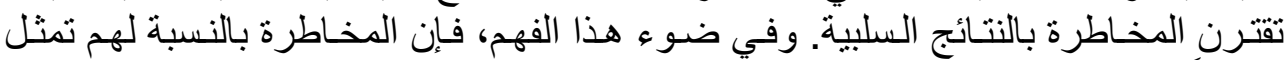

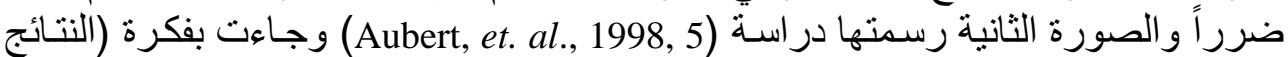

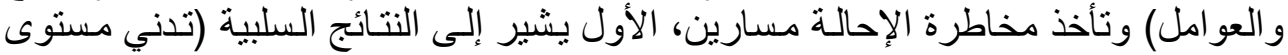

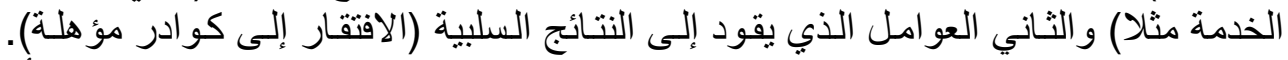

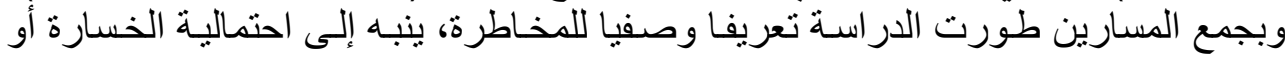

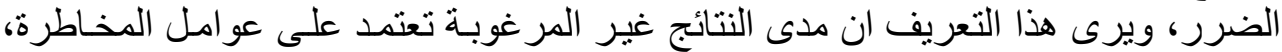

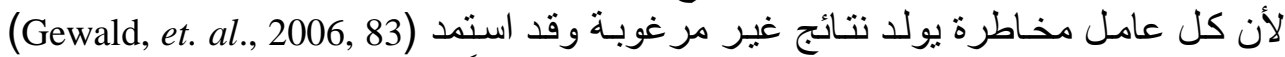

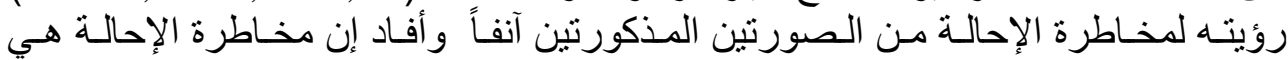

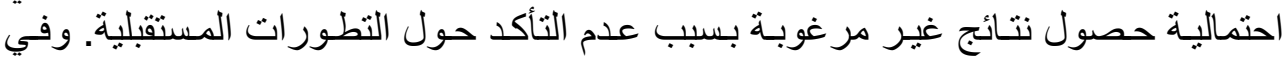
حديث متصل نبه (Wullenweber, 2005, 387) إلى أن المخـاطرة المدركة تعكس اعتقادات الفرد الذاتية حول النتائج السلبية لبعض أنواع السلوك او الفعل المخطط التي ترجع إلى عدم التها

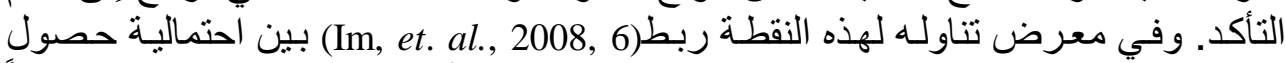

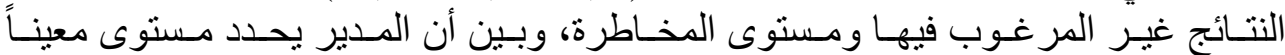

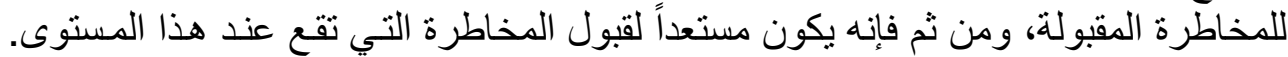

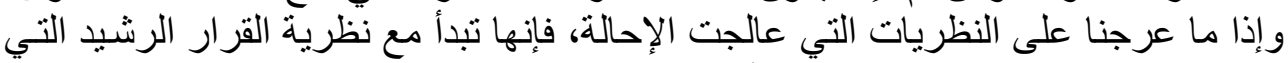

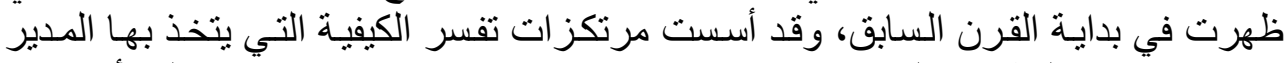

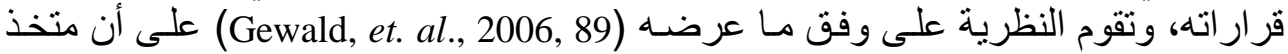

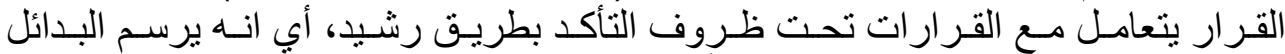

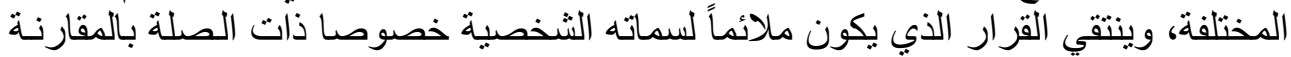

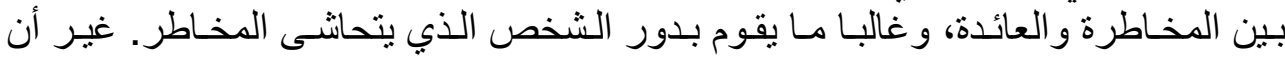

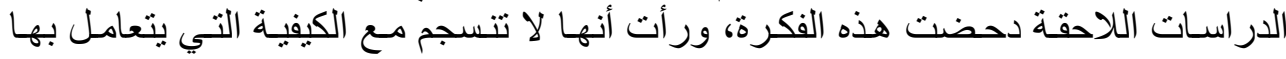

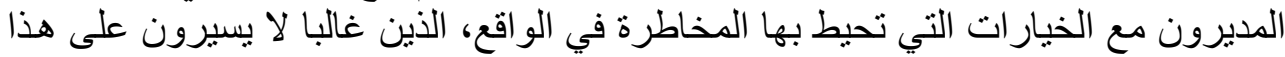




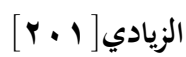

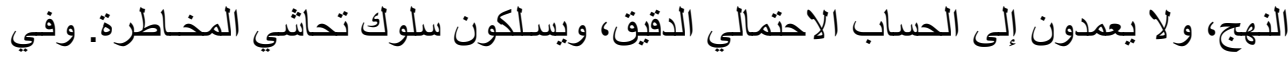

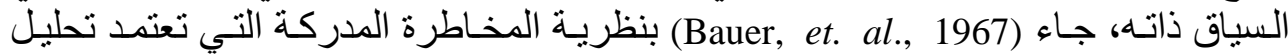

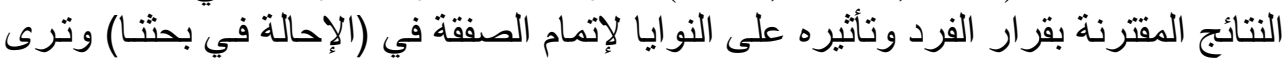

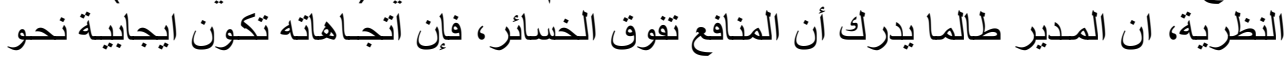

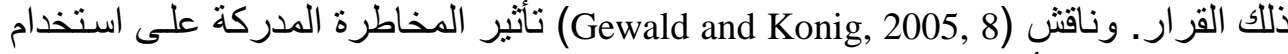

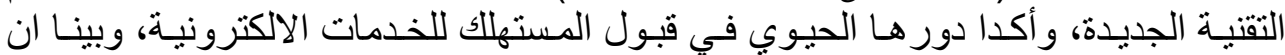

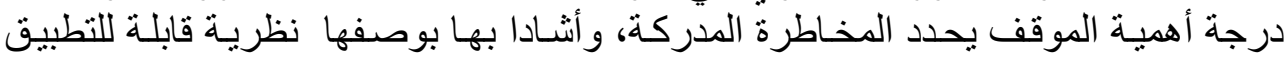

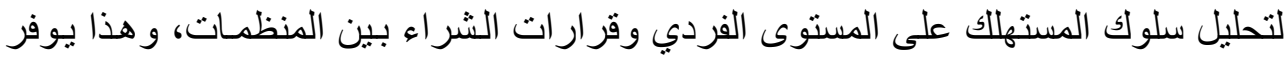

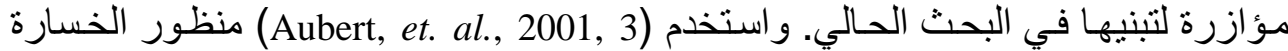

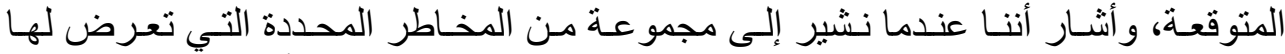

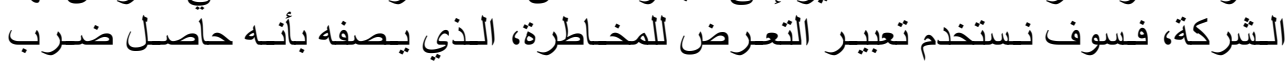

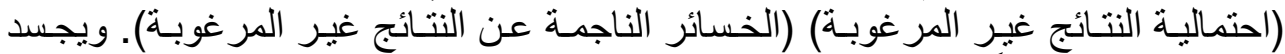

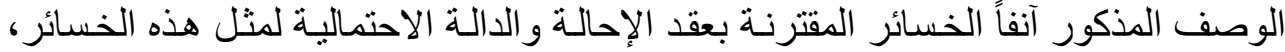

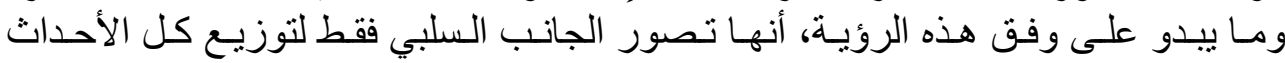
المرتقبة. وعزى (Aubert, et. al., 2005, 11) ذلك إلى الاتجاهـات الايجابيـة للهديرين

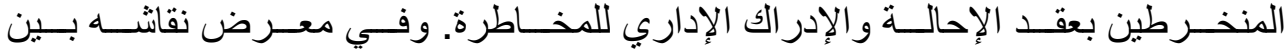

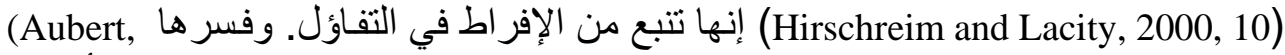
et. al., 2005, 8)

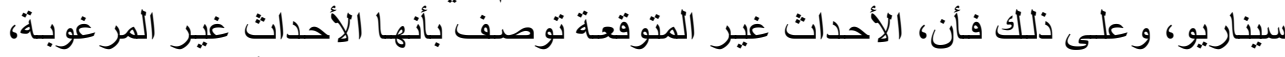

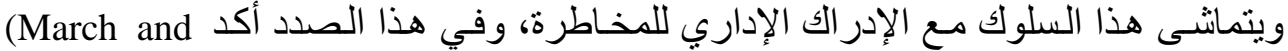
Shapia, 1987, 1410) أن المخاطرة تلازم النتائج السلبية.

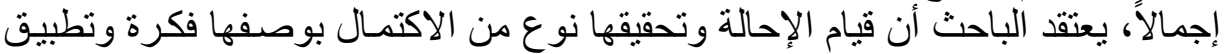

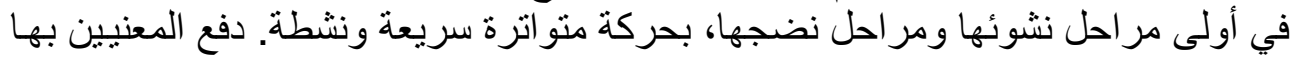

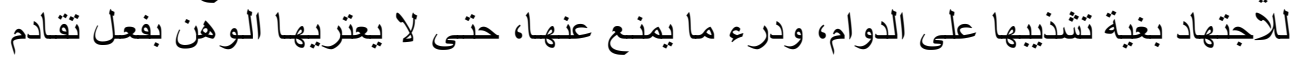

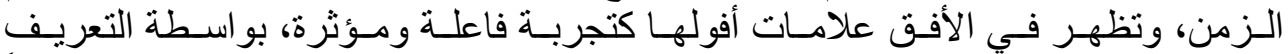

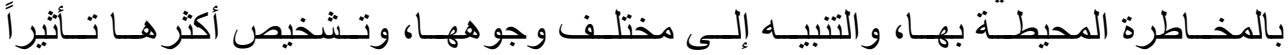

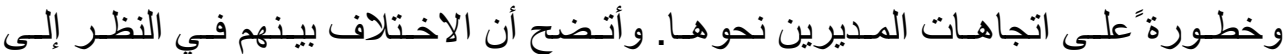

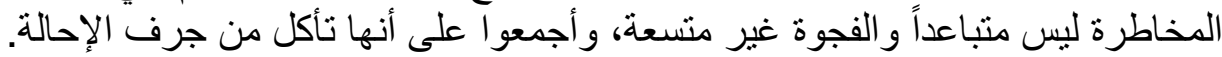

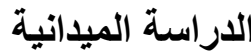

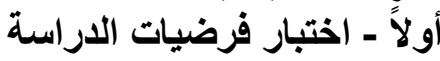

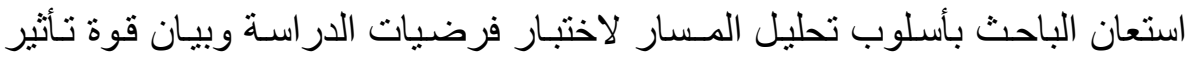

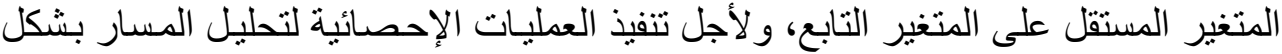
سليم يوصي (Igbaria, et. al., 1995, 243، بإتباع الخطوات النات آلاتية: ا ا. . حساب معامل الثبات للمقياس.

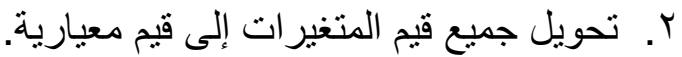

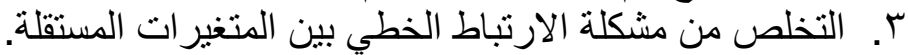

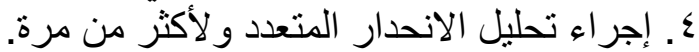




$$
\begin{aligned}
& \text { 0. التخلص من مشكلة الارتباط الذاتي بين بواقي علاقات الانحدار. } \\
& 7 \text { ا إجراء اختبار حسن المطابقة. }
\end{aligned}
$$

الخطوة الأولى: حساب معامل الثبات للمقياس.

وقام الباحث باستخر اج معامل الثبات كما أسلفنا القول.

\section{الخطوة الثانية: تحويل قيم المتغيرات إلى قيم معيارية.}

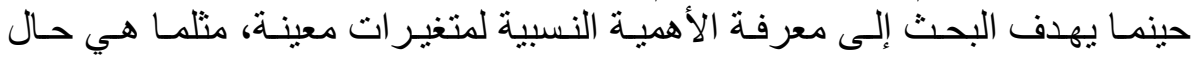

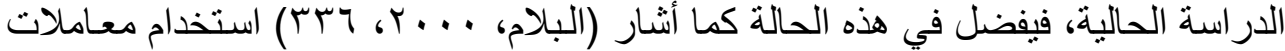

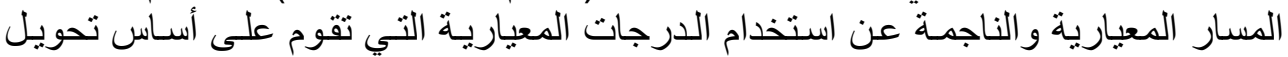

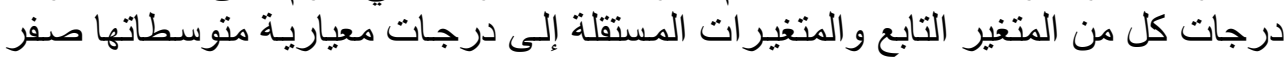

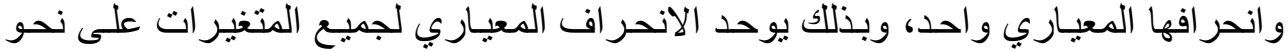

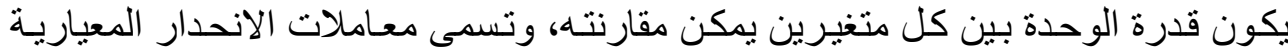
معاملات المسار المعيارية وتقرة ألغين عادة (Beta).

الخطوة الثالثة: التخلص من مشكلة الارتباط الخطي بين المتغيرات المستقلة

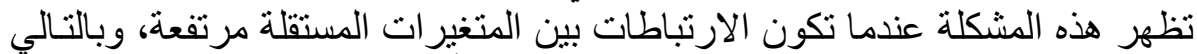

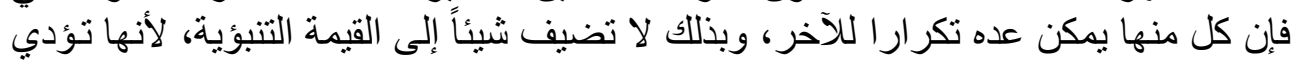

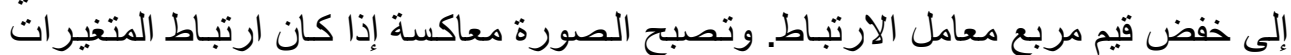

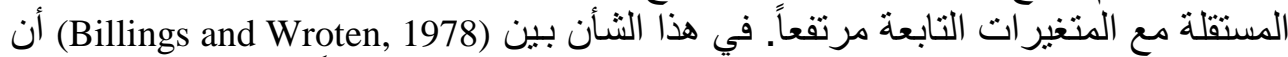

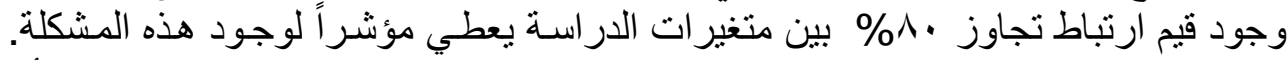

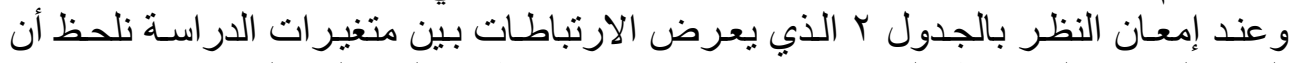

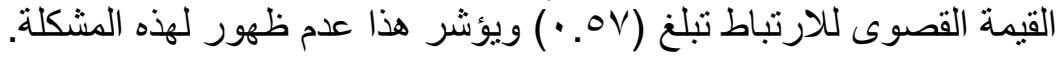

\section{الخطوة الرابعة: تحديد معاملات المسار المعيارية}

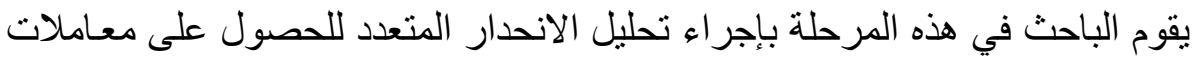

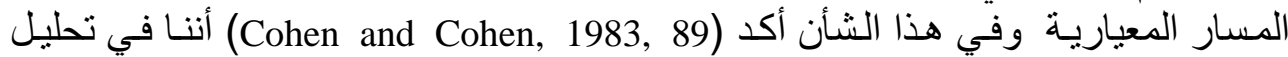
الانحدار المعتاد نقوم بإجراء تحليل الانحدار المتغير التابع على جميع المتغيرات التهرئ المستقلة

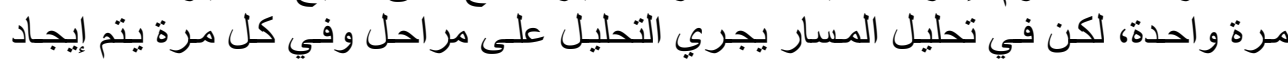

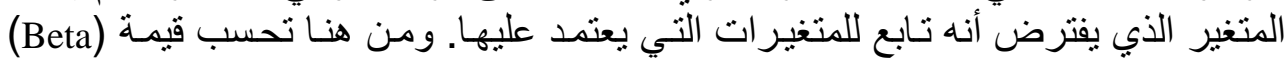

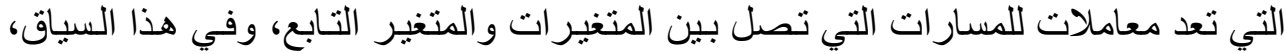

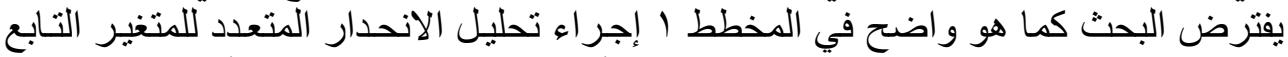

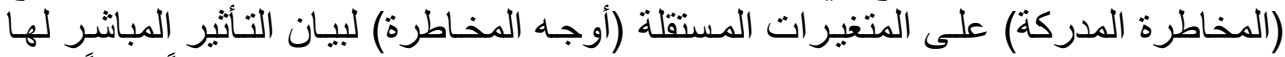

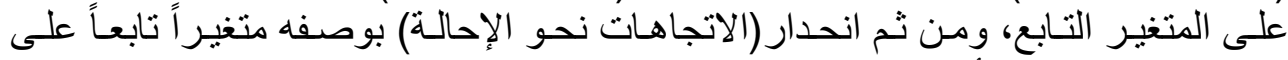

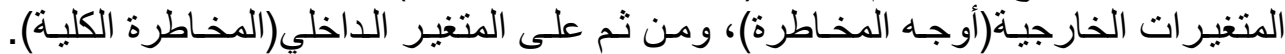
وستظهر النتائج النهائية على مخطط البحث بعد الاختبار .

الخطوة الخامسة: التخلص من مشكلة الارتباط الأتي

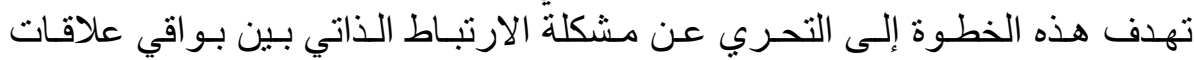




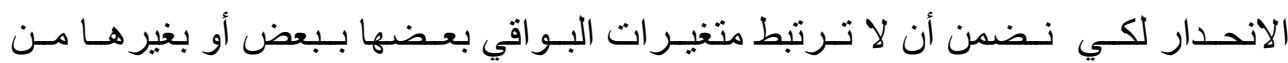

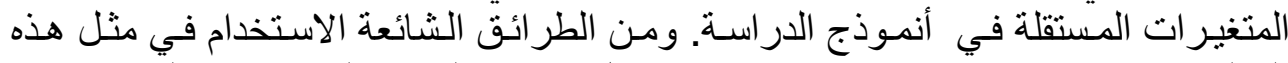

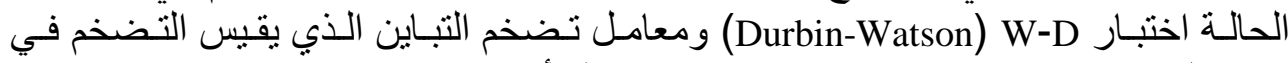

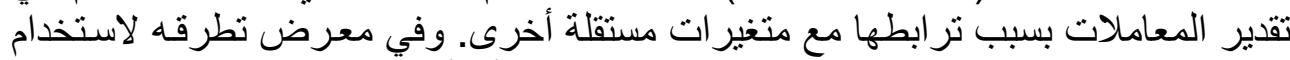

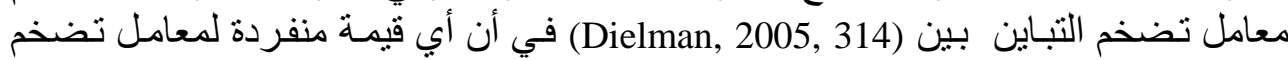

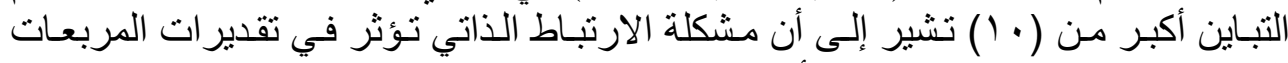

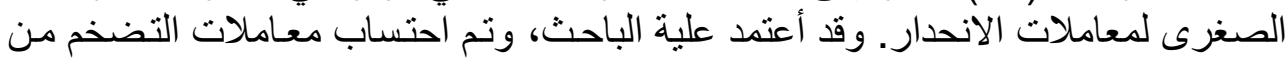

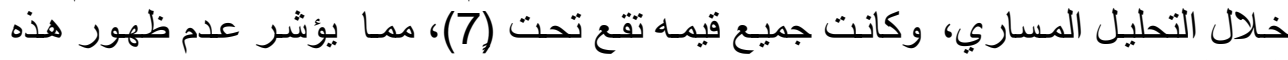

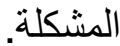

\section{الخطوة السادسة: إجراء حسن المطابقة}

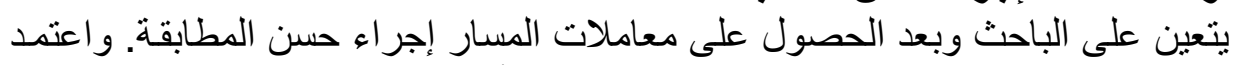

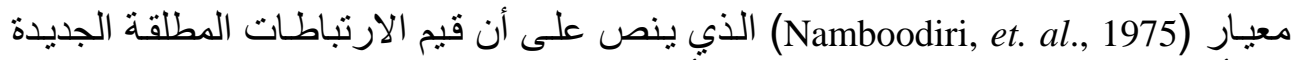

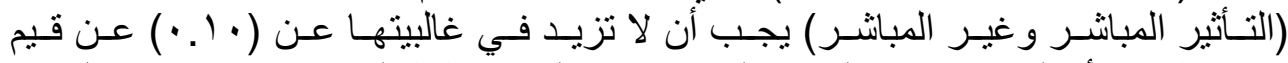

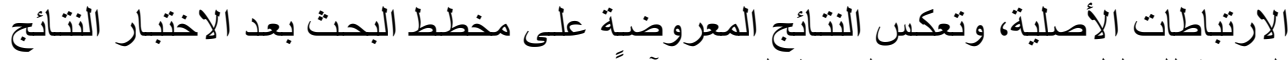

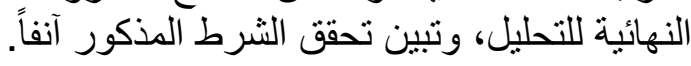

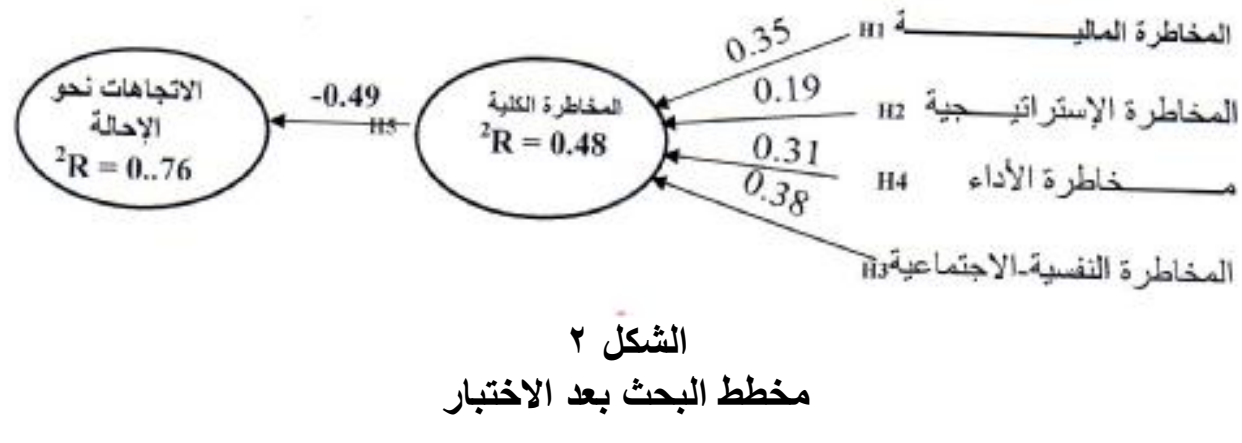

ثانياً- عرض وتحليل النتائج

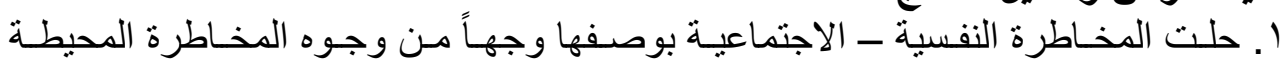

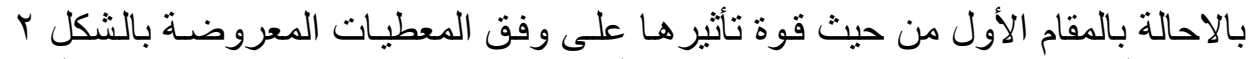

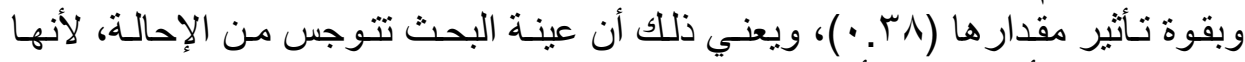

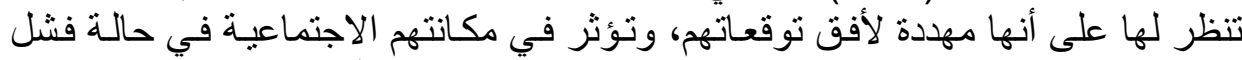

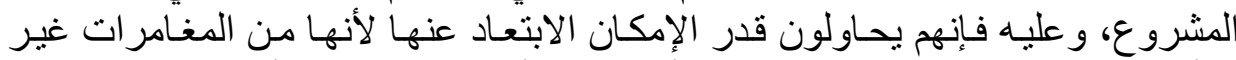

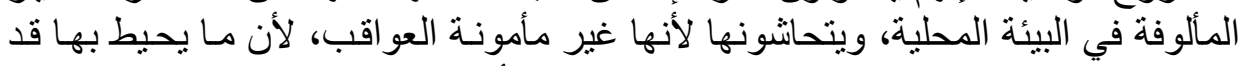

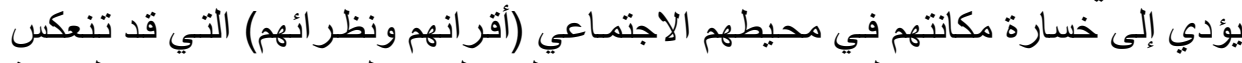
في خسارة موقعهم في السوق وتدمر مسار عملهم المستقبلي، ولا تبدو هذه النتيجة 


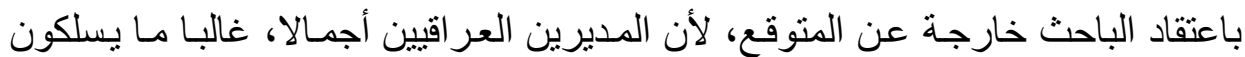

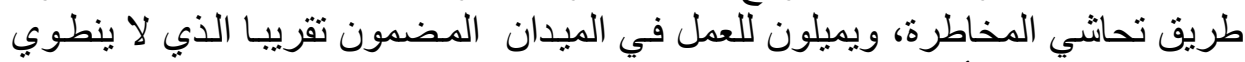

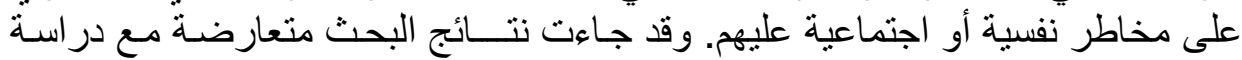

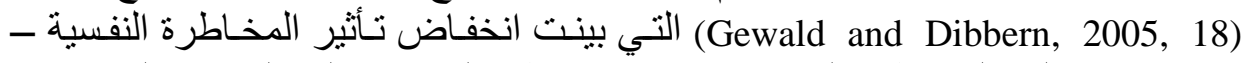

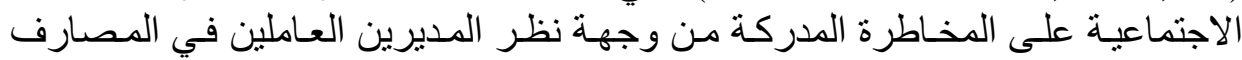

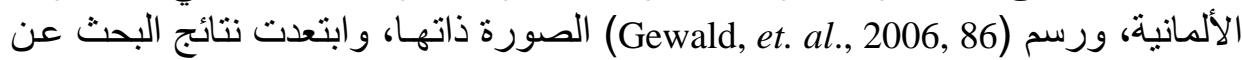

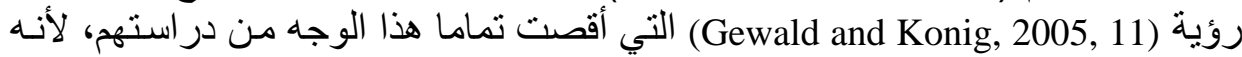

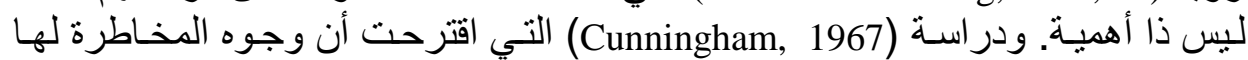

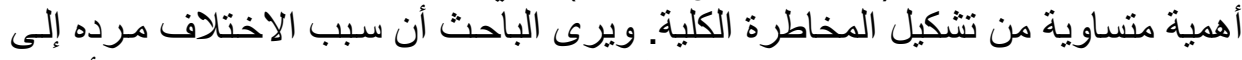

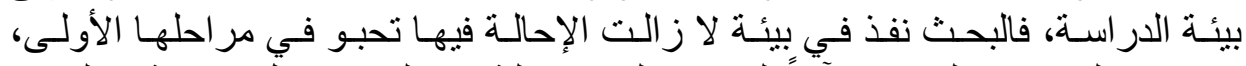

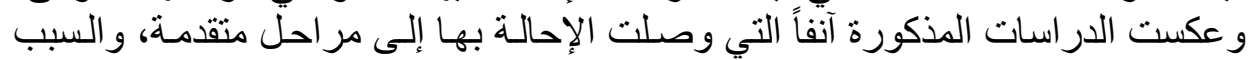

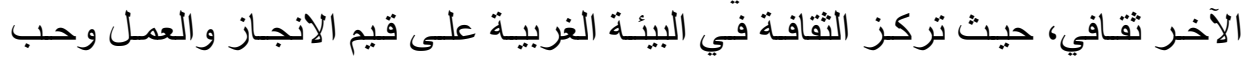

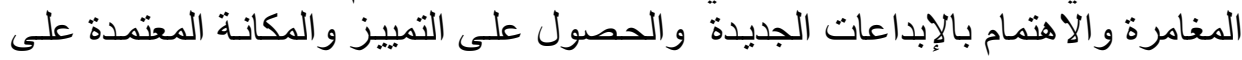

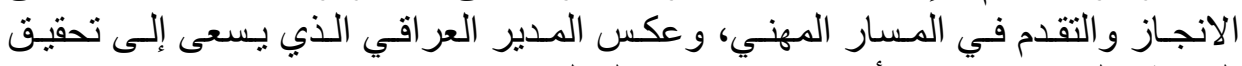

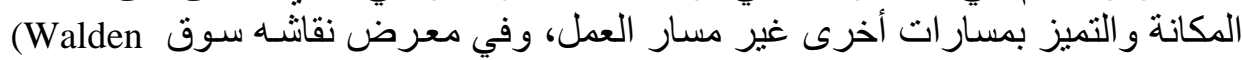

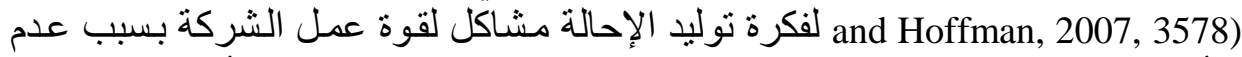

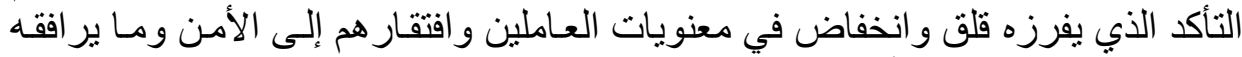

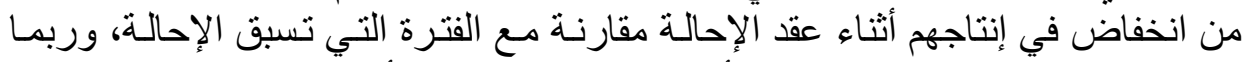

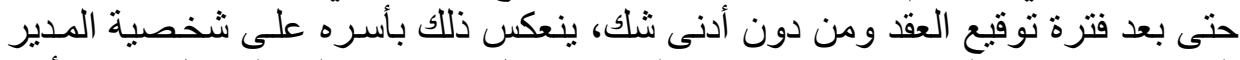

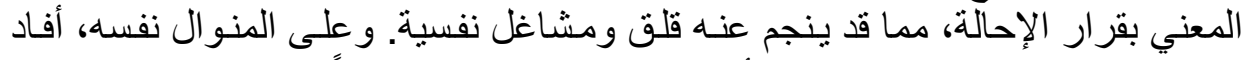

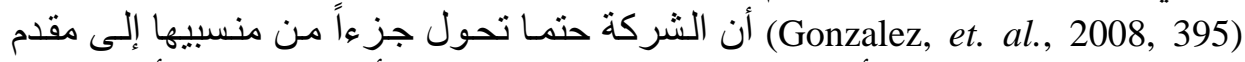

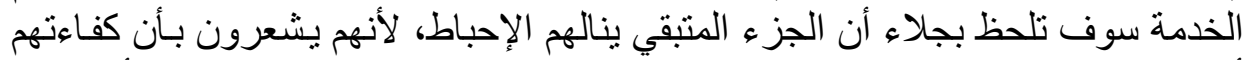

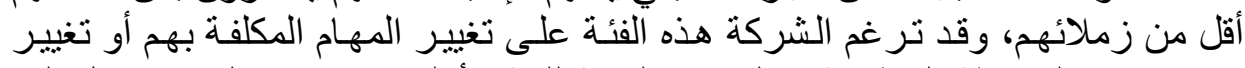

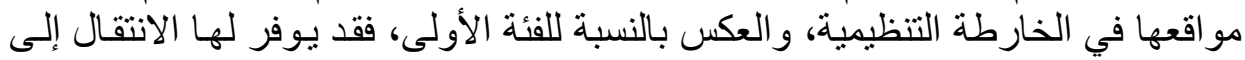

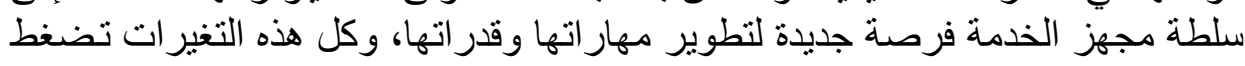

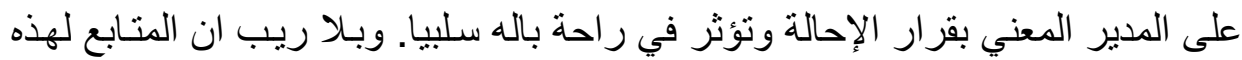

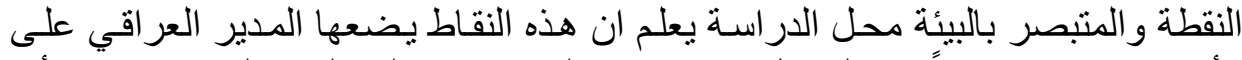

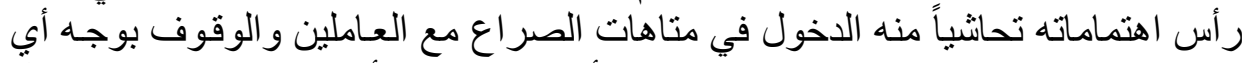

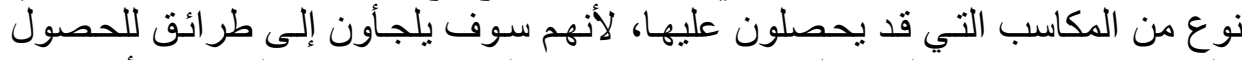

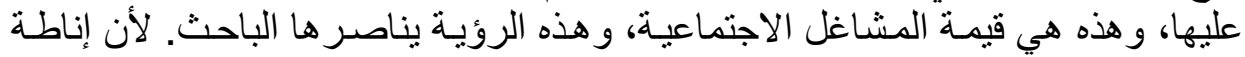

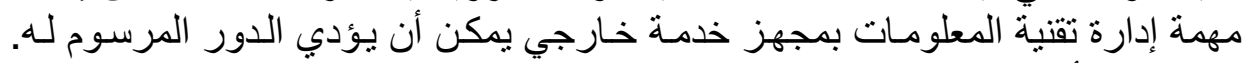

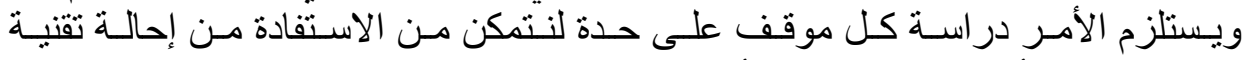

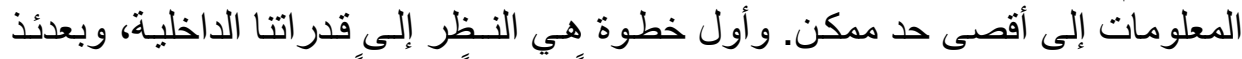

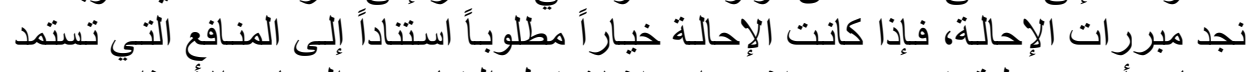

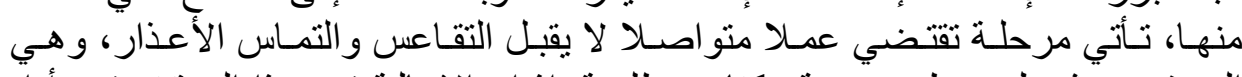

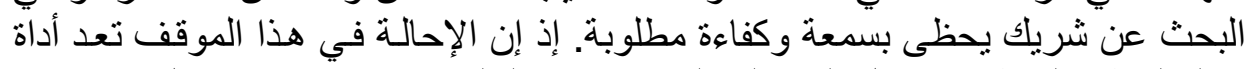

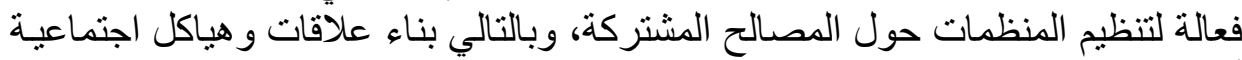

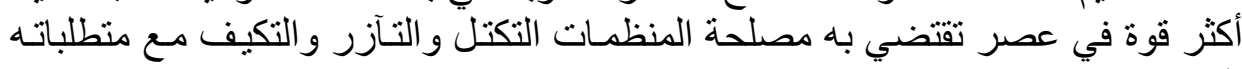




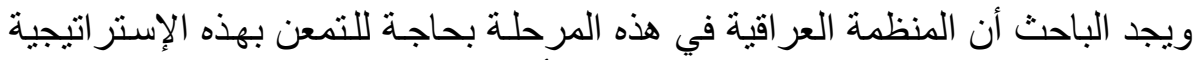

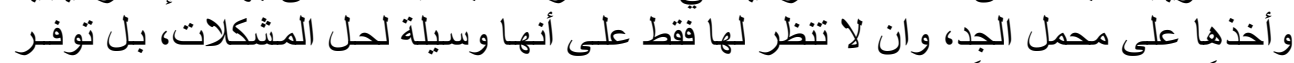

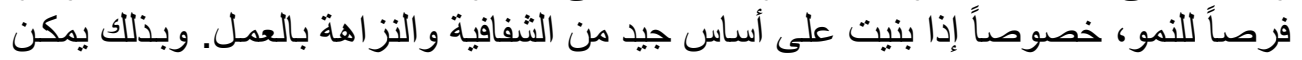
القول، تتحقق الفرضية الثالثة الذي مفادها (كلما ازدادت المخاطرة النفسية ـ الاجتماعية،

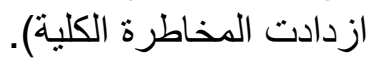

r. شغلت المخاطرة المالية المرتبة الثانية من حيث قوة تأثئثر ها في المخـاطرة الكلية، الأمر

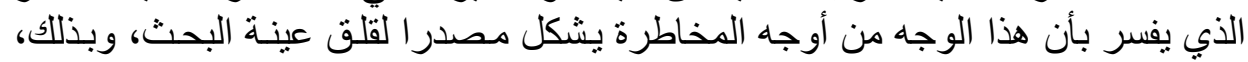

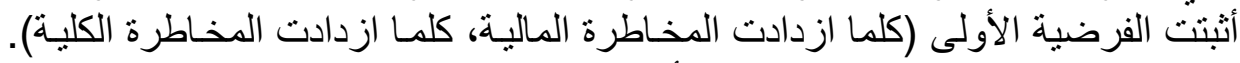

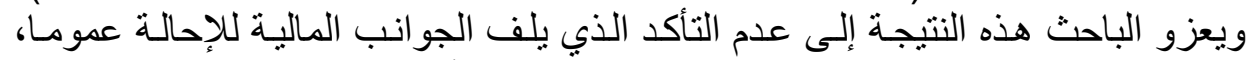

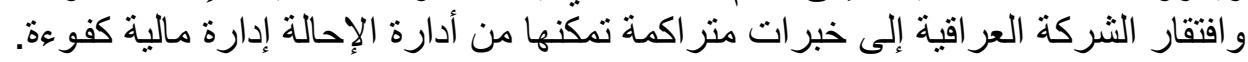

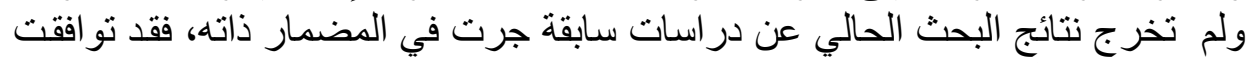

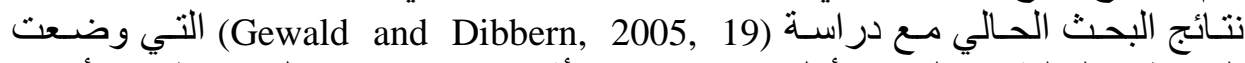

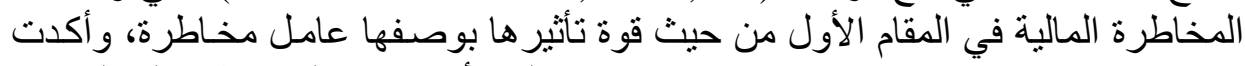

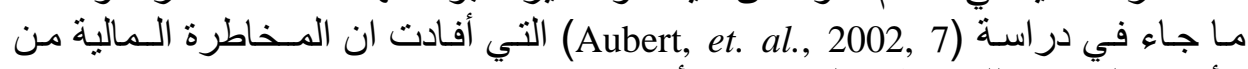

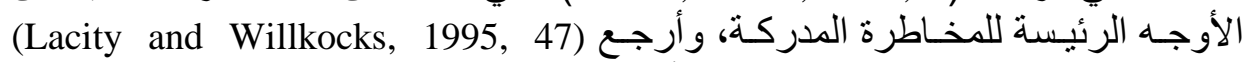

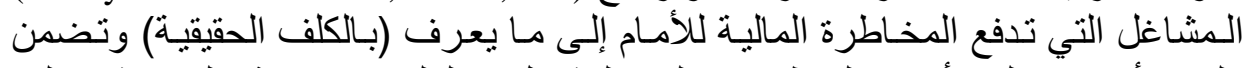

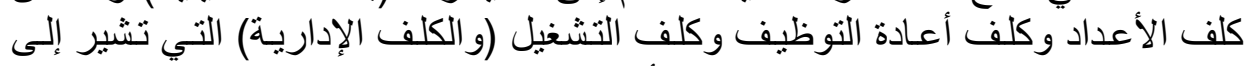

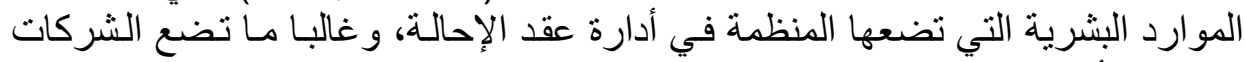

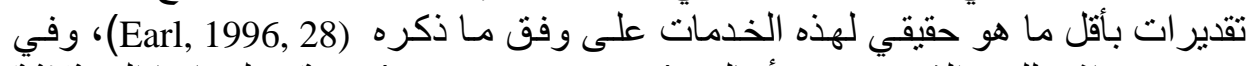

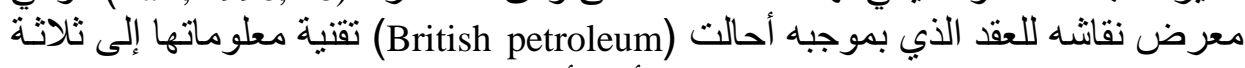

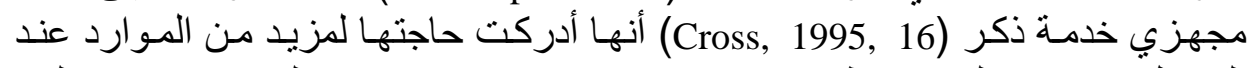

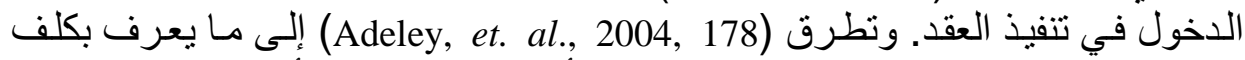

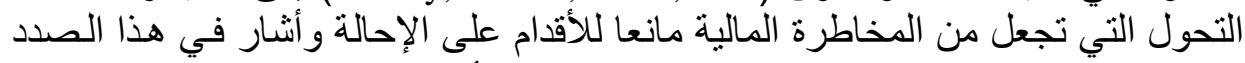

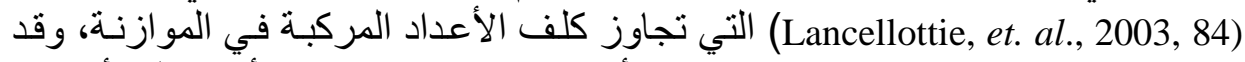

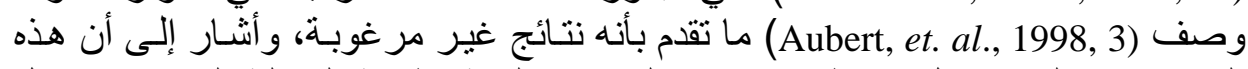

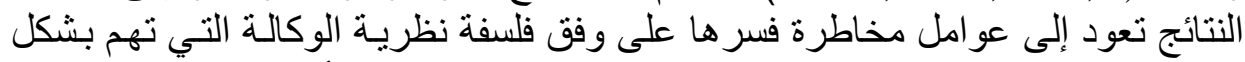
جو هري بمشاغل التحفيز و التنسيق المسنو طنة من العلاقة بين الأصيل (متلقي الخدمة) و الوكيل (مقدم الخدمة).

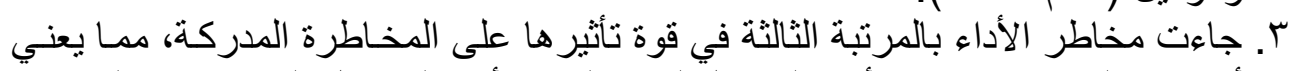

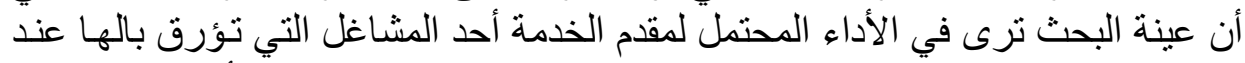

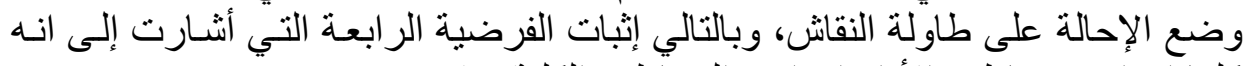

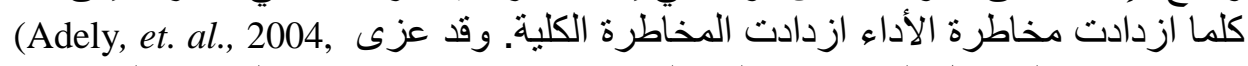

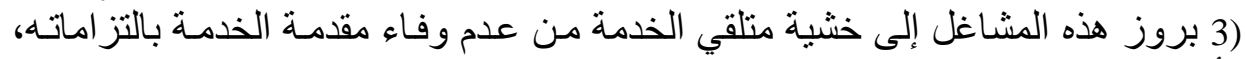

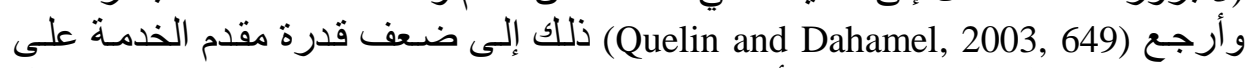

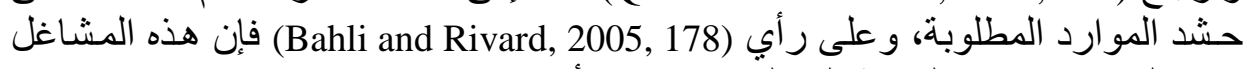

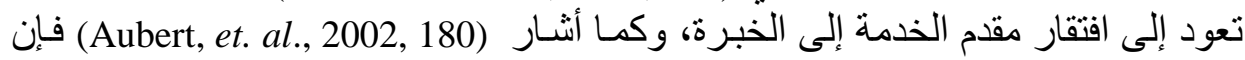

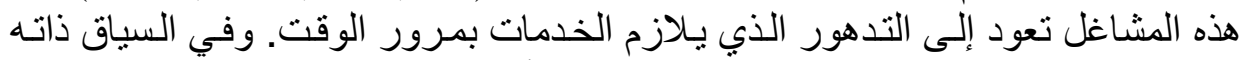

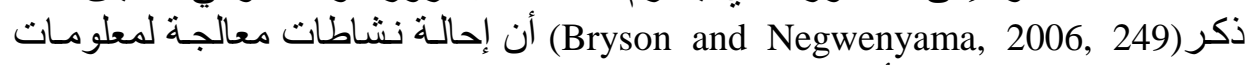
يتبعها فقدان الرقابة على أداء تلك النثاطات، وبالتالي يلازمها مخاطرة جوهرية تنمثيل 


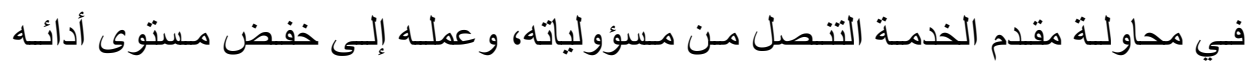

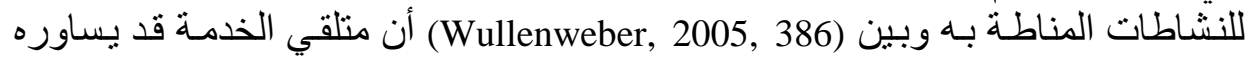

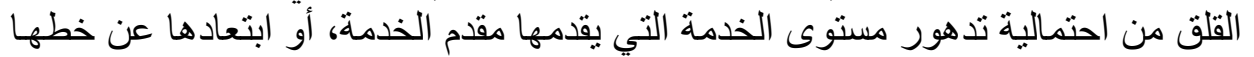

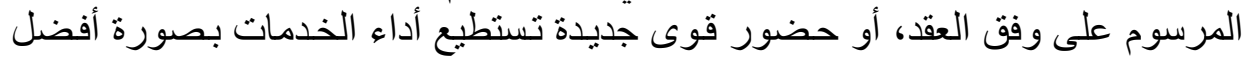

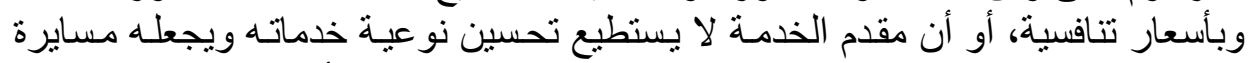

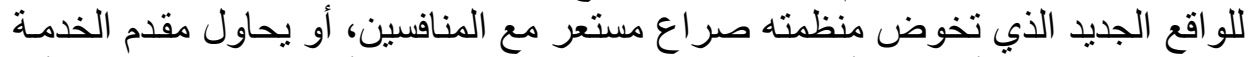

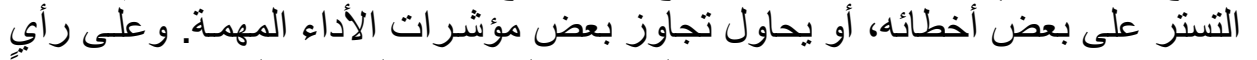
(Taffti, 2005, 630)

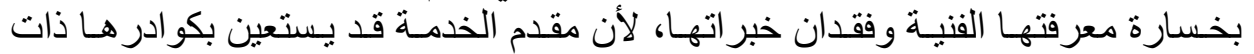

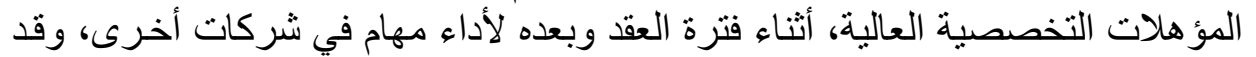



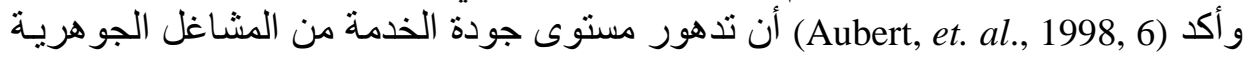

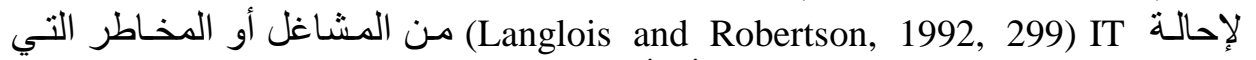

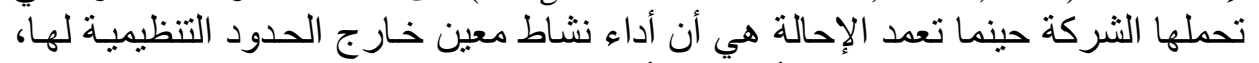

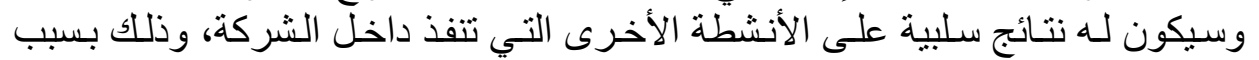
الطبيعة الترتيبية لبعض الأنشطة.

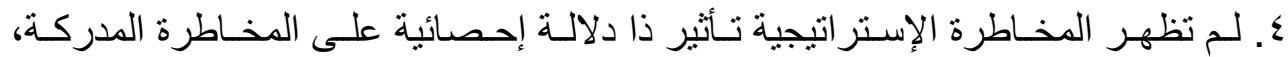

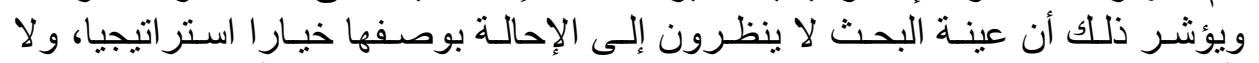

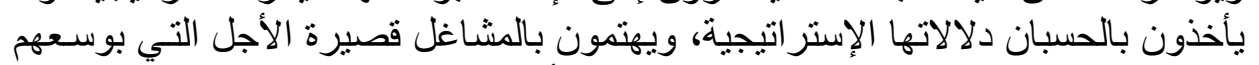

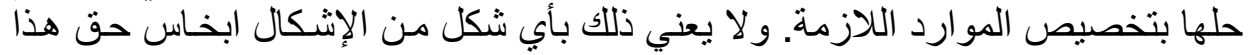

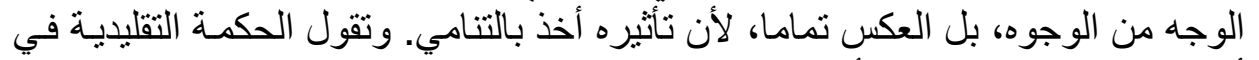

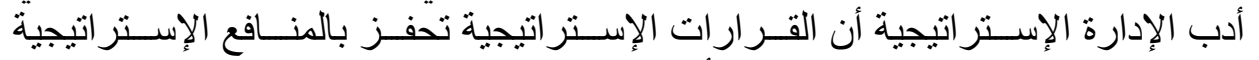

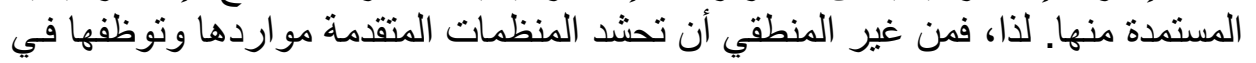

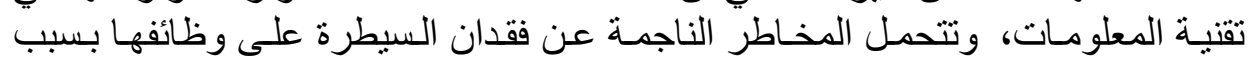

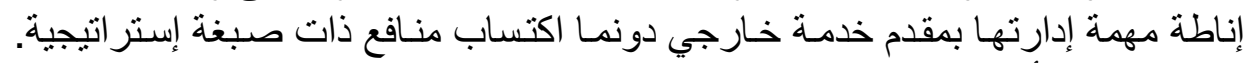

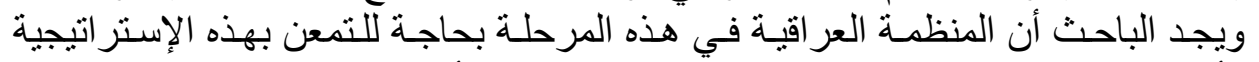

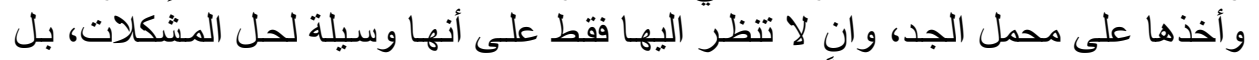

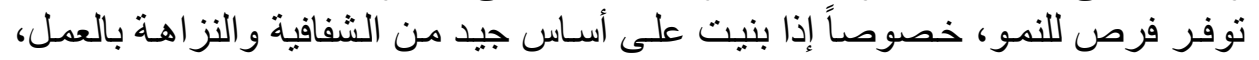

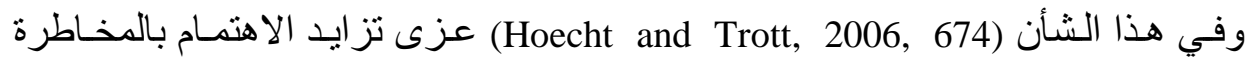

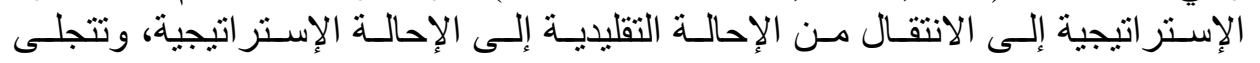

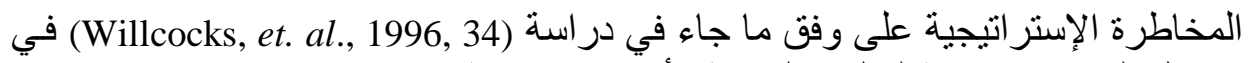

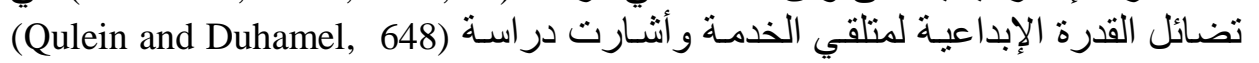
2003 إلى الاعتمـاد على مجهز خدمهة واحد، ونبـه (Hoecht and Prott, 2006, 675)

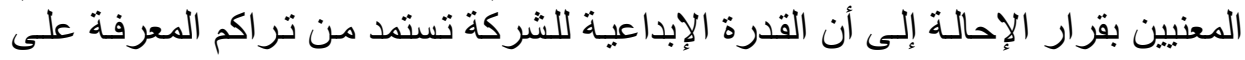

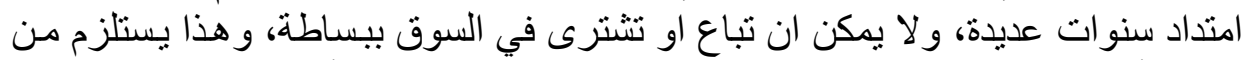

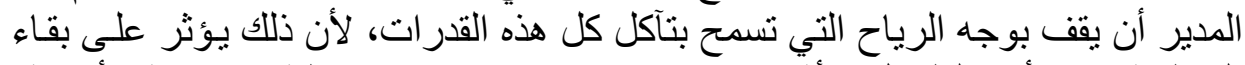

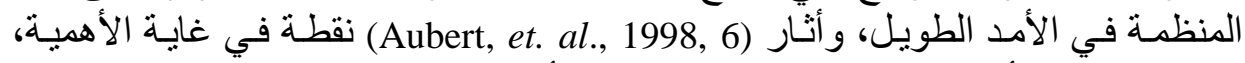

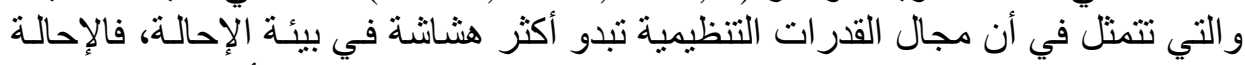

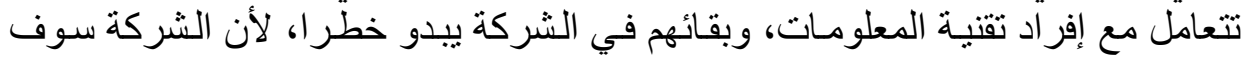




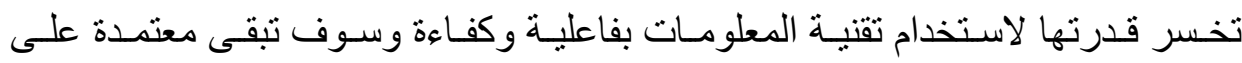

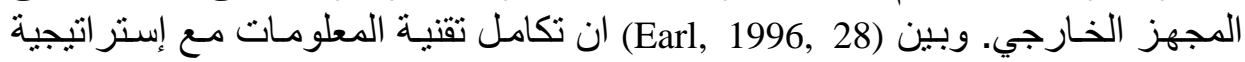

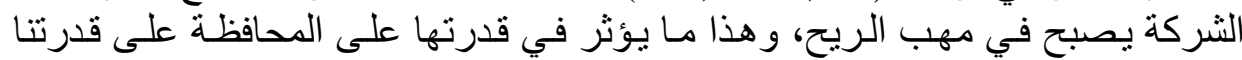

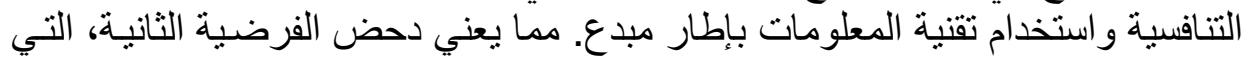

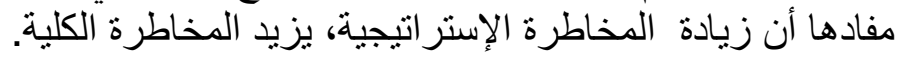

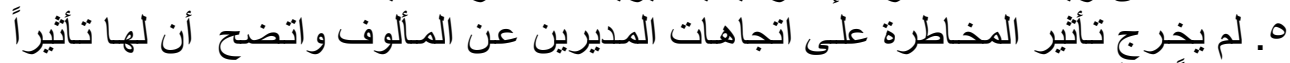

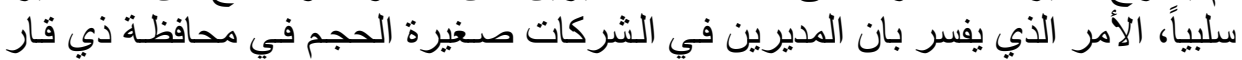

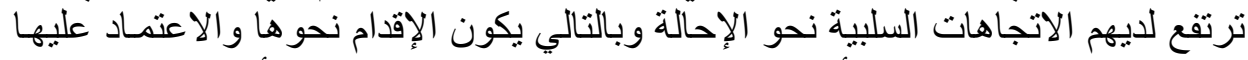

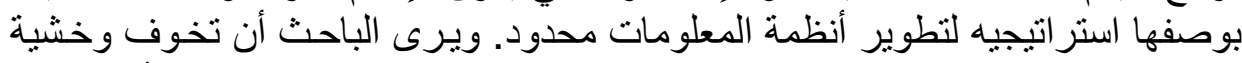

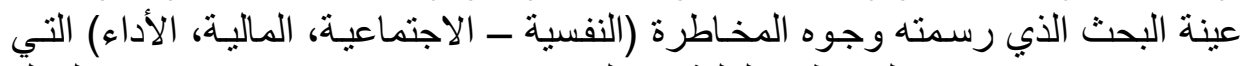

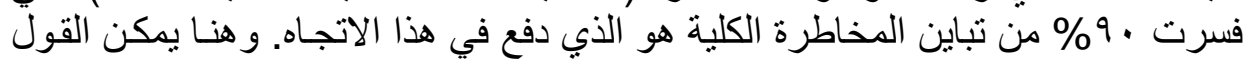

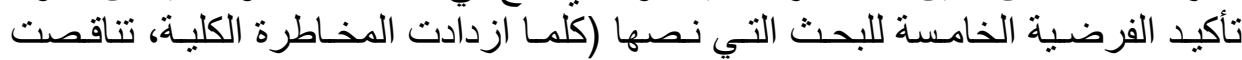

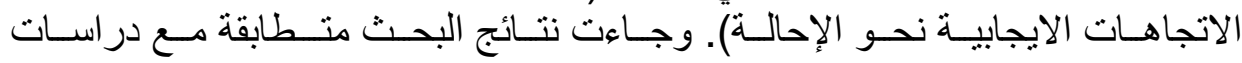
(Wullenweber, 2005, Gewald, et al., 2006, Gonzalez, et. al., 2008)

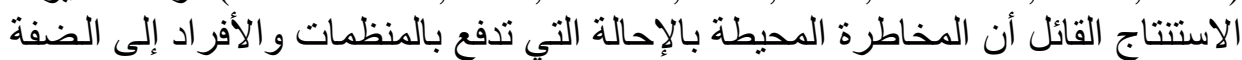

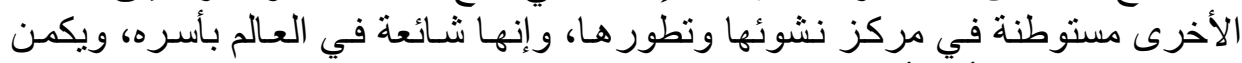

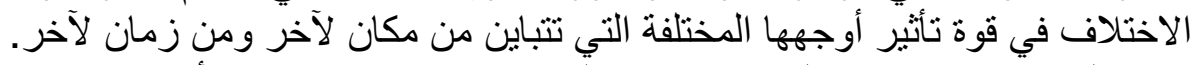

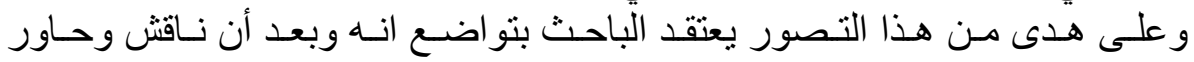

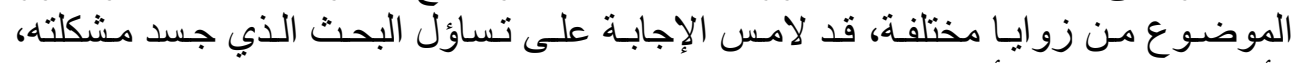
و أقترب نو عا ما من أهدافه.

الاستنتاجات و التوصيات الاستتناجات

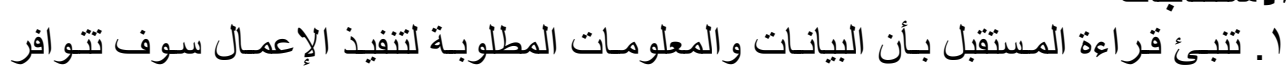

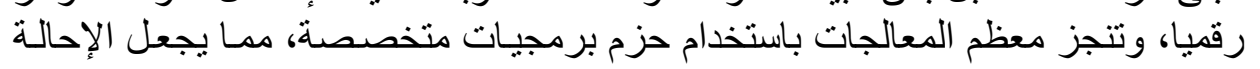
بشتى صور ها ورقة وتجة رابحة.

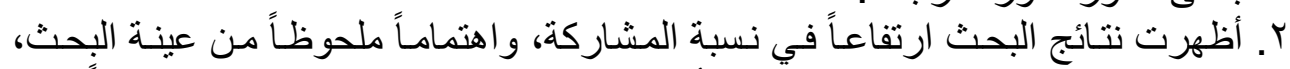

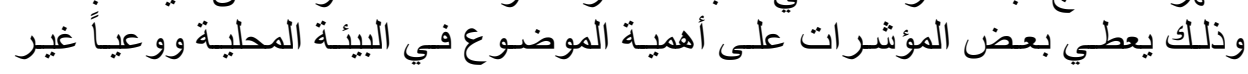
منوقع. بـ تجـاوز المقيـاس لاختبـار ات الصدق والثبـات ،ممـا يجعلـه مـؤهلا لأداء المهمـة المصمم لأجلها. ع. اتضح من نتائج البحث قوة تأثثر الأوجه المختلفة المخاطرة على صسيد معدلات التشبع و المعنوية. ○. بينت نتائج البحث أن أوجـه المخاطرة الأكثر أهمية (النفسية و الاجتماعبة، والمخـاطرة

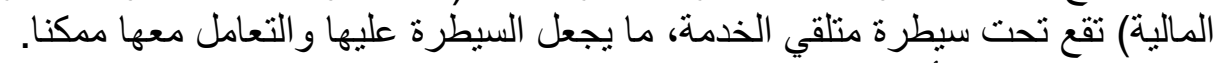
7. كثفت نتائج البحث أن عبط عينة البحث:

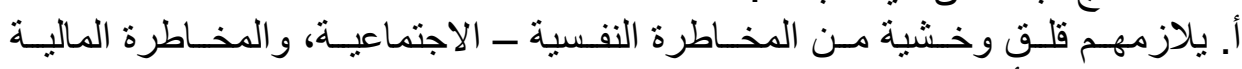

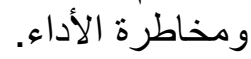
ب. لا تقرن المخـاطرة الإسـتراتيجية للديهم بقلق أو تـوجس لتركيز هم على النشاطات 
ج. يربطون انخفاض اتجاهاتهم نحو الإحالة بارتفاع المخاطرة المدركة للإحالة.

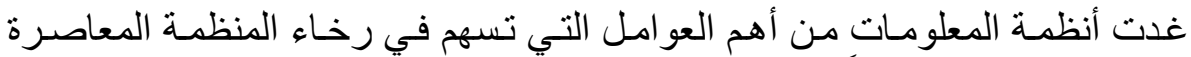
التوصيات

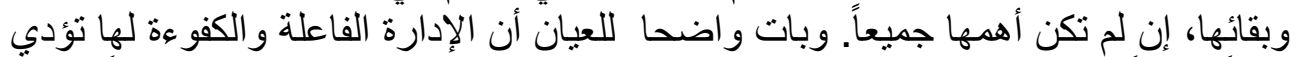

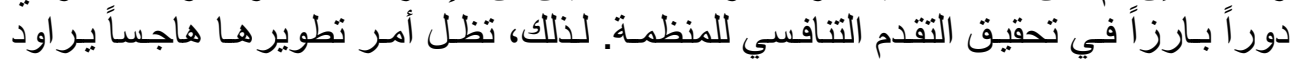

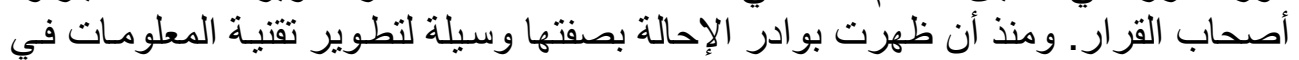

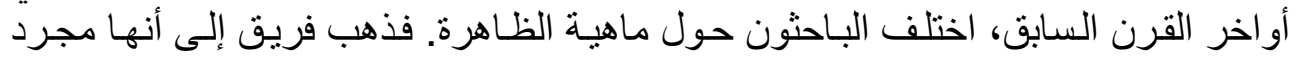

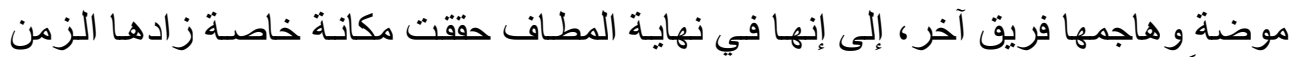

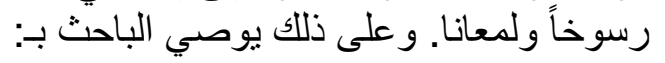
ا ـ تحفيز التفكير الاستر اتيجي لدى المدئي البيرين، لأن قرار الإحالة لم بعد قراراً روتيني بل هو

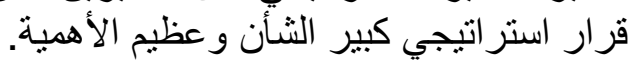

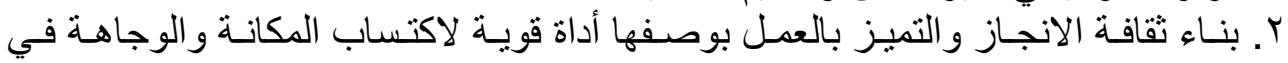

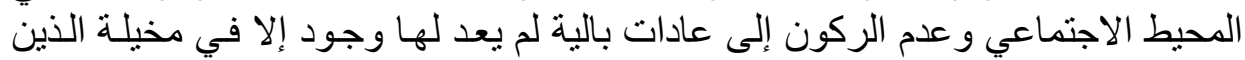

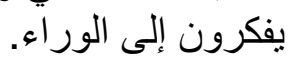

r. تطوير قدرات ومؤهلات كادر الشركات صـغيرة الحجم ورفع قدر اتهم الإداريـة-المالية

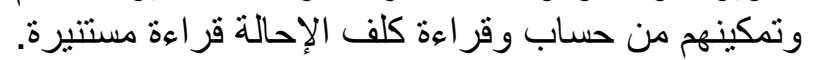

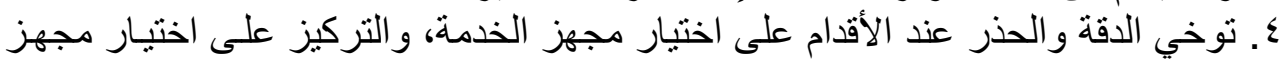

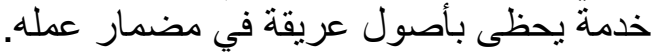

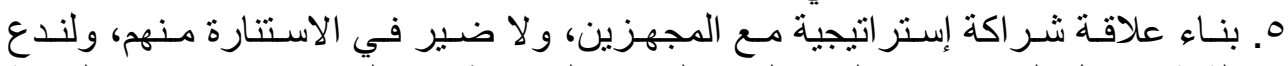

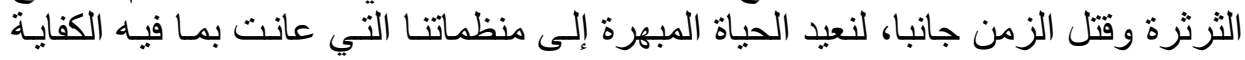

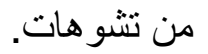

ثانياً- المراجع باللغة الأجنبية

1. Adeley, B., Annasiengh, F., and Nuens, B. 2004. Risk management practices in IS outsourcing: an investigation into commercial banks in Nigeria, International Journal of Information Management, Vol. 24 , No.2 .

2. Ajzen and Fishien, 1980. Understanding and predicting social behavior, Prentice-Hall, 1980 .

3. Allen ,M., and Yen, W.1979, Introduction to measurement theory .california , Brok.Cole

4. Aubert, A. Patly, M., Rivard, S., and Smith, H., 2001. I T outsourcing risk management 
at British Petroleum, Proceeding of the $34^{\text {th }}$ Hawaii International Conference on System Sciences.

5. Aubert, A. Rivard, S., and Patry, M. 2001 . Managing I T outsourcing risk: lessons learned,CIRANO, Montreal, Canada.

6. Aubert, A., Dussaults , S., Patry, M., and Rivard, S. 1998 . Managing the risk of I T outsourcing, proceeding of the 32nd Hawaii International Conference on System Sciences.

7. Aubert, A., Patry, A., and Rivard, S. 2005, A framework for information technology outsourcing risk management, The Data Base for Advance in Information Systems, Vol. 36 , No. 4 .

8. Bahli, B., and Rivard, S., 2002, A validation of measures associated with risk factor in information technology outsourcing, Proceeding of the $36^{\text {th }}$ Hawaii International Conference on System Sciences.

9. Bahli, B., and Rivard, S., 2005, Validating measures of information technology outsourcing risk factors, Omega, Vol. 33.

10. Barclay, D., Higgins, C., and Thompson, R. 1995, The partial least squares. Approach to causal modeling: personal Computer adoption use as on illustration, Technology Studies, Vol.2, No .2.

11. Bauer, R., 1967, Consumer behavior as risk taking, in Cox, D. (Ed) Risk taking and information handling in consumer behavior, Harvard University Press .

12. Baunerman, R. 2008, Risk and risk management in software projects, The Journal of Systems and Software.

13. Bebamati,H., and Rajkumar, T., 2002, The application development outsourcing decision: an application of technology acceptance model, Journal of Computer Information systems ,No.22.

14. Beulen, E., and Ribbers, P., 2002, IT outsourcing contract: Practical implications of contract theory, proceeding of the 36the Hawaii International Conference on System Sciences.

15. Billings, R., and Wroten, S., 1978, Use of path analysis industrial / organizational psychology: Criticisms and suggestions, Journal of Applied psychology, Vol. 63, No. 6.

16. Bryson, O. and Ngwenyama , K., 2006, Managing risks in information systems outsourcing : an approach to analyzing outsourcing risk and structuring incentive contract, European Journal of Operational Research , No. 174 .

17. Chin ,W., 1995., Overview of PLS method.www.ucalgart.ca/.chin

18. Cohen, and Cohen, 1983. Applied Multiple Regression/ Correlation Analysis for the Behavior Sciences, Second Edition, Hillsdale, New Jersey, Lawrence Erlbaum Associate.

19. Cohen, L., and Yong, A., 2005, Multsourcing: moving beyond outsourcing to achieve growth and agility ,Harvard Business School Press.

20. Costa, S., 2001, Information technology outsourcing in Australia:aliteature review, Information Management and Computer Security,Vol.9,No.5.

21. Cross , J., 1995, IT outsourcing : British petroleum's competitive approach, Harvard Business Review, May-June.

22. Cunningham, S., 1967, The major dimensions of perceived risk. Risk taking and information handling in consumer behavior .

23. Currie, w., Desai, B., Khan, N., Wang, X., and Weerakkody, V. 2002. Vendor strategies for process and applications outsourcing: Recent findings from field research, proceeding of the 36the Hawaii International Conference on System Sciences.

24. De Loof, 1995, Information systems outsourcing decision making: A framework organizational theories and case studies. Journal of Information Technology, No. 10. 
25. Desai, B., and Currie, W., 2003, Application service providers, A model in evolution. $5^{\text {th }}$ International Conference on Electronic Commerce, Pittsburgh.

26. Dibbern, J., 2003, The sourcing of application software development and maintenance, Springer, Berlin .

27. Dickson, G., Leitheiser, R., Wetherbe, J., and Nechis , M. 1984. Key information issues for the 1980s, MIS Quarterly, Vol. 8 , No. 3 .

28. Dielman ,T., 2005, Applied regression analysis 4thed,Brooks/Cole,division of Thomson learning.

29. Earl, M., 1996, The risks of outsourcing IT. Sloan Management Review Spring.

30. Ebel,R. , 1972, Essentials of education measurement, NJ Premtic - Hall inc .

31. Eisenhardt,M., 1989, Agency theory :an assessment and review ,Academy of Management Review,Vol.14,No.1.

32. Featherman, M., and Pavlou, A., 2003, Predicting e-service adoption: a perceived risk facets perspective, International Journal of Human - Computer Studies, No. 59.

33. Fornell, C. 1982. A second generation of multivariate analysis, Vol. I and, II : Methods, Praeger Special Studies, N. Y.

34. Fornell, C. and Larcker, D., 1981, Structural equation models with unobservable variables and measurement error, Journal of Marketing Research, No. 18.

35. Gewald , H., and Franke, J., 2005, A comparison of the risk in information technology outsourcing and business process outsourcing, proceeding of the Americas Conference on Information systems, Omaha, U.S.A .

36. Gewald, H. and Dibbern, J., 2005, The influential role of perceived risk versus perceived benefits in the acceptance of business process outsourcing. Empirical evidence from the German banking industry, working paper.

37. Gewald, H. and konig, W., 2005, Predicting the adoption of BPO : The role of perceived risk and technology acceptance.

38. Gewald,H.,Wullenweber,K., and Weitzel,T., 2006, The influence of perceived risk on banking managers intention to outsourcing business processes ,Journal of Electronic Commerce Research, Vol .7,No.2.

39. Gonzalez, R. Gasco, J., and Liopis, J., 2008, Information systems outsourcing reason and risk: an empirical study Proceedings of World Academy of Science, Engineering and Technology, Vol. 13.

40. Grover, V., Cheon, M., and Teng, J., 1996, The effect of service quality and partnership on the outsourcing of information systems functions. Journal of Management Information systems, spring, Vol. 12, No.4.

41. Hirschheim, R., and Lacity, M., 2000, The myths and realities of information technology in sourcing, Communications of the ACM , Vol. 43 , No. 2 .

42. Hoecht, A. and Trott, P., 2006, Innovation risks of strategic outsourcing, Technovation , No .

43. Igbaria, M. ,Iivari, J., and Maragahh, H., 1995, Why do individuals use computer technology? A Finnish case study, Information and Management, No. 29,.

44. Im , I., Kim, F., and Han, H., 2008, The effects of perceived risk and technology type on users acceptance of technologies, Information and Management, No. 45 .

45. Kakabadse, A., and Kakabads, N., 2002, Trends in outsourcing ; contrasting , U.S.A and Europe, European Management Journal, Vol. 20 , No.2 .

46. Khalfan, M., 2004, Information security considerations in 1S / IT outsourcing projects: a descriptive case study of two sectors. International Journal of information Management, Vol. 24, No.1.

47. Khan, N., Currie, W., Weerakkody, V., and Desai, 2002, Evaluating offshore IT outsourcing in India: Supplier and scenarios Proceeding of the 36the Hawaii International Conference on System Sciences. 


\section{الزيادي]}

48. Kirby, G., 1993, Duesbursys, Unisys U3 conference.

49. Lacity, M, and, Willcocks, L., 1995, IT outsourcing: maximize flexibility and control .Harvard Business Review, Vol.1,No.35.

50. Lacity, M., 1992, An interpretive investigation of the information outsourcing phenomenon. Unpublished doctoral dissertation, university of Houston, Houston, TX.

51. Lancellotti,R.,Schein, O., Spang, S., and Stadler, V., 2003, ICT and operation outsourcing in banking, No.45.

52. Langlois, R. and Robertson, P., 1992, Network and innovation a modular system . Lesson from Micro computer and stereo component, Industries . Research Policy, Vol. 21 .

53. Lee, J., and Kim, Y., 2002, Exploring a causal model for the understanding of outsourcing partnership, Proceeding of the 37the Hawaii International Conference on System Sciences.

54. Loh, L., and Venkatrman, N., 1992, Diffusion of information technology outsourcing: influence sources and the Kodak effect. Information systems Research, Vol.3, No.4.

55. March, J. and Shapria , G., 1987, Managerial perspectives on risk and risk taking, management science, Vol. 33 , No. 11.

56. Mitchel, W. 1999 Consumer perceived risk; conceptualizations and models, European Journal of Marketing, Vol. 33 , No.1.

57. Namboodiri, N., Carter, L., and Blalock, H., 1975, Applied multivariate analysis and experimental design, Mc- Grew Hill, New York.

58. Noor, H., Arshad, A., and May-lin, Y., 2007, ICT outsourcing: inherent risk , issues and challenges, Transaction on Business and Economics, Issue, 8 , Vol. 4 .

59. Nunnally, J., 1978, Psychometric theory, New York, Mc- Grew Hill.

60. Peter,J., and Ryan, M.1976.An investigation of perceived risk at the Brand level ,Journal of Marketing Research ,No.

61. Pfeffer, S., 1981, Power in organization, Pitman, Boston .

62. Premkumar, G. and Bhattacherjee, A. 2008 . Explaining information technology : a test of competing models . Omega , No. 36.

63. Quelin, B., and Duhamel, F.,2003, Bringing together strategic outsourcing and corporate strategy : Outsourcing motives and risk , European Management Journal , Vol. 21 , No. 5.

64. Rochester, J., and Douglass, D., 1990, Taking an objective look at outsourcing. I/S analyzer. Vol. 28, No.9.

65. Rouse, A., Corbitt, B., and, Aubert, B., 2001, Perspectives IT outsourcing success: covariance structure modeling of a survey of outsourcing in Australia, Proceeding of the 36the Hawaii International Conference on System Sciences.

66. Tafti, M., 2005, Risk factors associated with offshore I T outsourcing, Industrial Management and Data systems, Vol. 105 , No. 5.

67. Walden, E. and Haffman, J., 2007, Organizational form, incentives and the management of information technology opening the black box of outsourcing, Computers and Operation Research, Vol. 34 , No. 12.

68. Webster , 2005, Online dictionary . http://www.webster.com .

69. Wheelen, T., and Hunger, J., 2002, Strategic management and business policy. Eighth Edition, Prentice Hall, New Jersey.

70. WillCocks, L., and Kern, T., 1998, IT outsourcing as strategic partnering the case of the UK Inland Revenue. European Journal of Information systems, Vol.7,

71. WillCocks, L., and Lester. S., 1996, Beyond the IT productivity paradox. European Management Journal, Vol.14, No.3.

72. WillCocks, L., Fitzgerald, G. and Feeny, D., 1996, Souring decisions: developing an IT outsourcing strategy. Investing in information system, Chapman and Hall. 
73. Wixom,B.,and Todd, A., 2005, A theoretical integration of user satisfaction and technology acceptance, Information Systems Research,Vol.16,No.1.

74. Wullenweber, K., 2004, The role of managers risk attitude for outsourcing success, www.ade/ery.

75. Wullenweber, K., 2005, The interplay of outsourcing risks and benefits industry.www.ade/ery

76. Zikmund, W., 1994, Business research method, fourth ed., The Dryden press Orlando, Florid. 